INSTITUTO DE PESQUISAS ENERGÉTICAS E NUCLEARES

Autarquia associada à Universidade de São Paulo

\title{
QUANTIFICAÇÃO E IDENTIFICAÇÃO DE CARBONETOS NO AÇO FERRAMENTA AISI/SAE M2
}

MARILENE MORELLI SERNA

Tese apresentada como parte dos requisitos para obtenção do grau de Doutor em Ciências na Área de Tecnologia Nuclear - Materiais.

Orientador:

Dr. Jesualdo Luiz Rossi 
Eguiberto Galego

Vicente Serna Quinto

Lenita Maria Augusta Morelli Serna

Os pilares da minha vida. 


\section{Agradecimentos}

Ao Dr. Jesualdo Luiz Rossi

pela orientação, apoio e confiança que tornou possível a realização deste trabalho.

Ao Prof.Dr. Angelo Fernando Padilha e ao Dr. José Mestnik

pelas discussões e sugestões.

Ao Dr. Carlos O. Paiva-Santos

por dividir sua experiência no método de Rietveld.

Aos Drs. Fabio Furlan e Roosevelt Droppa Jr

físicos das linhas XPD e XRD1 do Laboratório Nacional de Luz Síncrotron pelo apoio na obtenção dos dados de difração de raios $\mathrm{X}$.

Aos Drs.Vera Lucia Ribeiro Salvador e José Roberto Martinelli

pelas análises de fluorescência de raios X.

Aos Drs. Reginaldo Mucillo, Sérgio Luís de Jesus, Hamilton Perez Soares Corrêa, e principalmente, aos inomináveis que na calada da noite, realizaram análises de difração de raios X sem as quais este trabalho não teria sido possível.

Ao Nildemar Aparecido Messias, Celso Vieira de Morais e Glauson A. F. Machado por ceder infinitas horas de microscopia de varredura na caça aos carbonetos.

Ao Olandir Vercino Correa

pela ajuda nos mistérios da química.

Aos meus amigos Marina, "Kiko" Breda, Cristiano, Edval, Luis Gallego, Hamilton, Oscar, Cebola, Jesualdo

pela paciência em escutar minhas divagações em voz alta e contribuírem com inúmeras sugestões.

Meu pai (um soldado da guerra civil espanhola e da segunda guerra mundial) sempre me disse que a solidão é a pior das prisões.

Agradeço ao meu marido Dr. Eguiberto Galego pela presença, pela amizade, pelo companheirismo e pela incansável ajuda nesta pequena jornada da caminhada de nossas vidas.

A minha família (Morellis, Sernas e Alves)

pelo apoio total e irrestrito.

Aqueles que involuntariamente não foram nominados. 


\title{
Quantificação e Identificação de Carbonetos no Aço Ferramenta AISI/SAE M2
}

\begin{abstract}
RESUMO
As propriedades mecânicas de ferramentas confeccionadas com aços rápidos estão intimamente ligadas às características dos carbonetos dispersos na microestrutura desses materiais. Neste trabalho foi estudado o efeito do ciclo comercial de tratamento térmico de austenitização e revenimento em amostras do aço AISI/SAE M2 produzidas por metalurgia convencional, metalurgia do pó e conformação por spray. Para a realização deste estudo foram desenvolvidos métodos para a extração seletiva dos carbonetos dos tipos $\mathrm{MC}$ e $\mathrm{M}_{6} \mathrm{C}$, onde $\mathrm{M}$ representa: vanádio, cromo, ferro, molibdênio e tungstênio, utilizando técnicas de dissolução química e eletrolítica. Estes métodos permitiram a quantificação por diferença de massa dos carbonetos do tipo $\mathrm{M}_{6} \mathrm{C}$ e MC. A extração seletiva revelou a existência de um carboneto do tipo MC com estequiometria ainda não reportada na literatura. Os parâmetros cristalográficos deste carboneto foram determinados utilizando-se o método de Rietveld. A estrutura cristalina foi refinada a partir de dados obtidos por difração de raios $\mathrm{X}$, utilizando energias próximas da borda de absorção dos elementos metálicos do carboneto, através do uso de radiação de luz síncrotron. Os resultados obtidos pelo método de Rietveld permitiram determinar o grupo espacial $F m-3 m$ para este carboneto, e que o parâmetro de rede e a estequiometria estão relacionados com a microestrutura e o teor de carbono do material antes do ciclo de tratamento térmico, porém indicando uma forte convergência para uma estequiometria comum. $\mathrm{O}$ conjunto dos resultados obtidos mostrou que o ciclo de tratamento térmico comercial, utilizado neste trabalho, induz ao aumento significativo da fração de carbonetos, quando comparado com o ciclo de tratamento térmico convencional descrito na literatura. A fração de carbonetos do tipo MC tem aumento mais significativo, que a do carboneto do tipo $\mathrm{M}_{6} \mathrm{C}$, como consequiência das alterações na estequiometria do carboneto do tipo MC.
\end{abstract}




\title{
Quantification and Identification of the Carbides in Tool Steel AISI/SAE M2
}

\begin{abstract}
The mechanical properties of tools made using high-speed steel are closely connected to the characteristics of the carbides dispersed in the microstructure of these materials. In this work the effect of commercial cycle heat treatment of austenitization and tempering on samples of steel AISI / SAE M2 produced by conventional metallurgy, powder metallurgy and spray forming was studied. To undertaken this study, methods for the selective extractions of the $\mathrm{MC}$ and $\mathrm{M}_{6} \mathrm{C}$ carbides were developed, where $\mathrm{M}$ equals: vanadium, chromium, iron, molybdenum and tungsten. The used techniques were chemical and electrolytic dissolution. These methods allowed for the quantification by mass difference of the $\mathrm{M}_{6} \mathrm{C}$ and $\mathrm{MC}$ carbides. The selective extraction showed the existence of MC-type carbide which composition has not yet been reported in the literature. The crystallographic parameters of carbide were determined using the Rietveld method. The crystal structure was refined from data obtained using X-ray diffraction, using energy near the absorption edge of the metal of the carbides, through the use of synchrotron radiation light. The results obtained using the Rietveld method allowed the determination of the space group $F$ $m-3 m$ for this material, and that the cell parameter and composition are related to the carbon content and the material microstructure existing before the heat treatment cycle. But, indicating a strong convergence to a common composition. All the results showed that the commercial heat treatment cycle, used in this work, leads to significant increase in the fraction of carbides when compared with the conventional heat treatment cycle described in the literature. The fraction of carbides MC had a most significant increase, in comparison to type $\mathrm{M}_{6} \mathrm{C}$ carbide, as a result of changes in the composition of carbide-type MC.
\end{abstract}




\section{Sumário}

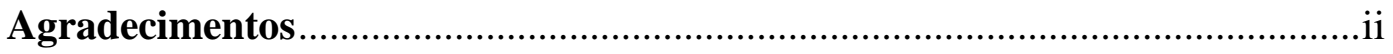

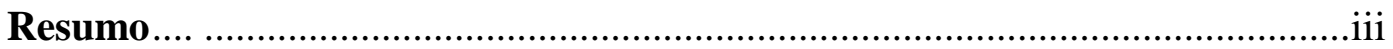

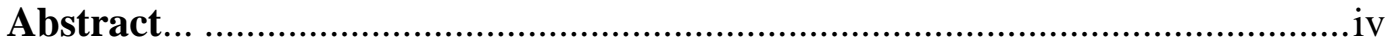

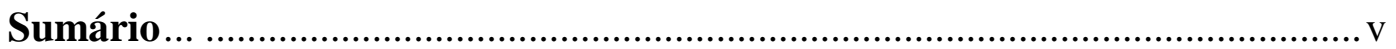

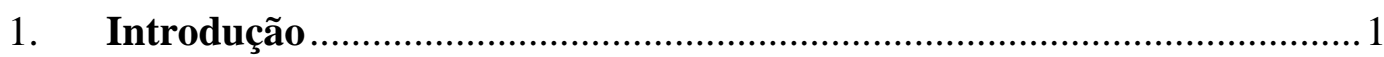

2. Os carbonetos nos aços rápidos...................................................... 4

2.1. Os carbonetos dos metais de transição ....................................................... 4

2.2. Mecanismos de formação de carbonetos nos aços .................................. 14

2.3. Os carbonetos no aço AISI/SAE M2 …................................................ 18

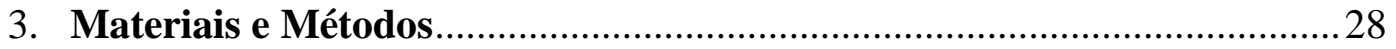

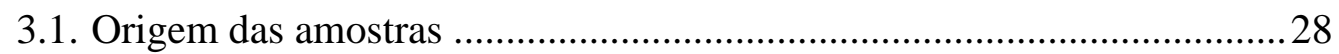

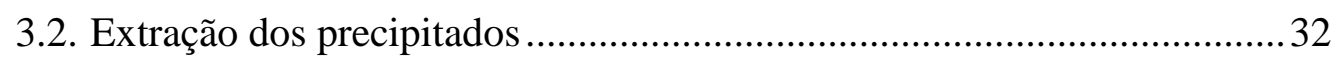

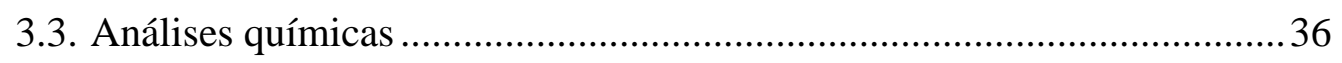

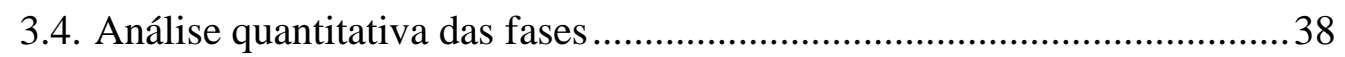

3.5. As análises por difração de raios $X$........................................................... 40

3.6. As condições experimentais para aplicação do método de Rietveld ........ 42

3.6.1. Os dados experimentais .............................................................42

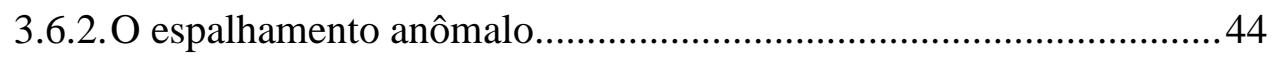

3.6.3. A obtenção dos parâmetros cristalográficos .................................... 47

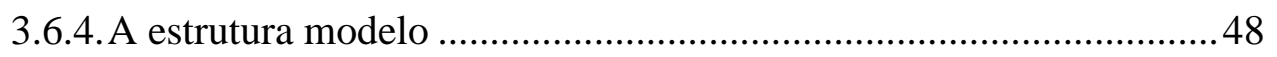

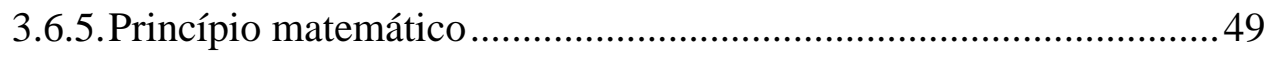

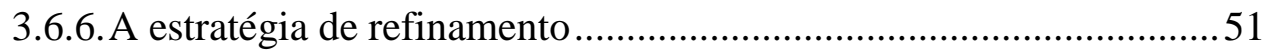

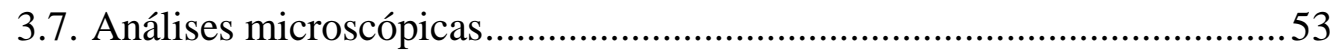

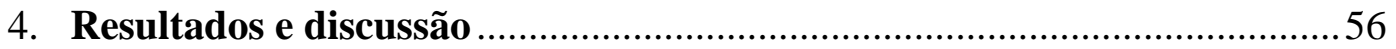

4.1. Caracterização das amostras no estado inicial........................................56 
4.2. Caracterização das amostras após tratamento térmico ............................. 67

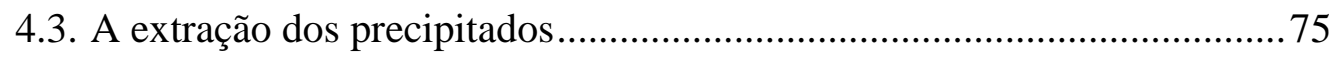

4.4. Determinação dos parâmetros cristalográficos ....................................... 84

4.5. Considerações finais ........................................................................ 91

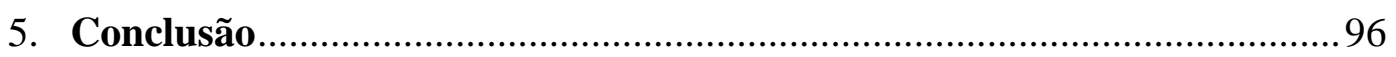

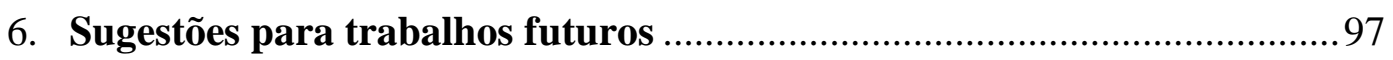

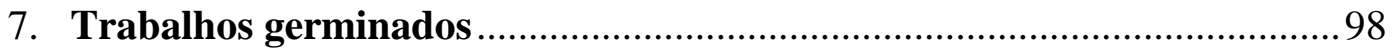

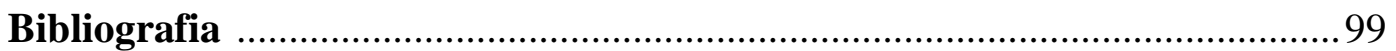

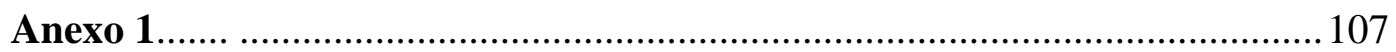




\section{Introdução}

A descoberta dos aços ferramentas, com a adição de tungstênio como elemento de liga foi realizada casualmente em 1868 por Robert Mushet, e seu desenvolvimento iniciou-se com os estudos realizados por Maunsed e White em 1898. A denominação aço ferramenta advém do fato destes aços terem como principal aplicação a confecção de ferramentas de corte e desbaste. Esta classe de aço está dividida em várias subclasses em função das condições de uso em serviço da ferramenta. O material utilizado neste trabalho pertence à subclasse dos aços rápidos, pois é utilizado em processos de corte ou desbaste que ocorrem em alta velocidade.

Até 1949 o principal elemento de liga deste material foi o tungstênio, a partir desta data a substituição de parte do tungstênio por molibdênio, sem alteração significativa das propriedades mecânicas marca o nascimento dos aços ao molibdênio. Dentre os aços com adição de molibdênio o AISI/SAE M2 tem se mantido como o mais popular aço ferramenta em função do seu vasto campo de aplicação, que incluí a confecção de ferramentas de usinagem para uso em alta taxa de desbaste, ferramentas de corte, matrizes para estampagem profunda, rolos de laminação, molas, mancais, entre outras.

A microestrutura dos aços rápidos é planejada principalmente para se obter uma alta taxa de desbaste, a qual é determinada pela resistência ao desgaste e pela dureza tanto a frio como a quente, uma vez que em seu emprego a temperatura na região de contato entre a ferramenta e a peça a temperatura é elevada. A microestrutura consiste de carbonetos com tamanhos da ordem de $1 \mu \mathrm{m}$ a $10 \mu \mathrm{m}$, chamados de primários, do tipo $\mathrm{M}_{6} \mathrm{C}$ e $\mathrm{MC}$ embebidos em uma matriz de martensita / ferrita revenida. Os carbonetos primários são responsáveis pela resistência ao desgaste. Durante o revenimento a matriz é endurecida pelo processo de endurecimento secundário, isto é, pela precipitação de carbonetos muito finos, com tamanho da ordem de $3 \mathrm{~nm}$ a $10 \mathrm{~nm}$, do tipo $\mathrm{MC}$ e $\mathrm{M}_{2} \mathrm{C}$. O carboneto secundário do tipo $\mathrm{M}_{2} \mathrm{C}$ apresenta estrutura hexagonal. Em todos os carbonetos 
citados acima $\mathrm{M}$ representa estequiometrias distintas formadas por átomos de vanádio, cromo, ferro, molibdênio e tungstênio.

Os dois carbonetos primários possuem estrutura cúbica de face centrada (CFC), sendo $\mathrm{o} \quad \mathrm{M}_{6} \mathrm{C}$ um carboneto misto de ferro, molibdênio e tungstênio podendo ainda apresentar vanádio em baixa concentração. Já o carboneto MC, identificado neste tipo de aço até o momento, é reportado como um carboneto rico em vanádio, podendo conter molibdênio e tungstênio, em baixa concentração, dissolvidos.

A microestrutura deste aço ferramenta é fortemente influenciada pela sua história mecanotérmica. Idealmente, espera-se que as melhores propriedades físicas sejam obtidas para uma microestrutura com distribuição homogênea dos carbonetos na matriz relativamente tenaz. No entanto, este tipo de microestrutura apresenta inúmeras dificuldades para sua obtenção, uma vez que a formação, o crescimento, a esferoidização e a dissolução dos carbonetos ocorrem nas diversas etapas do processo de produção.

Na busca pela microestrutura ideal, vários processos de produção têm sido utilizados. A escolha do processo mais indicado está intimamente relacionada à aplicação final do produto. O estabelecimento desta variedade de processos implicou na necessidade de otimização das variáveis de processo resultando na observação de microestruturas bastante diferentes, porém não foram reportadas diferenças significativas na composição química e cristalografia dos carbonetos.

A motivação para o desenvolvimento deste trabalho originou-se na tese de doutorado de Jesus (2004) que objetivou "a obtenção do aço rápido tipo AISI/SAE M2 pelo processo de conformação por spray, e a avaliação deste quanto as suas propriedades e ao seu desempenho como ferramenta de usinagem, mediante o confronto com o desempenho de materiais obtidos pela técnica da metalurgia convencional, e pela técnica da metalurgia do pó (MP)". Jesus verificou em seu trabalho que as diferenças de desempenho não foram tão significativas, quanto às observadas na microestrutura; aventando-se daí que tais diferenças poderiam estar relacionadas à quantidade e aos tipos de carbonetos formados em cada um dos diferentes processos. No trabalho de Jesus a quantificação dos carbonetos foi avaliada pela técnica de difração de raios X, porém como o autor ressalta os resultados obtidos foram um tanto díspares, quando comparados com os resultados publicados na literatura, sugerindo a necessidade de estudos posteriores que elucidassem a questão.

A proposta inicial deste trabalho tinha como objetivos: (1) utilizar o método de Rietveld para refinamento da estrutura cristalina e quantificação da fração volumétrica dos 
carbonetos presentes nos aços AISI/SAE M2; (2) utilizando os dados cristalográficos proceder à identificação de fases através da obtenção dos padrões de Kikuchi pela técnica de difração de elétrons retro-espalhados (EBSD), e conseqüentemente as relações de orientação entre os carbonetos e a matriz, possibilitando aumentar o conhecimento que pudesse ser utilizado no desenvolvimento de materiais com melhores propriedades mecânicas.

O início do levantamento bibliográfico mostrou que os objetivos propostos sem dúvida possuíam o caráter inédito que se espera de uma tese de doutorado, porém também vislumbraram as dificuldades que teriam de ser transpostas para se atingir estes objetivos. Somando-se a este fato, os resultados iniciais obtidos no presente trabalho indicaram que: a austenitização, o resfriamento e o revenimento, utilizados no tratamento deste material teriam forte influência nos tipos de carbonetos formados. Assim, foi necessária uma redefinição dos objetivos.

Portanto, o objetivo deste trabalho foi extração, quantificação e determinação dos parâmetros cristalográficos, pelo método de Rietveld, dos carbonetos presentes em amostras de aço AISI/SAE M2 obtidas pelo processo convencional, por compactação e sinterização de pós atomizados e por conformação por spray, após a realização do revenimento final. 


\section{Os carbonetos nos aços rápidos}

A revisão bibliográfica apresentada neste capítulo enfoca primordialmente o entendimento dos carbonetos presentes nos aços rápidos. Na primeira parte deste capítulo são apresentadas algumas considerações sobre a estrutura cristalina dos carbonetos dos metais de transição e sobre os mecanismos de precipitação destes carbonetos nos aços rápidos. $\mathrm{Na}$ segunda parte é feito um resumo sobre a formação dos carbonetos no aço AISI/SAE M2. Alguns aspectos dos processos metalúrgicos relacionados aos processos de obtenção das amostras utilizadas neste trabalho serão apresentados no capítulo 3.

\subsection{Os carbonetos dos metais de transição}

O vanádio, cromo, molibdênio, tungstênio e o ferro possuem, em sua forma metálica, estrutura cristalina cúbica de corpo centrado. As principais características destes metais são apresentadas na TAB. 2.1. Pode-se ver que o parâmetro de rede para o vanádio, cromo e ferro, que estão situados na mesma linha da tabela periódica, diminui com o aumento do número atômico, uma vez que o aumento do número atômico nestes casos implica na adição de elétrons na camada interna $3 d$ da eletrosfera. Em contrapartida o parâmetro de rede aumenta com o número atômico para os elementos da mesma família.

Tabela 2.1: Características do arranjo metálico do vanádio, cromo, molibdênio, tungstênio e ferro.

\begin{tabular}{|c|c|c|c|c|}
\hline Elemento & $\begin{array}{l}\text { Parâmetro } \\
\text { de rede } \\
(\AA) \\
\end{array}$ & Distribuição eletrônica & $\begin{array}{l}\text { Densidade } \\
\left({\left.\mathrm{g} . \mathrm{cm}^{-3}\right)}^{-3}\right.\end{array}$ & $\begin{array}{c}\text { Volume } \\
\text { da célula } \\
\left(\AA^{3}\right) \\
\end{array}$ \\
\hline $2{ }_{23} \mathrm{~V}$ & 3,0274 & $1 \mathrm{~s}^{2}, 2 \mathrm{~s}^{2}, 2 \mathrm{p}^{6}, 3 \mathrm{~s}^{2}, 3 \mathrm{p}^{6}, 4 \mathrm{~s}^{2}, 3 d^{3}$ & 6,097 & 27,747 \\
\hline${ }_{24} \mathrm{Cr}$ & 2,8839 & $1 \mathrm{~s}^{2}, 2 \mathrm{~s}^{2}, 2 \mathrm{p}^{6}, 3 \mathrm{~s}^{2}, 3 \mathrm{p}^{6}, 4 \mathrm{~s}^{2}, 3 d^{4}$ & 7,200 & 23,985 \\
\hline${ }_{26} \mathrm{Fe}$ & 2,8664 & $1 \mathrm{~s}^{2}, 2 \mathrm{~s}^{2}, 2 \mathrm{p}^{6}, 3 \mathrm{~s}^{2}, 3 \mathrm{p}^{6}, 4 \mathrm{~s}^{2}, 3 d^{6}$ & 7,874 & 23,551 \\
\hline${ }_{42} \mathrm{Mo}$ & 3,1472 & $\begin{array}{c}1 \mathrm{~s}^{2}, 2 \mathrm{~s}^{2}, 2 \mathrm{p}^{6}, 3 \mathrm{~s}^{2}, 3 \mathrm{p}^{6}, 3 \mathrm{~d}^{10} \\
4 \mathrm{~s}^{2}, 4 \mathrm{p}^{6}, 4 d^{5}, 5 \mathrm{~s}^{1}\end{array}$ & 10,220 & 31,173 \\
\hline${ }_{74} \mathrm{~W}$ & 3,1648 & $\begin{array}{c}1 \mathrm{~s}^{2}, 2 \mathrm{~s}^{2}, 2 \mathrm{p}^{6}, 3 \mathrm{~s}^{2}, 3 \mathrm{p}^{6}, 3 \mathrm{~d}^{10} \\
4 \mathrm{~s}^{2}, 4 \mathrm{p}^{6}, 4 \mathrm{~d}^{10}, 4 \mathrm{f}^{14}, 5 \mathrm{~s}^{2}, 5 \mathrm{p}^{6} \\
5 d^{4}, 6 \mathrm{~s}^{2}\end{array}$ & 19,265 & 31,699 \\
\hline
\end{tabular}


No caso destes metais a inserção do carbono para a formação de carbonetos implica no estabelecimento de uma nova estrutura cristalina que minimize a energia interna do sistema. As estruturas mais estáveis dos carbonetos dos metais de transição de interesse são apresentadas na TAB. 2.2. Para estes elementos a inserção do carbono resulta principalmente em carbonetos sub-estequiométricos que implicam na formação de diversas fases cristalinas em função da estequiometria, conforme pode ser visto nos diagramas de fases apresentados nas FIG. de 2.1 a 2.5.

Tabela 2.2: Estrutura dos carbonetos dos metais de transição de interesse.

\begin{tabular}{cccc}
\hline Elemento & $\begin{array}{c}\text { Estrutura e } \\
\text { Grupo Espacial }\end{array}$ & $\begin{array}{c}\text { Parâmetros de rede } \\
(\mathbf{A})\end{array}$ & $\begin{array}{c}\text { Densidade } \\
\left(\mathbf{g . c m}^{-\mathbf{3}} \mathbf{)}\right.\end{array}$ \\
\hline $\mathbf{V C}$ & $\begin{array}{c}\text { CFC } \\
F m 3 m\end{array}$ & a: 4,16500 & 5,786 \\
$\mathbf{C r}_{\mathbf{3}} \mathbf{C}_{2}$ & $\begin{array}{c}\text { Ortorrômbica } \\
\text { Pnam }\end{array}$ & a: 5,$5273 ;$ b: 11,$4883 ;$ c: 2,8286 & $6,650-6,680$ \\
$\mathbf{F e}_{3} \mathbf{C}$ & $\begin{array}{c}\text { Ortorrômbica } \\
\text { Pnma }\end{array}$ & a: 5,$0910 ;$ b: 6,$7434 ;$ c: 4,5260 & 7,675 \\
$\mathbf{M o}_{2} \mathbf{C}$ & $\begin{array}{c}\text { Hexagonal } \\
P 63 / m m c\end{array}$ & a: 3,$0124 ;$ c: 4,7352 & 9,140 \\
$\mathbf{W C}$ & $\begin{array}{c}\text { Hexagonal } \\
P-6 m 2\end{array}$ & a: 2,$90631 ;$ c: 2,83754 & 15,660 \\
\hline
\end{tabular}

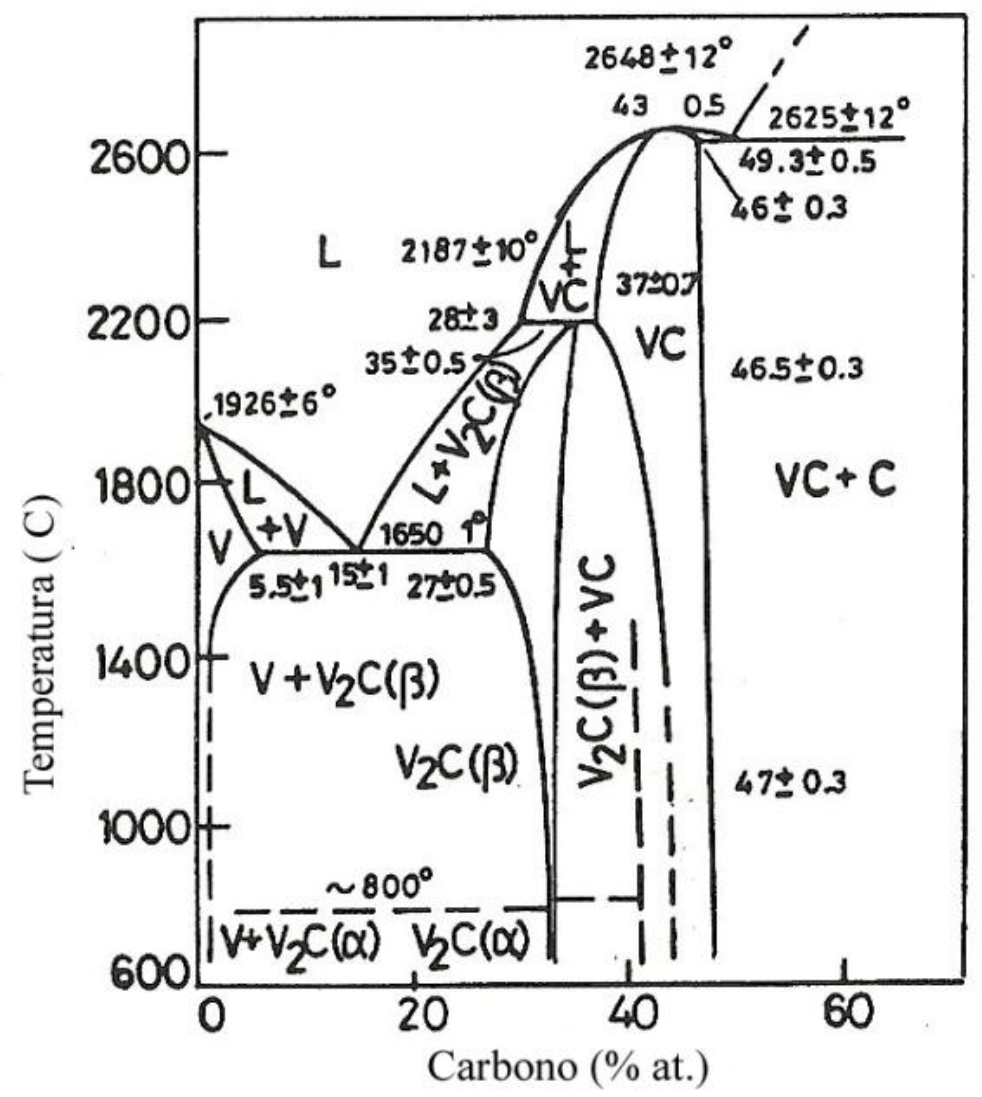

Figura 2.1: Diagrama de fases do sistema vanádio-carbono (Upadhyaya, 1996). 


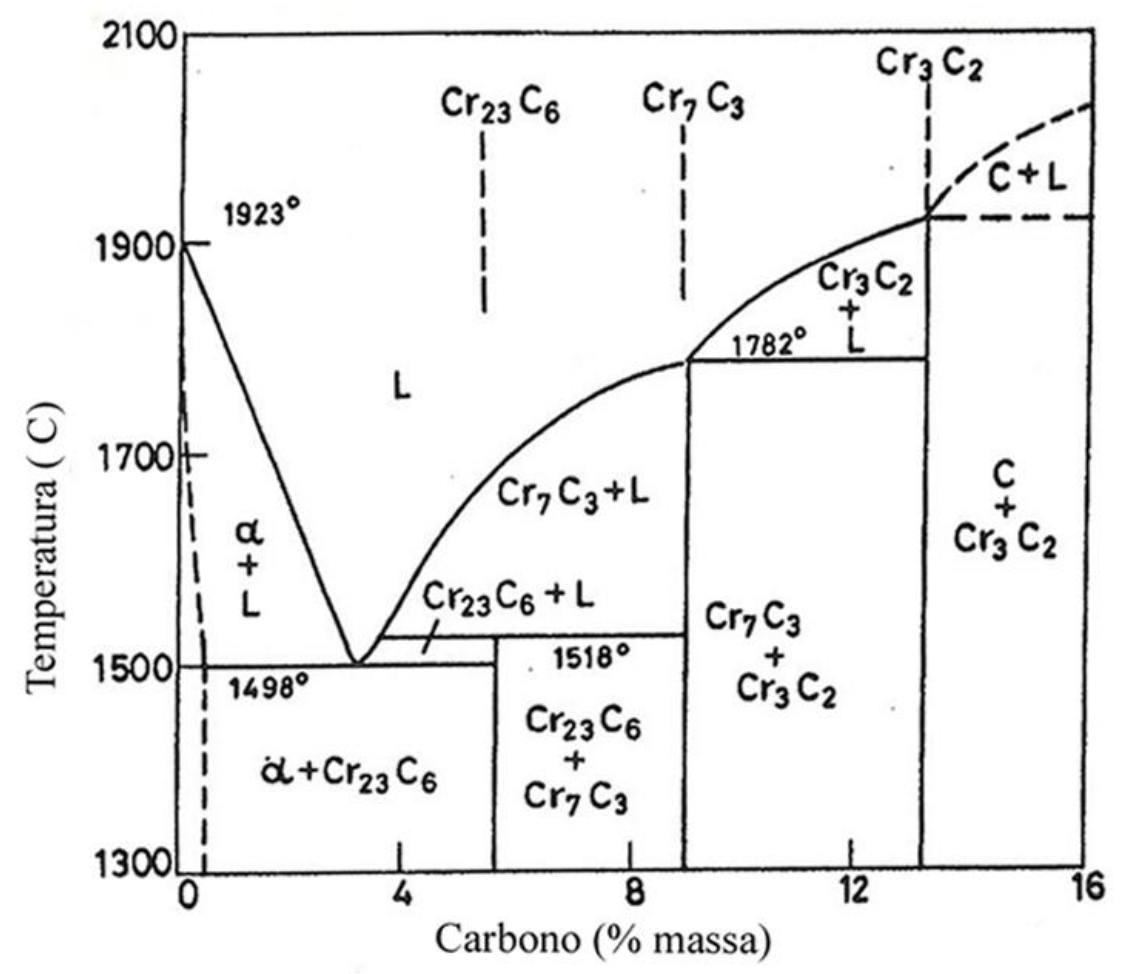

Figura 2.2: Diagrama de fases do sistema cromo-carbono (Upadhyaya, 1996).

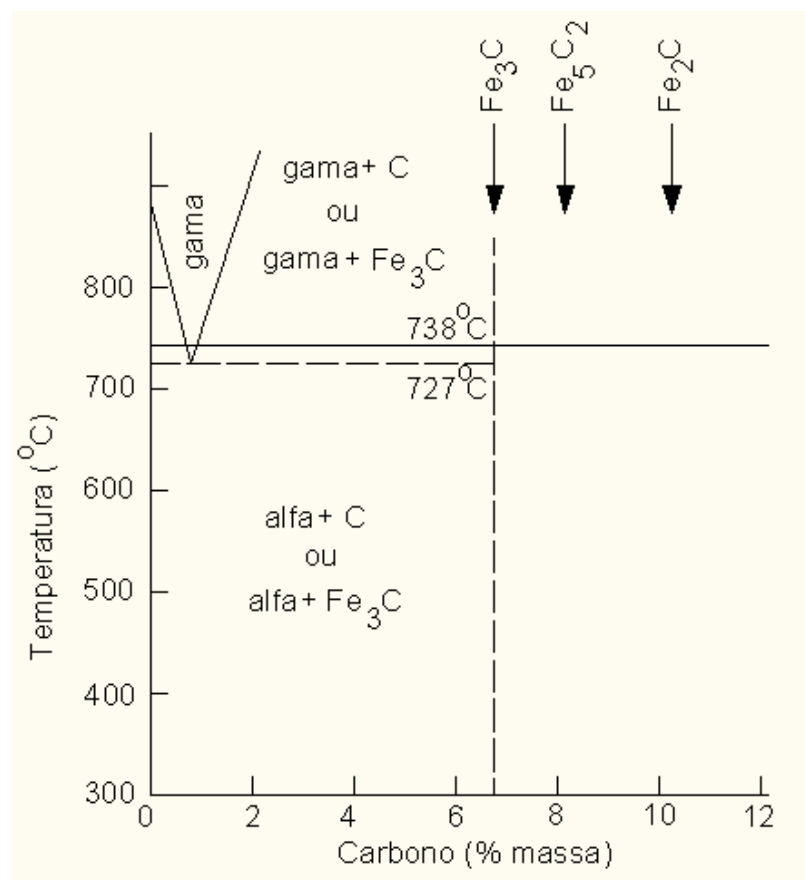

Figura 2.3: Diagrama de fases do sistema ferro-carbono (Upadhyaya, 1996). 


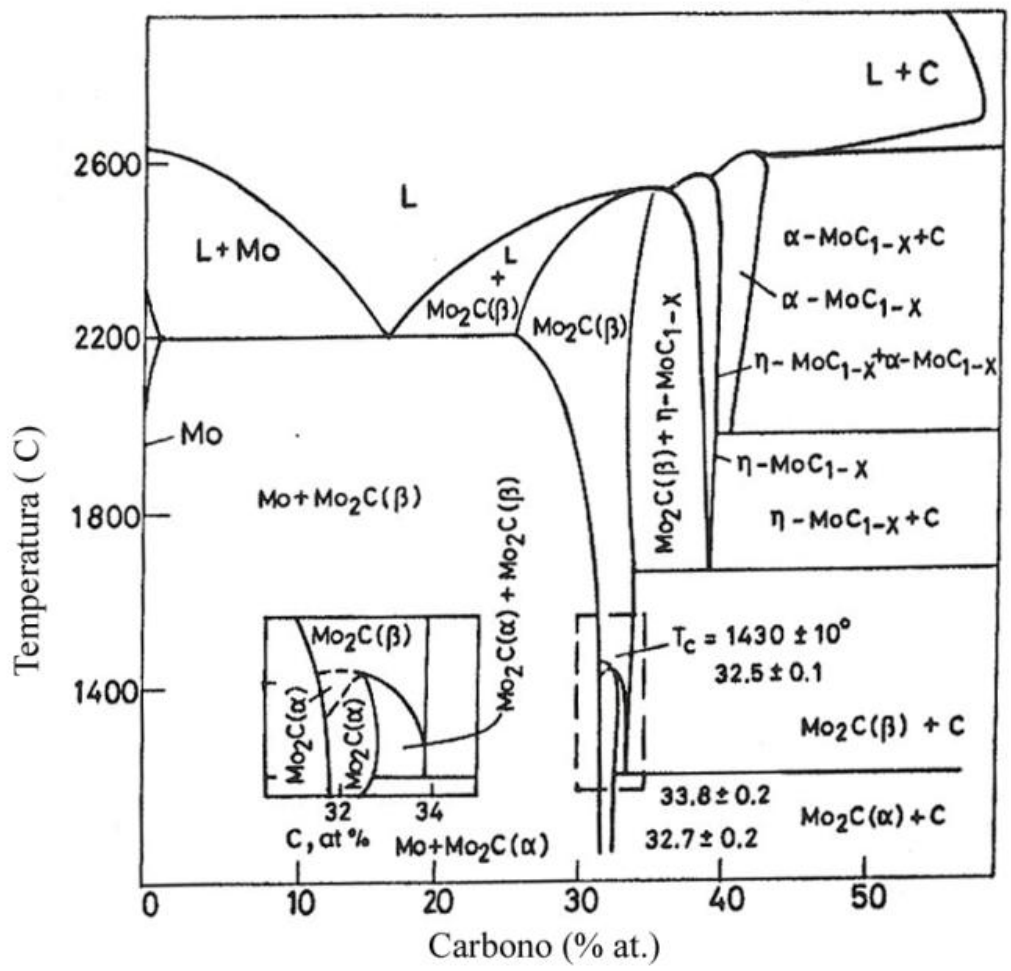

Figura 2.4: Diagrama de fases do sistema molibdênio-carbono (Upadhyaya, 1996).

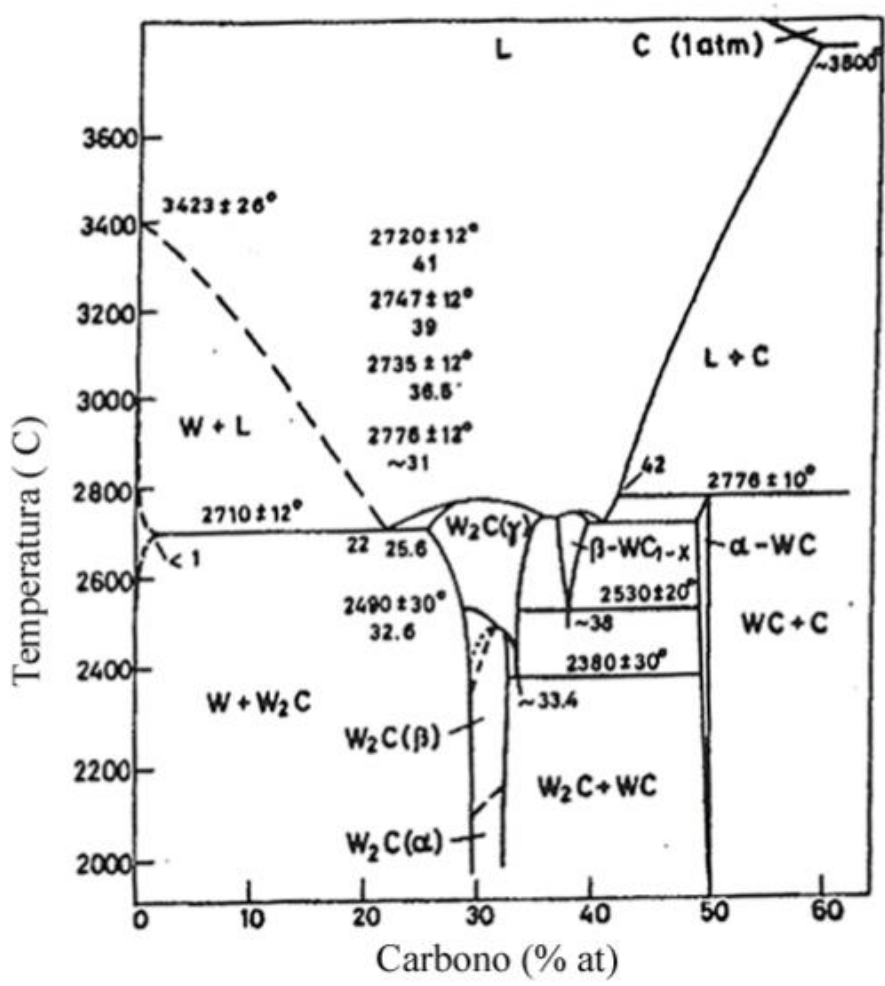

Figura 2.5: Diagrama de fases do sistema tungstênio-carbono (Upadhyaya, 1996). 
Os carbonetos puros tem sido objeto de muitos estudos em função das suas excelentes propriedades químicas, mecânicas, elétricas e magnéticas (Upadhyaya, 1996, Kosolapova, 1971; Storms, 1967). Os principais métodos para a obtenção dos carbonetos puros são: síntese a partir do elemento puro, redução do óxido, deposição a partir da fase gasosa, eletrólise do sal fundido e precipitação química (Kosolapova, 1971). A ocorrência de carbonetos na natureza é bastante rara, porém sua presença na forma de precipitados em aços é documentada desde o século XIX.

Os carbonetos encontrados nos aço são denominados de carbonetos intersticiais uma vez que nestes compostos o arranjo cristalino pode ser descrito como um arranjo de átomos metálicos com átomos de carbono ocupando os interstícios. Dentre todos os sistemas metais-carbono o sistema ferro-carbono, presente nos aços, foi objeto dos estudos mais aprofundados em função de sua importância tecnológica. Para a compreensão da estrutura cristalina e dos mecanismos de formação dos carbonetos nos aços ledeburiticos, como é o caso dos aços rápidos, é essencial o entendimento dos mecanismos de formação das fases: cementita $\left(\mathrm{Fe}_{3} \mathrm{C}\right)$, carboneto $\chi$ e carboneto $\varepsilon$, do sistema ferro-carbono.

Nos arranjos do ferro metálico, os interstícios podem ser classificados em dois tipos: tetraédricos formados por quatro átomos metálicos e octaédricos circundados por seis átomos metálicos. Nas três formas alotrópicas do ferro, vide FIG. 2.6 (cúbica de corpo centrado (CCC), cúbica de face centrada (CFC) e hexagonal compacta (HCP)) o carbono ocupa os interstícios octaédricos.

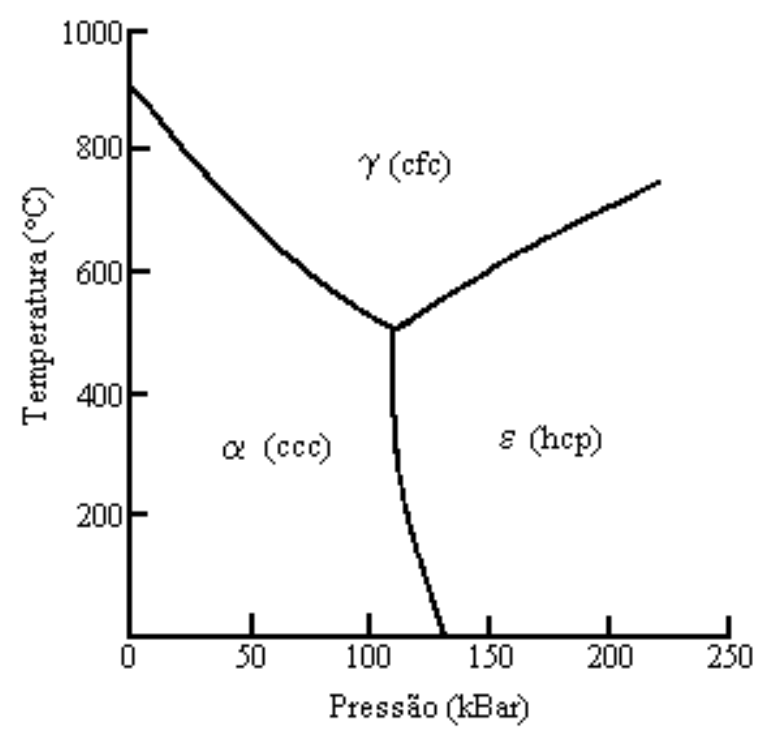

Figura 2.6: Formas alotrópicas do ferro em função da temperatura e pressão: cúbica de corpo centrado, cúbica de face centrada e hexagonal compacta (Jack e Jack, 1973). 
Na FIG. 2.7 pode-se ver que o octaedro regular formado pelos átomos metálicos é distorcido na estrutura cúbica de corpo centrado quando comparado com o mesmo interstício nas estruturas cúbica de face centrada e hexagonal compacta.

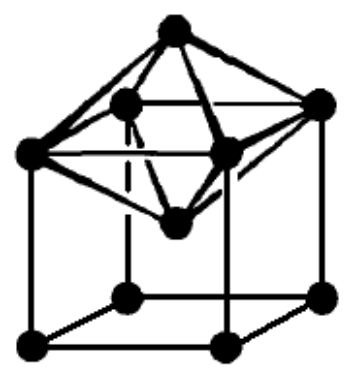

c.c.c.

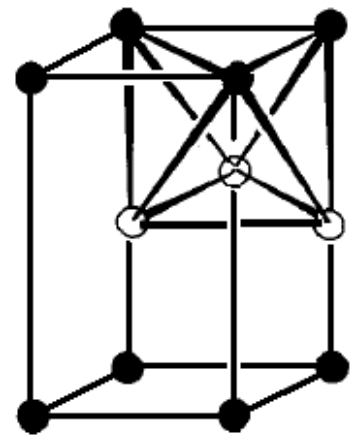

H.C.

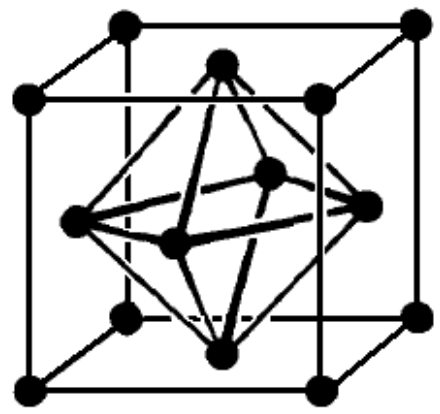

C.F.C

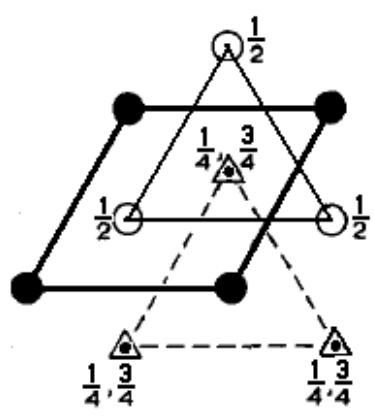

H.C. (plano)

Figura 2.7: Interstícios octaédricos das estruturas cristalina do ferro (Jack e Jack, 1973).

A inserção do carbono neste interstício octaédrico volta a estabelecer o ambiente regular do ferro, mas produz uma grande tensão anisotrópica na matriz ao redor, que resulta na baixa solubilidade do átomo de carbono na estrutura cúbica de corpo centrado do ferro $\alpha$.

A cementita $\left(\mathrm{Fe}_{3} \mathrm{C}\right)$ apresenta estrutura cristalina ortorrômbica. Esta estrutura pode ser descrita como um arranjo de átomos metálicos que formam um hexágono regular com distorções localizadas para a acomodação dos átomos de carbono. Nesta estrutura o ambiente do carbono é um prisma triangular de átomos de ferro, FIG. 2.8, e os prismas estão ligados pelos cantos e pelos lados para formar folhas, as quais estão empilhadas perpendicularmente ao eixo-c da estrutura da cementita, FIG. 2.9.

A temperatura de Curie para o ferromagnetismo da cementita é de $215{ }^{\circ} \mathrm{C}$, possibilitando a utilização desta característica física para sua identificação nos aços. Assim 
como nos demais carbonetos as dimensões da célula unitária são afetadas pela substituição parcial do ferro por elementos de liga encontrados nos aços comerciais.

Para o carboneto $\chi$, sintetizado por Hägg, inicialmente adotou-se a composição $\mathrm{Fe}_{2} \mathrm{C}$ e a partir da interpretação do padrão de difração de pó identificou-se a estrutura cristalina como ortorrômbica com a célula unitária $\mathrm{Fe}_{20} \mathrm{C}_{9}$. Estudos posteriores mostraram que a estrutura deste carboneto é monoclínica com a célula unitária $\mathrm{Fe}_{20} \mathrm{C}_{8}$ (Kosolapova, 1971).

No carboneto $\chi$ o ambiente do átomo de carbono é novamente um prisma trigonal, FIG. 2.8. Neste caso os prismas trigonais estão ligados pelo compartilhamento dos lados e cantos para formar folhas duplas no plano (100) da estrutura monoclínica, FIG. 2.9. É possível relacionar as estruturas do carboneto $\chi$ e da cementita, considerando uma distorção de $7,74^{\circ}$ na célula monoclínica do carboneto $\chi$, TAB. 2.3.
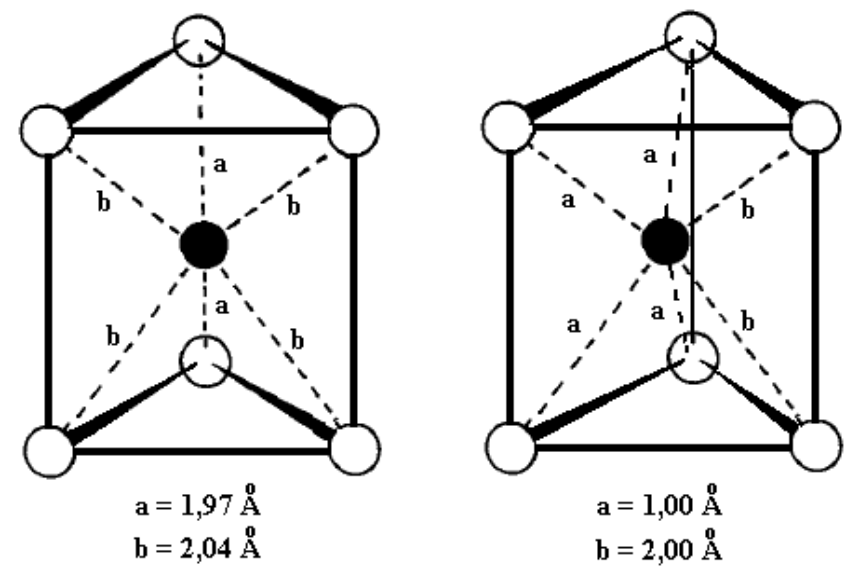

Figura 2.8: Ambiente do carbono na cementita $\left(\mathrm{Fe}_{3} \mathrm{C}\right)$ e no carboneto $\chi\left(\mathrm{Fe}_{5} \mathrm{C}_{2}\right)(\mathrm{Jack}$ e Jack, 1973).
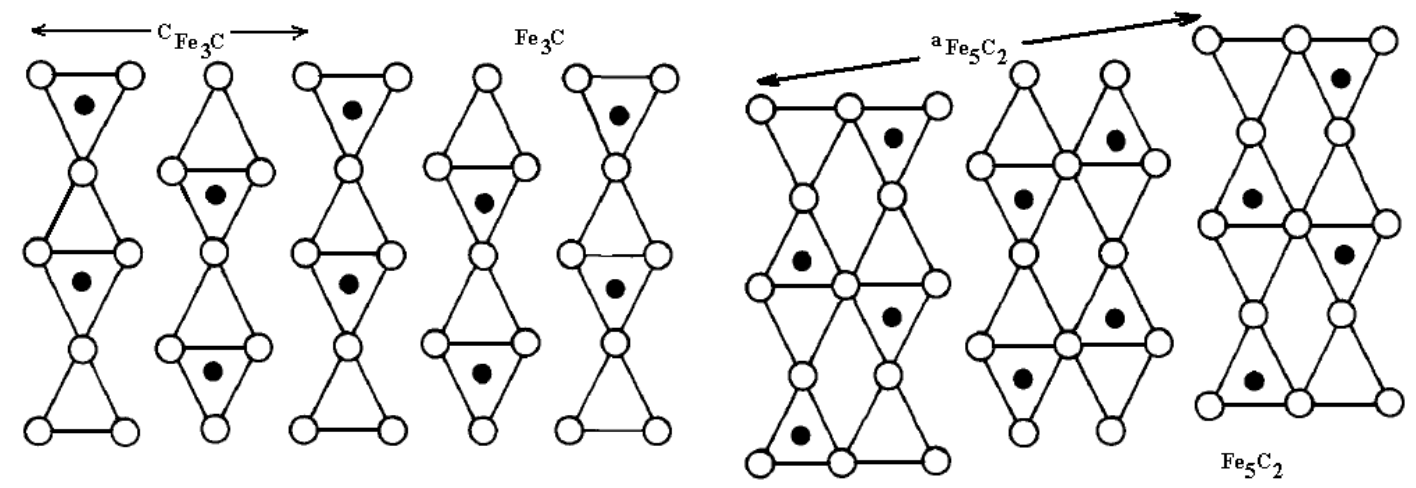

Figura 2.9: Arranjo das células unitárias na cementita $\left(\mathrm{Fe}_{3} \mathrm{C}\right)$ e no carboneto $\chi\left(\mathrm{Fe}_{5} \mathrm{C}_{2}\right)$ (Jack e Jack, 1973). 
Tabela 2.3: Relações cristalográficas entre a cementita e o carboneto $\chi$ (Jack e Jack, 1973).

\begin{tabular}{|c|c|}
\hline $\mathrm{Fe}_{3} \mathrm{C}$ & $\mathrm{Fe}_{5} \mathrm{C}_{2}$ \\
\hline$a=4,526$ & $a=11,562$ \\
\hline$b=5,087$ & $b=4,573$ \\
\hline$c=6,744$ & $\bar{c}=5,060$ \\
\hline$a_{\text {cem }} \sim b_{\chi}$ & $2 \mathrm{c}_{\mathrm{cem}} \sim \mathrm{a}_{\chi}$ \\
\hline
\end{tabular}

Assim como a cementita, o carboneto $\chi$ apresenta comportamento ferromagnético com a temperatura de Curie de $247^{\circ} \mathrm{C}$.

$\mathrm{O}$ carboneto $\varepsilon\left(\mathrm{Fe}_{\mathrm{x}} \mathrm{C}\right)$ é um carboneto não estequiométrico, onde o valor de ' $\mathrm{X}$ ' está intimamente relacionado com as dimensões da células unitária hexagonal. A partir de considerações sobre o volume atômico por átomo de ferro no carboneto $\varepsilon$ e em outras ligas com estruturas intersticiais estimou-se sua composição como $\mathrm{Fe}_{2,4} \mathrm{C}$. $\mathrm{O}$ arranjo dos átomos metálicos no carboneto $\varepsilon$ é hexagonal compacto (Kosolapova, 1971).

Diferentemente da cementita e do carboneto $\chi$, o ambiente do carbono no carboneto $\varepsilon$ é um octaedro de átomos metálicos. Sua temperatura de Curie ainda não foi determinada diretamente uma vez que a transformação para o carboneto $\chi$ ou para a cementita ocorre abaixo do ponto de Curie, mas pelo uso de ligas ferro-silício com precipitação apenas do carboneto $\varepsilon$ estima-se que esta temperatura esteja na faixa de $450^{\circ} \mathrm{C}$ $-500^{\circ} \mathrm{C}$ (Jack e Jack, 1973).

As estruturas cristalinas dos carbonetos dos metais de liga metalurgicamente significantes foram classificadas por Goldschmidt, (1967) como carbonetos binários com base no arranjo de seus átomos metálicos e considerando a seqüência de empilhamento dos planos para a formação da estrutura. Em todos os arranjos cristalinos há pelo menos um interstício octaédrico formado por átomos metálicos, mas somente uma parte destes interstícios pode ser preenchida, razão pela qual se formam as estruturas complexas e os carbonetos sub-estequiométricos. Em muitos casos o não preenchimento dos interstícios tem um arranjo específico, conseqüentemente a estrutura nestes casos é uma estrutura ordenada.

Parthé e Yvon (1970) propuseram uma classificação racional e uma notação a

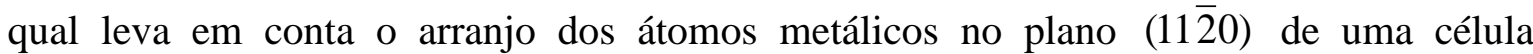


hexagonal e o grau de ordem dos átomos intersticiais. As cinco variações de empilhamento são apresentadas na FIG. 2.10, onde os círculos abertos representam os átomos metálicos e os círculos fechado o átomo de carbono, abaixo de cada arranjo é apresentado o símbolo de Jagodzinski-Wyckoff utilizado para designar o arranjo dos átomos metálicos.

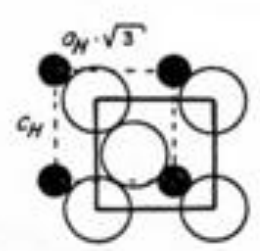

$\mathrm{h}$ $\mathrm{M}_{2} \mathrm{C}$

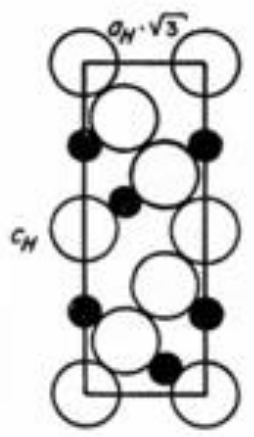

hcc

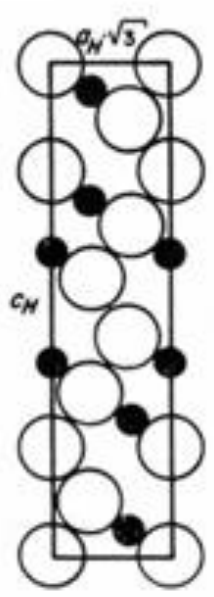

hhc

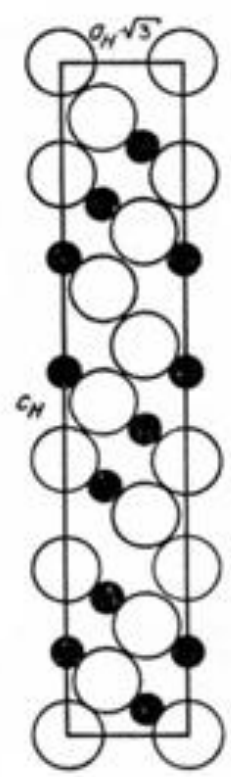

hhcc

$\mathrm{M}_{4} \mathrm{C}_{3}$

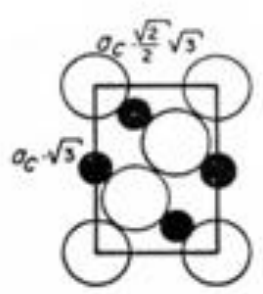

c

$\mathrm{MC}$

Figura 2.10: Arranjo atômico do plano $(11 \overline{2} 0)$ de uma célula hexagonal representado os possíveis empilhamentos para os átomos metálicos dos carbonetos de metais de transição, a fórmula representa a composição para o maior conteúdo de carbono (Parthé e Yvon, 1970).

As diferenças estequiométricas verificadas podem ser explicadas devido à restrição na ocupação dos interstícios octaédricos por átomos de carbono as quais dependem em particular do empilhamento dos átomos metálicos. A restrição impõe que se dois interstícios estão localizados diretamente acima um do outro somente um deles poderá ser preenchido, enquanto que o outro permanecerá vazio. Os estudos realizados por difração de nêutrons até o presente momento têm confirmado esta regra sem nenhuma exceção para as estruturas compactas. Um possível uso para esta regra é o cálculo da estequiometria máxima para cada um dos arranjos da FIG. 2.10.

Dos metais de transição utilizados como elementos de liga no aço AISI/SAE M2 apenas o vanádio forma o carboneto designado como MC. Porém, estudos realizados no sistema vanádio-carbono mostram que não é possível a obtenção da fórmula 
estequiométrica MC. Para a razão $C / V<1$, na faixa de $\mathrm{VC}_{0,65}$ a $\mathrm{VC}_{0,88}$ a estrutura é $F m 3$ $m$ (estrutura do $\mathrm{NaCl}$ ). Venables (1968), Billingh (1971 e 1972), Lipatnikov e Gusev (1999), Adnane (1992) e Kesri (1988a, 1988b) descreveram que arranjos ordenados ocorrem dentro desta faixa de composição como $\mathrm{V}_{8} \mathrm{C}_{7}$ e $\mathrm{V}_{6} \mathrm{C}_{5}$. No intervalo $\mathrm{VC}_{0,86}$ a $\mathrm{VC}_{0,88}$ é possível observar a fase ordenada $\mathrm{V}_{8} \mathrm{C}_{7}$ do tipo cúbica simples $\left(P 4_{3} 32\right.$ ou $\left.P 4_{1} 32\right)$. Já dentro do intervalo $\mathrm{VC}_{0,76}$ a $\mathrm{VC}_{0,86}$ aparece a fase ordenada $\mathrm{V}_{6} \mathrm{C}_{5}$ que pode apresentar estrutura trigonal $\left(P 3_{1}\right)$ ou monoclínica $(C 2$ ou $C 2 / m)$. O carboneto de vanádio encontrado nos aços possui estrutura cúbica de face centrada, e é costumeiramente designado pela formula $\mathrm{V}_{4} \mathrm{C}_{3}$.

Carbonetos grosseiros em aços, contendo alta concentração de carbono e vanádio, foram identificados como $\mathrm{V}_{6} \mathrm{C}_{5}$ utilizando-se microscopia eletrônica de transmissão de alta resolução e análise por difração de área selecionada (Epicier, 2008).

O cromo, o molibdênio e o tungstênio não se cristalizam com estrutura cúbica de face centrada na temperatura ambiente. $\mathrm{O}$ monocarboneto de cromo foi obtido por implantação iônica de carbono em filmes finos de cromo puro por Liu e Cheng (1992). O molibdênio pode formar monocarboneto (MoC) sob pressão elevada, com parâmetro de rede 4,2485 ̊̊ (Yosida e Oguro, 2006).

Haglung et al. (1993) realizaram um extenso estudo dos carbonetos dos metais de transição utilizando o método linear-muffin-tin-orbitals (LMTO). Os autores definiram os monocarbonetos dos metais de transição como sendo formados pela estrutura cúbica de face centrada dos átomos metálicos, para as quais calcularam os parâmetros de rede, vide TAB 2.4, na qual o carbono ocupa os interstícios octaédricos resultando no aumento do volume da célula.

Tabela 2.4: Parâmetros de rede calculados para a estrutura cúbica de face centrada (CFC) dos metais de transição e parâmetro de rede do monocarboneto.

\begin{tabular}{ccc}
\hline \multirow{2}{*}{ Elemento } & \multicolumn{2}{c}{ Parâmetro de rede $(\AA)$} \\
& Estrutura CFC & Monocarboneto \\
\hline \hline V & 3,6036 & 4,172 \\
Cr & 3,4343 & 4,03 \\
Mo & 4,0270 & 4,2485 \\
W & 4,0587 & 4,222 \\
\hline
\end{tabular}

$\mathrm{O}$ carboneto misto de ferro e tungstênio $(\mathrm{FeW})_{6} \mathrm{C}$, também chamado de carboneto $\eta$, foi primeiramente identificado nos aços rápidos e conseqüentemente tem sido referenciado como um carboneto do aço rápido. Nos aços ao molibdênio, como é o caso do 
AISI/SAE M2, parte do tungstênio é substituída por molibdênio. A estrutura cristalina é cúbica de face centrada do grupo $F d 3 \mathrm{~m}$ com noventa e seis átomos metálicos por célula unitária e vinte e quatro interstícios octaédricos, dezesseis dos quais estão preenchidos, FIG. 2.11 (Jack e Jack, 1973).

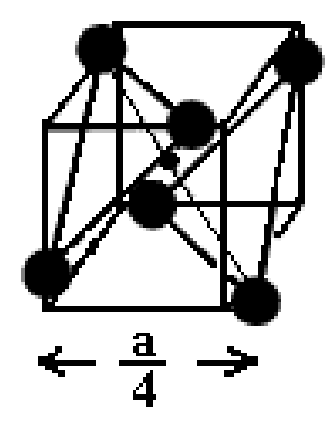

Figura 2.11: Esquema de 1/4 da célula unitário do carboneto do tipo $\mathrm{M}_{6} \mathrm{C}$ mostrando o interstício octaédrico formado pelos átomos metálicos.

A estequiometria do carboneto do tipo $\mathrm{M}_{6} \mathrm{C}$ tem sido reportada como variando entre $\mathrm{Fe}_{3} \mathrm{~W}_{3} \mathrm{C}$ a $\mathrm{Fe}_{3} \mathrm{Mo}_{3} \mathrm{C}$ (Fraker,1969, Shtansky, 1997, Giron, 1995). O parâmetro de rede varia de 11,0870 ̊ para o $\mathrm{Fe}_{3} \mathrm{~W}_{3} \mathrm{C}$ a $11,1355 \AA$ para o $\mathrm{Fe}_{3} \mathrm{Mo}_{3} \mathrm{C}$.

\subsection{Mecanismos de formação de carbonetos nos aços}

Os mecanismos de formação de carbonetos foram preponderantemente estudados através da formação dos carbonetos de ferro. No entanto, estes mecanismos são bastante explicativos para a formação de carbonetos dos elementos de liga presentes, considerando-se que estes aços são ledeburíticos e a solubilidade dos elementos de liga na fase matriz, vide TAB. 2.5.

Tabela 2.5: Solubilidade dos elementos de liga do aço AISI/SAE M2 nas estruturas cristalinas do ferro.

\begin{tabular}{cccc}
\hline Elemento de liga & $\begin{array}{c}\text { Fase alfa } \\
(\% \text { massa })\end{array}$ & $\begin{array}{c}\text { Fase gama } \\
(\% \text { massa })\end{array}$ & $\begin{array}{c}\text { Fase gama na presença de carbono } \\
(\%)\end{array}$ \\
\hline \hline $\mathrm{V}$ & $\infty$ & 2 & $4(0,20 \%$ massa $\mathrm{C})$ \\
$\mathrm{Cr}$ & $\infty$ & 12 & $20(0,50 \%$ massa $\mathrm{C})$ \\
$\mathrm{Mo}$ & 30 & 3 & $8(0,30 \%$ massa C $)$ \\
$\mathrm{W}$ & 32 & 6 & $11(0,25 \%$ massa $\mathrm{C})$ \\
\hline
\end{tabular}

Nos aços a precipitação de carbonetos ocorre durante a decomposição eutetóide da austenita, no revenimento da martensita e no envelhecimento da ferrita supersaturada. A 
decomposição do sistema austenita-carbono acima da temperatura para a formação da martensita $\left(\mathrm{M}_{\mathrm{S}}\right)$ resulta numa dispersão de cementita na ferrita. Apesar de a cementita ser metaestável em relação à grafita, a estrutura mantém-se por períodos prolongados em temperatura abaixo de $650{ }^{\circ} \mathrm{C}$.

$\mathrm{Na}$ transformação martensítica da austenita os átomos intersticiais não tem tempo para se mover dos interstícios que eles ocupavam na austenita e formam uma ferrita supersaturada de carbono na qual todos os interstícios ocupados têm seu eixo de expansão apontando para a mesma direção. Assim a martensita é considerada tetragonal e não cúbica.

A representação esquemática mais comum da estrutura martensítica é na realidade a representação de uma estrutura média, FIG. 2.12(a), considerando que a tetragonalidade dos domínios individuais de martensita depende da temperatura da transformação martensítica e da concentração local de carbono.

Uma representação mais conveniente foi proposta por Jack e Jack (1973), na qual existem conjuntamente unidades da estrutura distorcidas pela presença dos átomos intersticiais e unidades com os interstícios não preenchidos as quais em primeira aproximação tem a mesma dimensão do ferro $\alpha$, FIG. 2.12(b).

Entretanto, em uma solução sólida das fases ferrita, austenita, ferro $\varepsilon$ e martensita, o ambiente imediato de cada átomo de carbono é sempre o mesmo. A diferença está no número de octaedros preenchidos e na sua distribuição que determinam as alterações anisotrópicas dos parâmetros de rede da célula unitária. Na FIG. 2.13 é apresentada a variação dos parâmetros $a$ e $c$ em função do teor de carbono. Os parâmetros de rede obtidos por difração de raios X, pelo método do pó, refletem o tamanho médio dos domínios martensíticos (Wießner et al., 2005).

No entanto, quando o número de átomos intersticiais é pequeno a razão c/a é menor que aquela calculada pela extrapolação dos valores apresentados no gráfico da FIG. 2.13, e nestes casos a martensita é cúbica com parâmetro de rede maior que o do ferro $\alpha$. A tetragonalidade da martensita exerce um papel importante na formação dos carbonetos em razão da taxa de difusividade dos átomos de carbono e dos elementos de liga e da concentração de defeitos cristalinos provocados pela presença do carbono. Portanto, o mecanismo de formação de carbonetos no revenimento da martensita deve considerar a diferença entre estruturas com baixo e alto teor de intersticiais. 


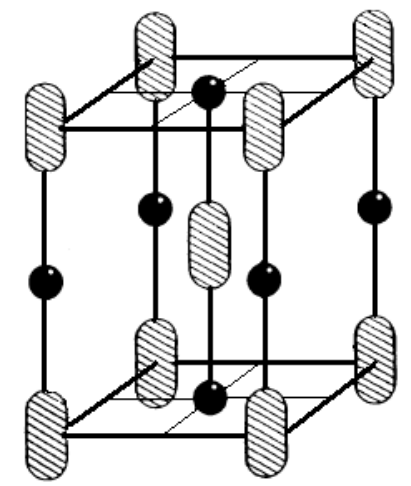

Posições possíveis para o átomo de Ferro

Átomos de Carbono

(a)

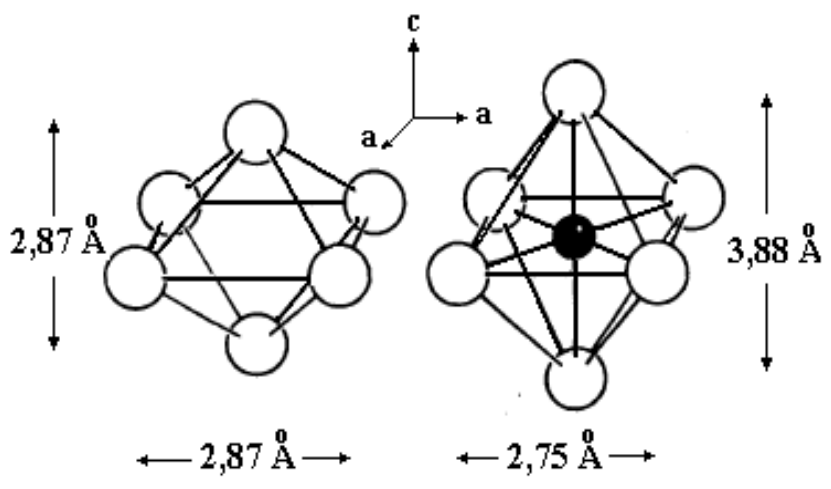

(b)

Figura 2.12: Representação da esquemática da célula unitária da martensita (Jack e Jack, 1973).

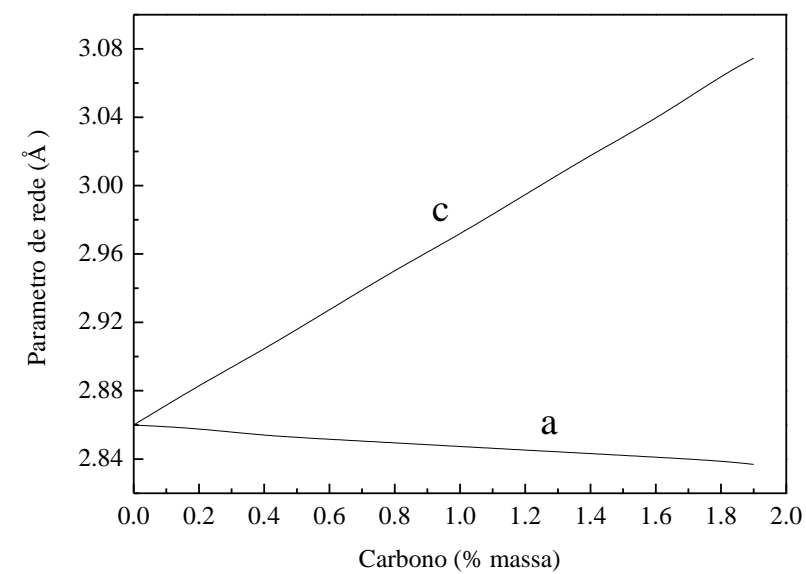

Figura 2.13: Parâmetros de rede da martensita em função do conteúdo de carbono.

Dentre as etapas de formação de carbonetos citadas anteriormente, a precipitação de carbonetos durante o revenimento da martensita é o mecanismo de maior interesse no estudo desenvolvido neste trabalho. A precipitação de carbonetos no revenimento da martensita tetragonal, isto é, com alto teor de carbono (>0,7\% massa) pode ser descrita como um processo de três etapas:

(i) $80-200{ }^{\circ} \mathrm{C}$, precipitação de carboneto $\varepsilon$;

(ii) $200-300{ }^{\circ} \mathrm{C}$, decomposição da austenita retida;

(iii) $\quad 200-600{ }^{\circ} \mathrm{C}$, precipitação de carboneto $\chi$ e da cementita.

Nestes processos o mecanismo predominante é a difusão atômica do carbono e, no caso dos aços multi-elementares, dos elementos de liga. Na FIG. 2.14 é apresentado um 
gráfico da taxa de difusão em função da temperatura para o átomo de carbono e a média da taxa de difusividade dos elementos de liga do aço AISI/SAE M2.

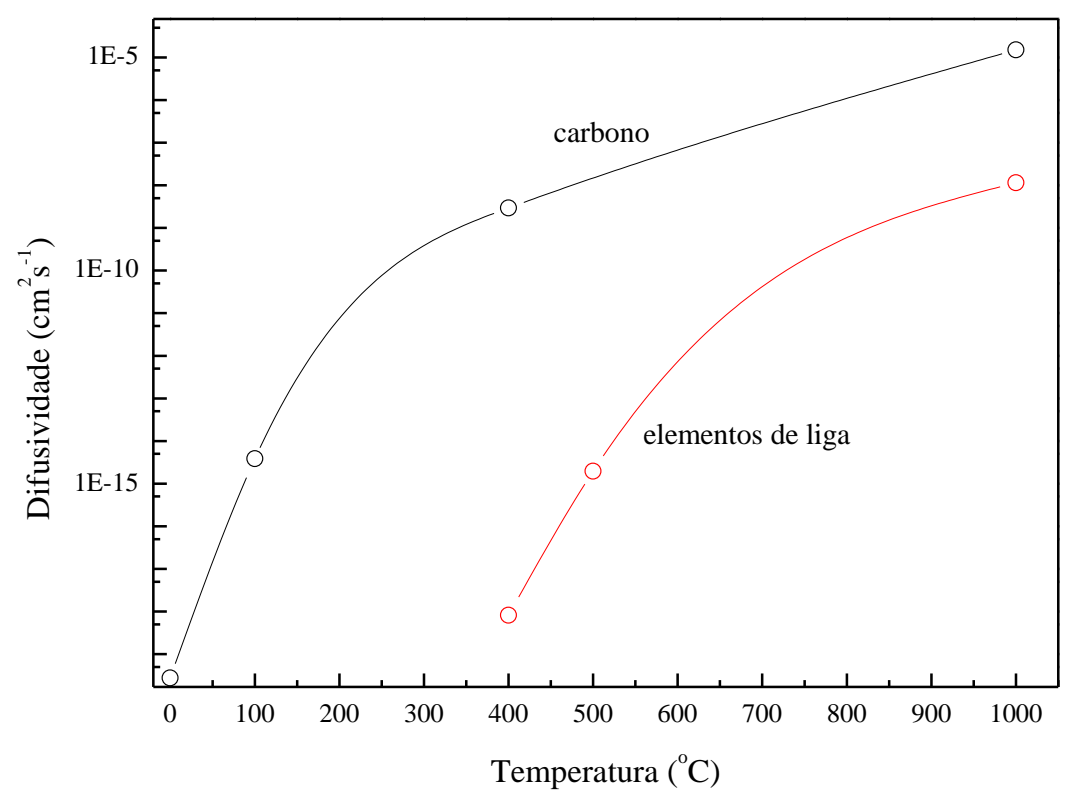

Figura 2.14: Coeficiente de difusão dos átomos dos elementos de liga na martensita.

Nos primeiros estágios do revenimento ocorre a precipitação do carboneto $\varepsilon$, de estrutura hexagonal, já que a mobilidade dos átomos de liga nesta faixa de temperatura é muito baixa. As intensidades das reflexões do espectro de difração de raios X, obtidas em estudos realizados no sistema ferro-carbono, sugerem a existência de orientação preferencial normal aos planos $(101)_{\varepsilon}$ o que pode ser devido a existência de cristalitos na forma de agulhas com crescimento preferencial nesta direção. A relação entre os parâmetros de rede do arranjo dos átomos de metais no carboneto $\varepsilon$ e as fases ferrítica e martensítica leva a proposição da relação de orientação:

$$
(001)_{\varepsilon}\left\|(011)_{\alpha}:[100]_{\varepsilon}\right\|[2 \overline{1} 1]_{\alpha}
$$

Esta relação implica no paralelismo dos planos $(101)_{\varepsilon} \|(101)_{\alpha}$ e $(100)_{\varepsilon} \|$ $(2 \overline{1} 1)_{\alpha}$ com uma defasagem de menos de $1 \%$ entre os espaçamentos interplanares. A análise por microscopia eletrônica de transmissão e por dados de difração de monocristais confirmam esta relação de orientação, mas outras relações de orientação e morfologias também têm sido observadas. 
O carboneto $\varepsilon$ é altamente instável, com relação ao carbono e a presença de discordâncias. De maneira que aços com alto teor de carbono e severamente deformados plasticamente podem não apresentar formação de carboneto $\varepsilon$.

Com a elevação da temperatura iniciam-se o segundo e o terceiro estágios do revenimento, onde ocorrem a decomposição da austenita e a precipitação do carboneto $\chi \mathrm{e}$ da cementita. As alterações nas intensidades relativas do espectro de difração de raios $\mathrm{X}$ são um forte indicativo que a cementita precipita em forma de finas plaquetas com crescimento preferencial na direção $c$. As relações apresentadas na TAB. 2.3 permitem concluir que as placas de cementita e de carboneto $\chi$ com uma leve distorção na estrutura monoclínica podem ser consideradas quase como estruturas isomorfas.

$\mathrm{Na}$ temperatura em que ocorre o terceiro estágio do revenimento a difusão dos elementos de liga para o carboneto $\chi$ e para a cementita é significativa levando a ocorrência de reações que resultam na precipitação dos carbonetos.

No revenimento da martensita com baixo teor de carbono não ocorre a formação de carboneto $\varepsilon$ devido a segregação do carbono para as discordâncias que são locais mais estáveis. Neste caso a formação do carboneto $\chi$ e da cementita ocorre em temperatura cerca de $50{ }^{\circ} \mathrm{C}$ mais baixa que na martensita com maior teor de carbono.

\subsection{Os carbonetos no aço AISI/SAE M2}

A formação dos carbonetos no aço AISI/SAE M2 inicia-se na etapa de solidificação do metal fundido. A temperatura de fusão deste aço é da ordem de $1625^{\circ} \mathrm{C}$ (Hoyle, 1988).

$\mathrm{Na}$ transição do estado líquido para o estado sólido $\left(1435{ }^{\circ} \mathrm{C}-1425{ }^{\circ} \mathrm{C}\right)$ surgem os primeiros núcleos de ferrita- $\delta$. Nesta ferrita estão dissolvidos os principais elementos de liga: tungstênio, molibdênio, vanádio e cromo. A solubilidade do carbono, na estrutura cúbica de corpo centrado, por ocupar posições intersticiais, é muito mais baixa que a dos elementos de transição (substitucionais). Assim, o carbono é segregado para fora da ferrita permanecendo na fase ainda líquida.

A diminuição da temperatura $\left(1335^{\circ} \mathrm{C}-1325^{\circ} \mathrm{C}\right)$ inicia as reações peritéticas que levam a transformação da ferrita em austenita e a precipitação dos carbonetos. As reações peritéticas ocorrem até temperaturas da ordem de $1240{ }^{\circ} \mathrm{C}$, quando ainda existe fase líquida entre as dendritas já solidificadas (Galda e Kraft, 1974; McLaughlin et al., 1977). Toda a ferrita- $\delta$ terá se decomposto em austenita e na formação de carbonetos 
quando a temperatura "solidus" for atingida. As transformações de fases peritéticas podem ser descrita pela seguinte reação adaptada:

$$
\text { metal fundido }+ \text { ferrita- } \delta \rightarrow \text { austenita }+ \text { carbonetos }
$$

Esta reação pode ser descrita por duas reações binárias, uma reação peritética adaptada e outra eutetóide, que ocorrem ao mesmo tempo:

1) Reação peritética: metal fundido $\rightarrow$ austenita + carboneto eutético ledeburítico;

2) Reação eutetóide: ferrita- $\delta \rightarrow$ austenita + carboneto eutetóide- $\delta$.

Para MacLaughlin et al. (1977) a primeira parte ocorre por volta de $1330{ }^{\circ} \mathrm{C}$, quando o núcleo de ferrita- $\delta$ ainda esta rodeado por fase líquida transformando-se em austenita. A segunda parte ocorre entre a ferrita- $\delta$ e o centro da dendrita onde, inicialmente a ferrita- $\delta$ se transforma em austenita com baixo teor de carbono e subseqüentemente em carboneto. As reações eutetóides iniciam-se por volta de $1280{ }^{\circ} \mathrm{C}$ e são controladas pela difusão atômica nas diversas fases presentes a esta temperatura.

Esta seqüência de solidificação ocorre tanto na obtenção do aço pelo processo convencional de lingotamento, como nos processos por metalurgia do pó (obtenção de pós atomizados e conformação por spray). A diferença nestes processos esta na taxa de resfriamento. Enquanto no processo de lingotamento esta taxa é de cerca de $10^{-3}{ }^{\circ} \mathrm{Cs}^{-1}$, na metalurgia do pó trabalha-se com taxa da ordem de até $10^{6}{ }^{\circ} \mathrm{Cs}^{-1}$ e na conformação por spray de $10^{4}$ a $10^{5}{ }^{\circ} \mathrm{Cs}^{-1}$. Nos estágios iniciais da solidificação esta diferença de taxa de resfriamento leva à diminuição do espaçamento inter-dendritico (Wießner et al., 2008).

A composição química normalizada para o aço AISI/SAE M2 define que este aço pode ser produzido com alto ou baixo teor de carbono. No AISI/SAE M2 com alto teor de carbono este elemento pode estar na faixa de $0,95 \%$ a $1,05 \%$ em massa, e na versão de baixo teor de $0,78 \%$ a $0,88 \%$. A concentração de carbono além de influenciar na fração de carbonetos precipitada, também influencia na sequiência de solidificação. Com o aumento do teor de carbono observa-se que a solidificação inicia-se no campo austenítico, portanto, nestes casos não ocorrem reações peritéticas (Fredrikson e Brising, 1976).

As reações eutéticas ocorridas na formação dos carbonetos são fortemente influenciadas pela taxa de resfriamento e pela concentração de carbono no aço. Quando o teor de carbono está no início da faixa de concentração normalizada $(\sim 0,78 \%$ massa) e a taxa de resfriamento é baixa a precipitação inicia-se pelo carboneto do tipo $\mathrm{M}_{6} \mathrm{C}$ devido a 
segregação do tungstênio e do molibdênio da fase líquida para a sólida, conseqüentemente a fase líquida torna-se rica em cromo e vanádio propiciando a força motriz para a precipitação do $\mathrm{MC}$ que surge $20{ }^{\circ} \mathrm{C}$ abaixo do inicio da precipitação do $\mathrm{M}_{6} \mathrm{C}$. Ao mesmo tempo ocorre a precipitação do $\mathrm{M}_{6} \mathrm{C}$ na ferrita- $\delta$ ainda remanescente.

Já para o teor de carbono de cerca de 0,78 \% massa com alta taxa de resfriamento, o carboneto MC é o primeiro a se formar. Com o aumento da taxa de resfriamento a segregação do tungstênio, do molibdênio e do cromo para a fase sólida é maior que do vanádio. Na fase líquida então ocorre a precipitação do MC. Blickwede et al.(1950), mostraram que o aumento do teor de vanádio resulta na formação da fase intermetálica $\mathrm{F}_{3} \mathrm{M}_{2}$ (M representa os elementos de liga). Mecanismo semelhante deve ocorrer na fase líquida rica em vanádio que proporciona a precipitação do $\mathrm{MC}$ primeiramente. $\mathrm{O}$ surgimento do $\mathrm{M}_{6} \mathrm{C}$ ocorre $14{ }^{\circ} \mathrm{C}$ abaixo da temperatura em que começa o surgimento do MC. Enquanto que na ferrita- $\delta$ a precipitação ocorre pela formação do $\mathrm{M}_{2} \mathrm{C}$.

Surpreendentemente, para teores de aproximadamente de 0,90\% massa de carbono a taxa de resfriamento não exerce influência significativa. Neste caso, a precipitação é iniciada pela formação do carboneto do tipo $\mathrm{M}_{2} \mathrm{C}$ que domina o processo de solidificação.

Com o aumento do teor de carbono, agora atingindo o valor máximo normalizado (1,05\% massa), durante o resfriamento lento ocorre predominantemente a formação inicial do $\mathrm{M}_{2} \mathrm{C}$ e concomitantemente, em escala reduzida, o $\mathrm{M}_{6} \mathrm{C}$ e subseqüentemente surge o MC. O aumento da taxa de resfriamento implica no aumento da formação de austenita (Kulmburg, 1998a). Neste caso, observa-se que o vanádio e o tungstênio são segregados da fase líquida para a fase sólida, permanecendo na fase líquida o cromo e o molibdênio, que possui menor solubilidade na austenita e tende a estabilizar a ferrita. Como o inicio da precipitação do $\mathrm{M}_{6} \mathrm{C}$ na fase sólida, o vanádio é segregado de volta para a fase líquida e dissolvido do $\mathrm{M}_{2} \mathrm{C}$. $\mathrm{O}$ aumento da concentração de molibdênio e a diminuição da concentração de vanádio na fase líquida favorecem a formação do $\mathrm{M}_{6} \mathrm{C}$. $\mathrm{O}$ surgimento do MC ocorre quando a concentração de vanádio supera os limites de solubilidade nas fases sólida e líquida.

No resfriamento rápido de aços com teor de carbono da ordem 1,05\% massa o processo de solidificação é semelhante ao observado, quando o teor de carbono é de aproximadamente $0,78 \%$ massa. Neste caso, a taxa de resfriamento é mandatória do processo de solidificação. 
A formação de uma rede de carboneto nos contornos de grãos austeníticos é usualmente observada nos eutéticos ledeburíticos. A distribuição do tamanho médio das células é função da composição química e da taxa de resfriamento (Fischer e Kohlhaas, 1975).

Os carbonetos do tipo $\mathrm{M}_{6} \mathrm{C}$ e $\mathrm{MC}$ são carbonetos estáveis, enquanto que o $\mathrm{M}_{2} \mathrm{C}$ predominante na estrutura, em muitos casos, é um carboneto instável que se dissocia no recozimento ou trabalho a quente em temperaturas superior a $1000{ }^{\circ} \mathrm{C}$, segundo a reação geral (Gongqi et al., 1992):

$$
\left(M_{2} C \rightarrow M_{6} C+M C\right) F e-C
$$

Onde: $F-C$ representa o ambiente de ferrita- $\delta$ ou austenita.

Kulmburg, 1998b, sugere para a dissociação do $\mathrm{M}_{2} \mathrm{C}$ a seguinte reação:

$$
2 \mathrm{M}_{2} \mathrm{C}+3 \mathrm{Fe} \rightarrow \mathrm{M}_{6} \mathrm{C}+\mathrm{MC}
$$

onde: M representa o átomo de elemento de liga, desta forma o ferro da matriz é aproveitado na reação e permite a acomodação do $M_{6} C$ formado a partir do $M_{2} C$ com baixo teor de ferro.

Jurči (1998) mostrou que em pós atomizados por solidificação rápida a microestrutura das partículas é semelhante à obtida na solidificação de lingotes produzidos por metalurgia convencional. Como esperado para uma taxa de resfriamento alta as principais fases identificadas foram a ferrita, a martensita, a austenita retida e o MC, porém não se observou a formação de nenhum outro carboneto. Fato semelhante foi observado por Kim et al. (1979) na fusão superficial por fonte LASER.

A composição química dos carbonetos formados na solidificação é apresentada na TAB. 2.6, os valores apresentados por Ghomashchi e Sellars (1984) foram obtidos para o material obtido por metalurgia convencional e os valores apresentados por Lee et al. (1998a) refere-se a um material obtido por conformação por spray. A composição química do material estudado por Lee et al. é semelhante ao AISI/SAE M2 porém com adição de 7 $\%$ massa de cobalto.

Após a solidificação é comum a prática de trabalhado a quente, seja por forjamento ou laminação. Durante estes processos ocorre principalmente a dissolução de carbonetos mais finos e a fragmentação dos carbonetos primários recozidos. 
Tabela 2.6: Composição química dos carbonetos primários, a primeira linha refere-se à composição química expressa em \% massa e a segunda linha, em itálico, refere-se à composição química expressa em \% atômica.

\begin{tabular}{|c|c|c|c|c|c|c|}
\hline \multirow{2}{*}{ Carboneto } & \multicolumn{6}{|c|}{ Composição química } \\
\hline & W & Mo & V & $\mathrm{Cr}$ & $\mathbf{F e}$ & Co \\
\hline \multirow{2}{*}{ MC* } & 33 & 14,5 & 46,3 & 5,1 & $\overline{1,1}$ & - \\
\hline & 13,2 & 11,1 & 67,8 & 7,2 & 1,5 & - \\
\hline \multirow{2}{*}{ MC ** } & 26,7 & 18,2 & 45,9 & 5,2 & 4,0 & - \\
\hline & 10,3 & 13,5 & 64,0 & 7,1 & 5,1 & - \\
\hline \multirow{2}{*}{$\mathbf{M}_{2} \mathbf{C}^{*}$} & 49,3 & 21,3 & 14,7 & 7,6 & 7,2 & - \\
\hline & 25,4 & 21,1 & 27,4 & 13,9 & 12,2 & - \\
\hline \multirow{2}{*}{$\mathbf{M}_{2} C^{* *}$} & 36,4 & 29,5 & 13,7 & 6,9 & 10,4 & 3,2 \\
\hline & 17,3 & 26,8 & 23,4 & 11,5 & 16,3 & 4,7 \\
\hline \multirow{2}{*}{$\mathbf{M}_{6} \mathbf{C}^{*}$} & 38,3 & 20,3 & 4,3 & 3,0 & 34,1 & - \\
\hline & 17,8 & 18,0 & 7,2 & 4,9 & 52,1 & - \\
\hline \multirow{2}{*}{$\mathbf{M}_{6} \mathbf{C}^{* *}$} & 35,1 & 21,8 & 3,4 & 6,1 & 30,0 & 3,6 \\
\hline & 15,9 & 18,9 & 5,5 & 9,8 & 44,8 & 5,1 \\
\hline
\end{tabular}

* valores apresentados por Ghomashchi e Sellar (1984) (metalurgia convencional)

** valores apresentados por Lee et al. (1998a) (conformação por spray)

A partir do mapeamento da distribuição elementar ao longo dos carbonetos e da matriz em amostra previamente forjadas, Pospescu (2007) verificou que durante a deformação plástica à quente ocorre a homogeneização da estrutura de carbonetos por difusão dos elementos de liga dos carbonetos primários para a matriz, e não apenas pela fragmentação mecânica deste carbonetos e sua dispersão na matriz. Devido ao processo de difusão ocorre o enriquecimento da matriz em elementos de liga e o surgimento de uma nova geração de carbonetos quaternários, formados por concentração semelhante de molibdênio, tungstênio, cromo e em menor concentração vanádio.

Em seqüência ao trabalho a quente o aço é submetido a tratamento de homogeneização. Neste estágio a microestrutura deste aço é constituída por uma matriz ferrítica / martensítica na qual estão embebidos carbonetos do tipo $\mathrm{MC}, \mathrm{M}_{6} \mathrm{C}$ e $\mathrm{M}_{23} \mathrm{C}_{6}$, dependendo do histórico termomecânico do material.

Apesar de se encontrar na literatura informações da presença de carboneto do tipo $\mathrm{M}_{23} \mathrm{C}_{6}$ neste aço no estado recozido (Blickwede e Cohen, 1949; Kaiser e Cohen, 1952; Kim et al, 1979), nos estudos de formação de carbonetos realizados por análise térmica diferencial não foram observadas descontinuidades na curva referentes à formação deste tipo de carboneto(Galda e Kraft, 1974; Fredrikson e Brising, 1976).

A homogeneização do pó obtido por Jurči (1998) promoveu a definição da rede de carbonetos e a esferoidização dos carbonetos situados no interior das células. Observou- 
se a ocorrência de precipitação do $\mathrm{M}_{6} \mathrm{C}$ em temperatura acima de $700{ }^{\circ} \mathrm{C}$. Porém. somente a partir de $1000{ }^{\circ} \mathrm{C}$ observou-se um aumento mais significativo da fração de $\mathrm{M}_{6} \mathrm{C}$.

As alterações ocorridas durante a homogeneização podem ser divididas em duas partes: a primeira é a dissolução do $\mathrm{M}_{2} \mathrm{C}$, se este ainda estiver presente, com formação dos carbonetos $\mathrm{M}_{6} \mathrm{C}$ e $\mathrm{MC}$ ao mesmo tempo em que os carbonetos mais finos, preferencialmente o MC, dissolvem enriquecendo a matriz e formando pequenas ilhas de austenita; na segunda parte ocorre a esferoidização dos carbonetos do tipo $\mathrm{M}_{6} \mathrm{C}$ e o crescimento dos carbonetos $\mathrm{M}_{6} \mathrm{C}$ e MC (Ghomashchi e Sellars, 1984; Ghomashchi, 1998).

Os processos de esferoidização e de crescimento do $\mathrm{M}_{6} \mathrm{C}$ são controlados pela difusão do tungstênio na austenita, esta difusão é dificultada pelo raio atômico do tungstênio ser maior que do ferro. Inicialmente ocorrem as mudanças morfológicas seguidas pelo crescimento. A fração de carbonetos esferoidizada é distinta para carbonetos localizados nos contornos da rede e para carbonetos intracelulares.

Os carbonetos $\mathrm{MC}$ originados da dissociação do $\mathrm{M}_{2} \mathrm{C}$ já se formam esferoidizados, portanto o único mecanismo a atuar na homogeneização é o crescimento, que também neste caso é controlado pela difusão do vanádio na austenita presente. $\mathrm{Na}$ TAB. 2.7 está apresentada a fração volumétrica de carbonetos encontrada no estado recozido por diversos autores.

Tabela 2.7: Fração volumétrica de carbonetos no aço AISI/SAE M2 no estado recozido.

\begin{tabular}{cccccc}
\hline \multirow{2}{*}{ Autor } & \multicolumn{5}{c}{ Fração } \\
\cline { 2 - 6 } & $\begin{array}{c}\text { Total } \\
(\% \text { massa) }\end{array}$ & $\begin{array}{c}\mathbf{M}_{\mathbf{6}} \mathbf{C} \\
(\boldsymbol{\%} \text { \%ol) }\end{array}$ & $\begin{array}{c}\text { MC } \\
\text { (\%olumétrica) }\end{array}$ \\
\hline \hline Blickwede e Cohen(1949) & 21,7 & 23,0 & 13,0 & 2,0 & 8,0 \\
Kaiser e Cohen (1952) & 20,8 & 18,0 & 13,0 & 2,5 & 2,5 \\
Kulmburg (1998) & - & 24,0 & 14,0 & 2,0 & 8,0 \\
\hline
\end{tabular}

Estudos realizados por Ozaki et al. (2000) na esferoidização dos carbonetos, realizados na temperatura de $1200{ }^{\circ} \mathrm{C}$, mostraram que em tempos superiores a um minuto ocorre crescimento significativo da fração de carbonetos e da dissolução dos carbonetos finos.

A seqüência de tratamentos térmicos convencionais aos quais são submetidas as ferramentas confeccionadas com aços rápidos é apresentada esquematicamente na FIG. 2.15 . 


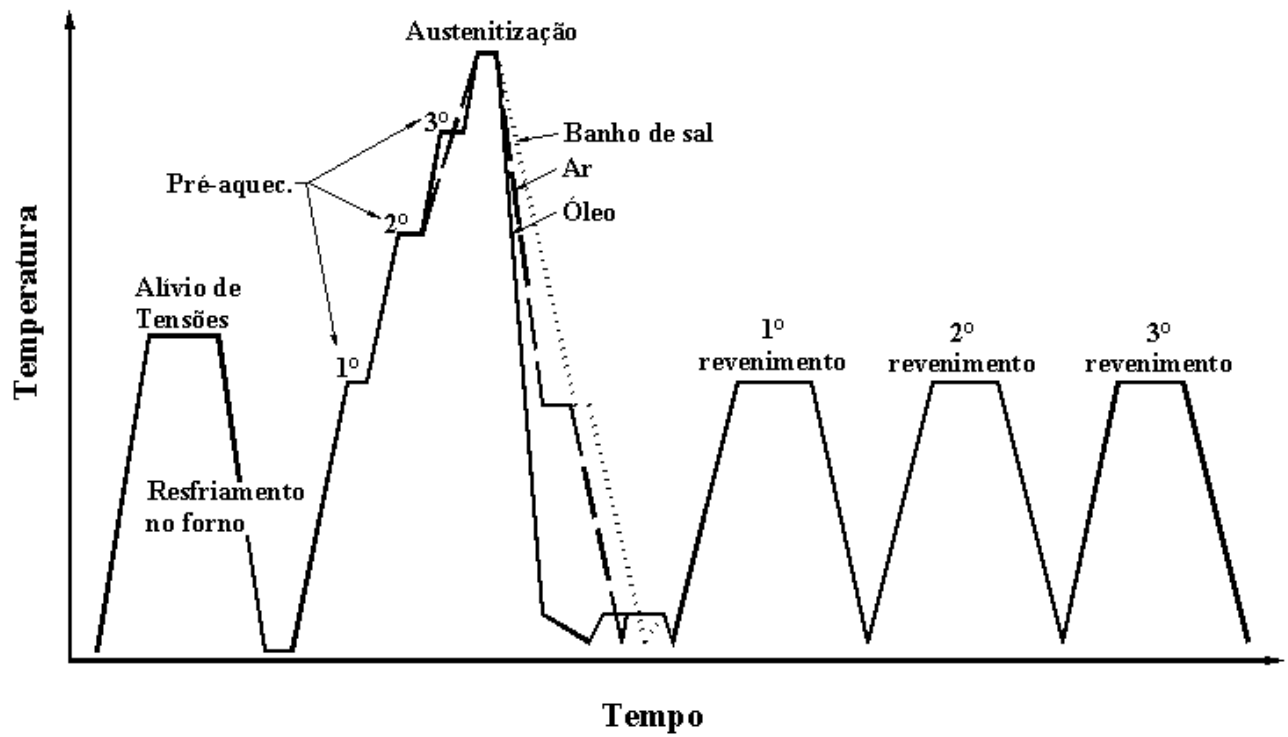

Figura 2.15: Esquema da seqüência de tratamentos térmicos aos quais são submetidas ferramentas confeccionadas com aços rápidos (Pippel et al., 1999).

O primeiro ciclo de aquecimento em geral ocorre a temperaturas da ordem de $600{ }^{\circ} \mathrm{C}$ com o objetivo de aliviar tensões internas e minimizar as variações dimensionais. $\mathrm{Na}$ literatura revisada para a elaboração deste trabalho não foram encontrados relatos sobre a realização desta etapa de tratamento térmico e sobre sua conseqüência na microestrutura final. Esta é uma importante questão a se considerar já que nas temperaturas utilizadas há precipitação de carbonetos e também aumento da taxa de difusividade dos átomos de soluto.

As condições de tempo e temperatura da etapa de austenitização e têmpera são determinadas pelas propriedades mecânicas desejadas para o material. Objetivando-se evitar alterações dimensionais significativas o aquecimento até a temperatura de austenitização é realizado em patamares.

Nas TAB. 2.8 e 2.9 são apresentadas as composições químicas para os carbonetos do tipo $\mathrm{MC}$ e $\mathrm{M}_{6} \mathrm{C}$ observados no aço AISI/SAE M2 após a austenitização e têmpera do material. Os valores para as frações de carbonetos após a austenitização reportados na literatura são apresentados na TAB. 2.10.

No revenimento ocorre o endurecimento secundário devido a precipitação de carbonetos secundários com dimensões da ordem de $3 \mathrm{~nm}$ a $10 \mathrm{~nm}$. O tamanho nanométrico dos carbonetos secundários impediu seu estudo pelas técnicas de microscopia conhecidas até 1980. O estudo dos carbonetos secundários por microscopia eletrônica de transmissão utilizando amostras preparadas por extração de réplicas e por folha fina, 
forneceu indícios valiosos de que o vanádio atuaria como formador de precipitados do tipo MC. Enquanto que a precipitação de carbonetos do tipo $\mathrm{M}_{3} \mathrm{C}$ e $\mathrm{M}_{2} \mathrm{C}$ eram devidas aos demais elementos de liga e ao próprio ferro da matriz.

Tabela 2. 8: Composição química do carboneto MC após a têmpera, a primeira linha refere-se a composição química expressa em \% massa e a segunda linha, em itálico, refere-se a composição química expressa em \% atômica.

\begin{tabular}{cccccc}
\hline Autor & W & Mo & V & Cr & Fe \\
\hline \hline & 16,3 & 11,6 & 68,7 & - & 3,4 \\
Peter e Kohlhaas (1967) & $\mathbf{5 , 5}$ & $\mathbf{7 , 5}$ & $\mathbf{8 3 , 3}$ & - & $\mathbf{3 , 8}$ \\
& 19,6 & 12,9 & 56,6 & 7,6 & 3,4 \\
& $\mathbf{6 , 8}$ & $\mathbf{8 , 6}$ & $\mathbf{7 1 , 2}$ & $\mathbf{9 , 4}$ & $\mathbf{3 , 9}$ \\
Kulmburg (1998 b) & 23,5 & 14,1 & 52,9 & 4,7 & 4,7 \\
& $\mathbf{8 , 6}$ & $\mathbf{9 , 9}$ & $\mathbf{6 9 , 8}$ & $\mathbf{6 , 1}$ & $\mathbf{5 , 7}$ \\
Rong et al. $\mathbf{( 1 9 9 2 )}$ & 18,5 & 17,4 & 52,7 & 5,1 & 6,3 \\
& $\mathbf{6 , 6}$ & $\mathbf{1 1 , 9}$ & $\mathbf{6 7 , 7}$ & $\mathbf{6 , 4}$ & $\mathbf{7 , 4}$ \\
\hline
\end{tabular}

Tabela 2. 9: Composição química do carboneto $\mathrm{M}_{6} \mathrm{C}$ após a têmpera, a primeira linha refere-se a composição química expressa em \% massa e a segunda linha, em itálico, refere-se a composição química expressa em \% atômica.

\begin{tabular}{cccccc}
\hline Autor & W & Mo & V & Cr & Fe \\
\hline \hline \multirow{2}{*}{ Peter e Kohlhaas (1967) } & 30,3 & 26,7 & 4,9 & 5,3 & 32,8 \\
& $\mathbf{1 3 , 4}$ & $\mathbf{2 2 , 7}$ & $\mathbf{7 , 8}$ & $\mathbf{8 , 3}$ & $\mathbf{4 7 , 8}$ \\
Kulmburg (1998 b) & 35,7 & 20,4 & 3,1 & 5,1 & 35,7 \\
& $\mathbf{1 6 , 1}$ & $\mathbf{1 7 , 6}$ & $\mathbf{5 , 1}$ & $\mathbf{8 , 1}$ & $\mathbf{5 3 , 1}$ \\
Rong et al. (1992) & 36,1 & 24,5 & 3,4 & 3,3 & 32,7 \\
& $\mathbf{1 6 , 8}$ & $\mathbf{2 1 , 9}$ & $\mathbf{5 , 7}$ & $\mathbf{5 , 4}$ & $\mathbf{5 0 , 2}$ \\
Karagöz et al. (1992) & 38,9 & 22,6 & 2,8 & 3,2 & 32,5 \\
& $\mathbf{1 8 , 5}$ & $\mathbf{2 0 , 6}$ & $\mathbf{4 , 8}$ & $\mathbf{5 , 4}$ & $\mathbf{5 0 , 7}$ \\
\hline
\end{tabular}

Tabela 2.10: Fração volumétrica de carbonetos no aço AISI/SAE M2 após a austenitização.

\begin{tabular}{cccccc}
\hline \multirow{2}{*}{ Autor } & \multicolumn{5}{c}{ Fração } \\
\cline { 2 - 6 } & $\begin{array}{c}\text { Total } \\
(\% \text { massa) }\end{array}$ & $\begin{array}{c}\mathbf{M}_{\mathbf{6}} \mathbf{C} \\
(\%)\end{array}$ & $\begin{array}{c}\text { MC vol) } \\
\text { volumétrica) }\end{array}$ \\
\hline \hline Blickwede e Cohen(1949) & 10,7 & 5,6 & 5,0 & 0,6 & - \\
Kaiser e Cohen (1952) & 11,3 & 8,3 & 6,7 & 1,6 & - \\
Fischer e Kohlhaas (1975) & - & 6,7 & 5,4 & 1,3 & - \\
Karägoz et al. (1989) & - & 6,7 & 5,0 & 1,7 & \\
Rong et al. (1998) & - & 7,5 & 6,1 & 1,4 & - \\
\hline
\end{tabular}

Andrén (1981) foi um dos pioneiros no uso da "sonda atômica" acoplada ao microscópio eletrônico de transmissão (atom-probe field ion microscopy) para o estudo dos carbonetos secundários nos aços rápidos. Em seu trabalho inicial no aço: Fe-2,26C-6,7W- 
7,0Mo-6,4V-4,2Cr-10,3Co mostrou que o MC precipitado neste material possui uma quantidade significativa de molibdênio e tungstênio dissolvidos.

Estudos realizados por Karagöz et al. (1992a, 1992b) mostraram que no aço AISI/SAE M2 no revenimento formam-se carbonetos do tipo $\mathrm{MC}$ e $\mathrm{M}_{2} \mathrm{C}$. O MC formado tem morfologia de placas com dimensões de $5 \mathrm{~nm}$ de diâmetro e espessura de $1 \mathrm{~nm}$ a $2 \mathrm{~nm}$. Enquanto que o $\mathrm{M}_{2} \mathrm{C}$ apresenta uma morfologia do tipo cilíndrica com diâmetro de $1 \mathrm{~nm}$ a $2 \mathrm{~nm}$ e comprimento de $5 \mathrm{~nm}$ a $10 \mathrm{~nm}$. A composição química observada para estes carbonetos, após o revenimento da amostra a $550{ }^{\circ} \mathrm{C}$ por 3 vezes, é apresentada na TAB. 2.11 .

Tabela 2.11: Composição química dos carbonetos secundários, a primeira linha refere-se à composição química expressa em \% massa e a segunda linha, em itálico, refere-se à composição química expressa em \% atômica.

\begin{tabular}{ccccc}
\hline \multirow{2}{*}{ Carboneto } & \multicolumn{4}{c}{ Composição Química } \\
\cline { 2 - 5 } & W & Mo & V & Cr \\
\hline \hline \multirow{2}{*}{ MC } & 11,6 & 52,6 & 24,3 & 11,1 \\
& $\mathbf{4 , 8}$ & $\mathbf{4 1 , 8}$ & $\mathbf{3 6 , 4}$ & $\mathbf{1 7 , 0}$ \\
\multirow{2}{*}{$\mathbf{M}_{2} \mathrm{C}$} & 18,3 & 52,7 & 9,8 & 19,2 \\
& $\mathbf{8 , 2}$ & $\mathbf{4 5 , 4}$ & $\mathbf{1 5 , 9}$ & $\mathbf{3 0 , 5}$ \\
\hline
\end{tabular}

Tratamentos térmicos realizado em temperaturas superiores às temperaturas de revenimento $\left(\sim 560{ }^{\circ} \mathrm{C}\right.$ ) (overtempering) utilizadas no tratamento deste aço e tempos longos mostraram que podem ocorrer variações significativas na composição química do MC e do $\mathrm{M}_{2} \mathrm{C}$. Os resultados obtidos por Karagöz et al. (1992b) são apresentados na TAB 2.12 .

Comportamento semelhante ao observado por Karägoz et al., no estudo sobre a microestrutura do estado revenido e overtempering, foram observados por Stiller et al. (1984) para um aço rápido com maiores teores de elementos de liga. Neste caso, os autores também estudaram as alterações que o tratamento térmico de revenimento induz nos carbonetos primários. Na TAB. 2.13 são apresentadas as composições químicas reportadas pelos autores. 
Tabela 2.12: Composição química dos carbonetos secundários após tratamentos térmicos de overtempering, a primeira linha refere-se à composição química expressa em \% massa e a segunda linha, em itálico, refere-se à composição química expressa em \% atômica.

\begin{tabular}{|c|c|c|c|c|c|}
\hline \multirow{2}{*}{$\begin{array}{c}\text { Carboneto/ } \\
\text { Tratamento térmico }\end{array}$} & \multicolumn{5}{|c|}{ Composição Química } \\
\hline & $W$ & Mo & $V$ & $\mathrm{Cr}$ & Fe \\
\hline MC & 4,0 & 499,5 & 24,1 & 22,4 & - \\
\hline $600{ }^{\circ} \mathrm{C} / 100 \mathrm{~min}$ & 1,5 & 35,8 & 32,8 & 29,9 & - \\
\hline MC & 27,0 & 41,3 & 17,5 & 14,2 & - \\
\hline $600{ }^{\circ} \mathrm{C} / 300 \mathrm{~min}$ & 12,3 & 36,0 & 28,8 & 22,9 & - \\
\hline $\mathbf{M}_{2} \mathrm{C}$ & 11,3 & 43,6 & 11,3 & 18,8 & - \\
\hline $600{ }^{\circ} \mathrm{C} / 100 \mathrm{~min}$ & 12,1 & 38,5 & 18,8 & 30,6 & - \\
\hline $\mathrm{M}_{2} \mathrm{C}$ & 26,9 & 44,0 & 12,9 & 16,2 & - \\
\hline $600{ }^{\circ} \mathrm{C} / 300 \mathrm{~min}$ & 12,5 & 39,2 & 21,7 & 26,6 & - \\
\hline $\mathbf{M}_{2} \mathbf{C}$ & 31,0 & 50,2 & 4,6 & 13,2 & 1,1 \\
\hline $600{ }^{\circ} \mathrm{C} / 3000 \mathrm{~min}$ & 16,0 & 49,6 & 8,5 & 24,1 & 1,8 \\
\hline
\end{tabular}

Tabela 2.13: Composição química dos carbonetos secundários após tratamentos térmicos de overtempering, a primeira linha refere-se à composição química expressa em \% massa e a segunda linha, em itálico, refere-se à composição química expressa em \% atômica.

\begin{tabular}{ccccccc}
\hline \multirow{2}{*}{ Carboneto } & W & Mo & Vomposição Química & Cr & Fe & Co \\
\hline \hline MC & 22,6 & 26,0 & 42,1 & 5,5 & 3,3 & 0,6 \\
primário & $\mathbf{8 , 8}$ & $\mathbf{1 9 , 4}$ & $\mathbf{5 9 , 3}$ & $\mathbf{7 , 6}$ & $\mathbf{4 , 2}$ & $\mathbf{0 , 7}$ \\
M $_{\mathbf{6}} \mathrm{C}$ & 32,0 & 27,5 & 3,0 & 3,7 & 28,3 & 5,5 \\
MC & $\mathbf{1 4 , 6}$ & $\mathbf{2 4 , 1}$ & $\mathbf{4 , 9}$ & $\mathbf{5 , 9}$ & $\mathbf{4 2 , 6}$ & $\mathbf{7 , 8}$ \\
secundário & $\mathbf{7 , 4}$ & 47,5 & 20,4 & 14,7 & - & - \\
M $_{2} \mathbf{C}$ & 16,7 & $\mathbf{3 8 , 9}$ & $\mathbf{3 1 , 5}$ & $\mathbf{2 2 , 2}$ & - & - \\
& $\mathbf{6 , 6}$ & $\mathbf{3 2 , 4}$ & 3,1 & 28,3 & 17,8 & 1,5 \\
& & $\mathbf{2 4}$ & $\mathbf{4 , 4}$ & $\mathbf{3 9 , 5}$ & $\mathbf{2 3 , 1}$ & $\mathbf{1 , 8}$ \\
\hline
\end{tabular}




\section{Materiais e métodos}

\subsection{Origem das amostras}

As amostras estudadas neste trabalho foram produzidas por: metalurgia convencional, metalurgia do pó e por conformação por spray.

Na metalurgia convencional os aços rápidos são produzidos pela fusão do ferro e de fragmentos de materiais intermetálicos contendo os diversos elementos de liga em fornos a arco elétrico (FIG. 3.1).

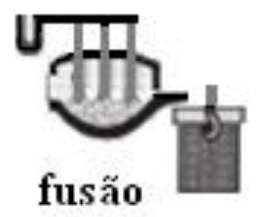

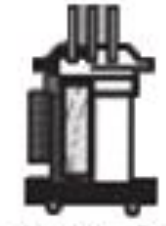

ajuste da composição

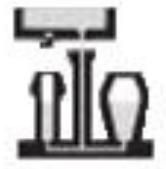

lingotamento

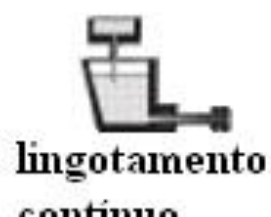

forjamento
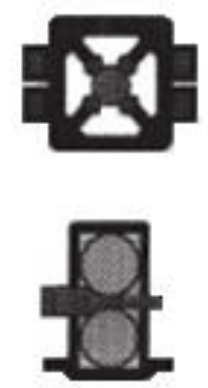

trefilação

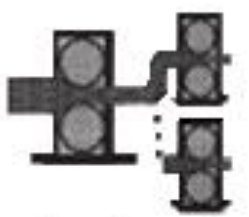

laminação

Figura 3.1: Esquema da rota de produção por metalurgia convencional do aço rápido.

O metal fundido é posteriormente tratado em um segundo cadinho, no qual são ajustados os teores dos elementos de liga e do carbono, nesta etapa da produção também ocorre a desoxidação e a retirada de inclusões não metálicas por aeração do metal fundido com gás inerte (argônio ou nitrogênio). Na etapa seguinte o metal fundido é vertido em lingoteira convencional ou alimenta uma lingoteira contínua, onde ocorre a solidificação e formação dos carbonetos primários. A taxa de resfriamento no lingotamento contínuo é maior que no lingotamento convencional produzindo um material com uma estrutura mais refinada. 
Os lingotes solidificados são re-aquecidos e forjados ou laminados a quente para a obtenção do pré-formado. Este pré-formado é recozido para que ocorra o amolecimento que permite a usinagem das ferramentas, que serão submetidas a tratamento térmico para endurecimento e revenimento. Comercialmente o recozimento pode ser realizado tanto pelo produtor como pelo adquirente do material.

Um dos materiais utilizado neste trabalho, foi produzido por metalúrgica convencional, e adquirido da empresa ThyssenKrupp. Na TAB. 3.1 são apresentadas as condições recomendadas pelo produtor para o tratamento térmico das ferramentas produzidas com este aço.

Tabela 3.1: Condições para os tratamentos térmicos sugeridas pela ThyssenKrupp para o aço THYRAPID 3343.

\begin{tabular}{ccccc}
\hline $\begin{array}{c}\text { Amolecimento } \\
\left({ }^{\circ} \mathbf{C}\right)\end{array}$ & $\begin{array}{c}\text { Alívio de } \\
\text { tensões }\left({ }^{\circ} \mathbf{C}\right)\end{array}$ & $\begin{array}{c}\text { Austenitização } \\
\left({ }^{\circ} \mathbf{C}\right)\end{array}$ & Têmpera & $\begin{array}{c}\text { Revenimento } \\
\left({ }^{\circ} \mathbf{C}\right)\end{array}$ \\
\hline $\begin{array}{c}770-860 \\
\text { (resfriamento } \\
\text { no forno) }\end{array}$ & $\begin{array}{c}\text { Até } 400 \\
\text { (com circulação } \\
\text { de ar no forno) }\end{array}$ & $1190-1230$ & $\begin{array}{c}\text { banho de sal até } \\
500{ }^{\circ} \mathrm{C} ; \\
\text { óleo; } \\
\text { ar. }\end{array}$ & $\begin{array}{c}530-560 \\
(\text { no mínimo } \\
\text { duas vezes })\end{array}$ \\
\hline
\end{tabular}

Os pós de aço AISI/SAE M2 utilizados nos processos de metalurgia do pó são produzidos por atomização em água, gás inerte, ou ar. A micro-estrutura resultante destes processos apresenta diferenças significativas, e a escolha é realizada em função do emprego do material. A prensagem isostática a quente (HIP) de pós de aço AISI/SAE M2 atomizados ao ar é a rota de produção mais utilizada comercialmente. Por esta rota são obtidos materiais com microestrutura de elevada homogeneidade.

Alternativamente pode-se obter sinterizados de aço rápido seguindo-se as etapas de compactação uniaxial, sinterização à vácuo e tratamentos térmicos. O aço AISI/SAE M2 obtido por metalurgia do pó (MP), utilizado neste trabalho, foi gentilmente cedido pelo grupo de Metalúrgia do Pó do Centro de Ciência e Tecnologia dos Materiais (CCTM) do Instituto de Pesquisas Energéticas e Nucleares (IPEN).

Na obtenção deste material foi utilizado o pó de aço AISI/SAE M2 atomizado a água, com o qual foram confeccionadas pastilhas por prensagem uniaxial a $800 \mathrm{MPa}$ e sinterizadas a $1249{ }^{\circ} \mathrm{C}$. Informações pormenorizadas podem ser encontradas na bibliografia do grupo de Metalurgia do Pó relacionada no Anexo 1.

Na conformação por spray, vide esquema na FIG. 3.2, o aço é fundido e mantido a uma temperatura de $140{ }^{\circ} \mathrm{C}$ a $250{ }^{\circ} \mathrm{C}$ acima da temperatura de fusão. $\mathrm{O}$ metal 
fundido é então atomizado em uma câmara com gás inerte (Lee et al, 1998b). Durante o tempo de vôo das gotículas dentro da câmara inicia-se o processo de solidificação pela reação peritética. Neste estágio a parte líquida da gotícula é rica em carbono, vanádio e molibdênio. As gotículas do metal fundido ainda não totalmente solidificadas sofrem impacto com o substrato de deposição fragmentado-se. Neste estágio a temperatura da gotícula ainda é elevada e o processo de solidificação perdura sobre o substrato, onde ocorrem reações peritéticas e eutéticas que levam à nucleação e ao crescimento dos carbonetos.

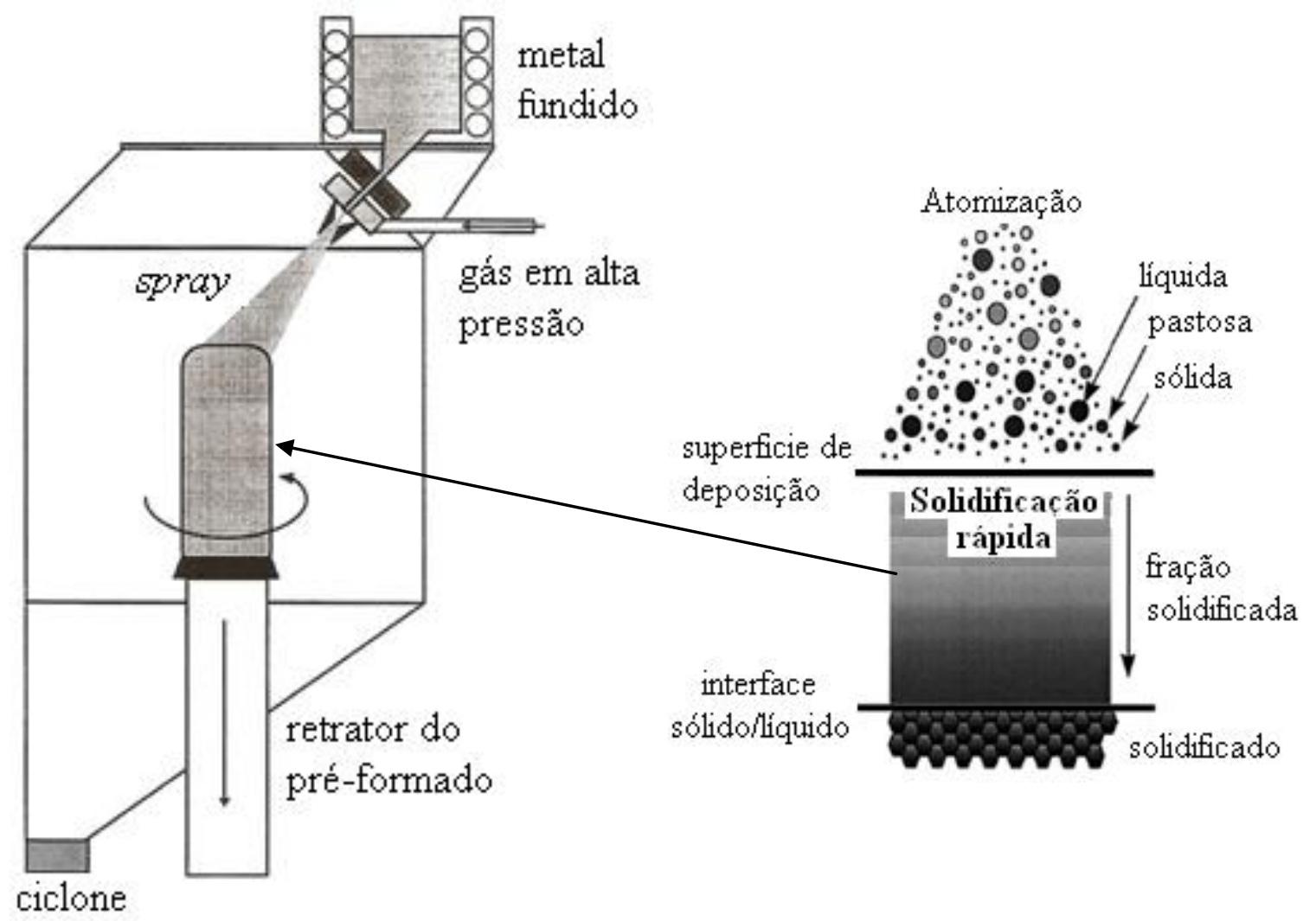

Figura 3.2: Esquema de produção do pré-formado obtido pela rota de conformação por spray (Lee, 1998a).

A microestrutura obtida é função da temperatura de sobre-aquecimento, da pressão dentro da câmara e do tempo de vôo da gotas. Quando estes parâmetros estão otimizados obtêm-se uma dispersão homogênea de carbonetos em uma matriz ferrítica e martensítica.

O material conformado por spray foi obtido utilizando-se um equipamento da marca Osprey (Sandvik Osprey Ltd.); devido a cláusulas de confidencialidade não poderão ser especificadas as condições de obtenção. Porém, as micrografias apresentadas na FIG. 
4.6 mostraram que os parâmetros, de fluxo de gás e de distância de deposição, utilizados permitiram a obtenção da microestrutura esperada para um material obtido por conformação por spray. Já a análise das fases presentes, resultados que serão apresentados no capítulo 4, na região central do pré-formado indica que a temperatura de superaquecimento do metal fundido foi suficiente para a formação das fases características do material obtido por esta técnica com alta temperatura de super-aquecimento.

Para a obtenção da microestrutura desejada para a elaboração das ferramentas de corte, Jesus (2004) optou pela realização de deformação plástica por laminação à quente com a finalidade de refinar a estrutura da rede de carbonetos e principalmente remover a porosidade remanescente, cerca de $3 \%$ em volume (Hoyle, 1988). O material utilizado na etapa de laminação a quente foi retirado da parte central do pré-formado. As amostras obtidas possuíam redução de $50 \%$ e $72 \%$ em espessura.

Com os materiais obtidos pelas etapas descritas nos parágrafos precedentes foram confeccionadas pastilhas de corte. As pastilhas foram submetidas aos tratamentos de austenitização e revenimento, conforme os ciclos esquematizados na FIG. 3.3. Estes tratamentos térmicos foram realizados pela empresa Hurth Infer. As condições de tratamento térmico empregadas nestas amostras foram as mesmas utilizadas pela empresa no tratamento térmico comercial de ferramentas confeccionadas com este tipo de aço.

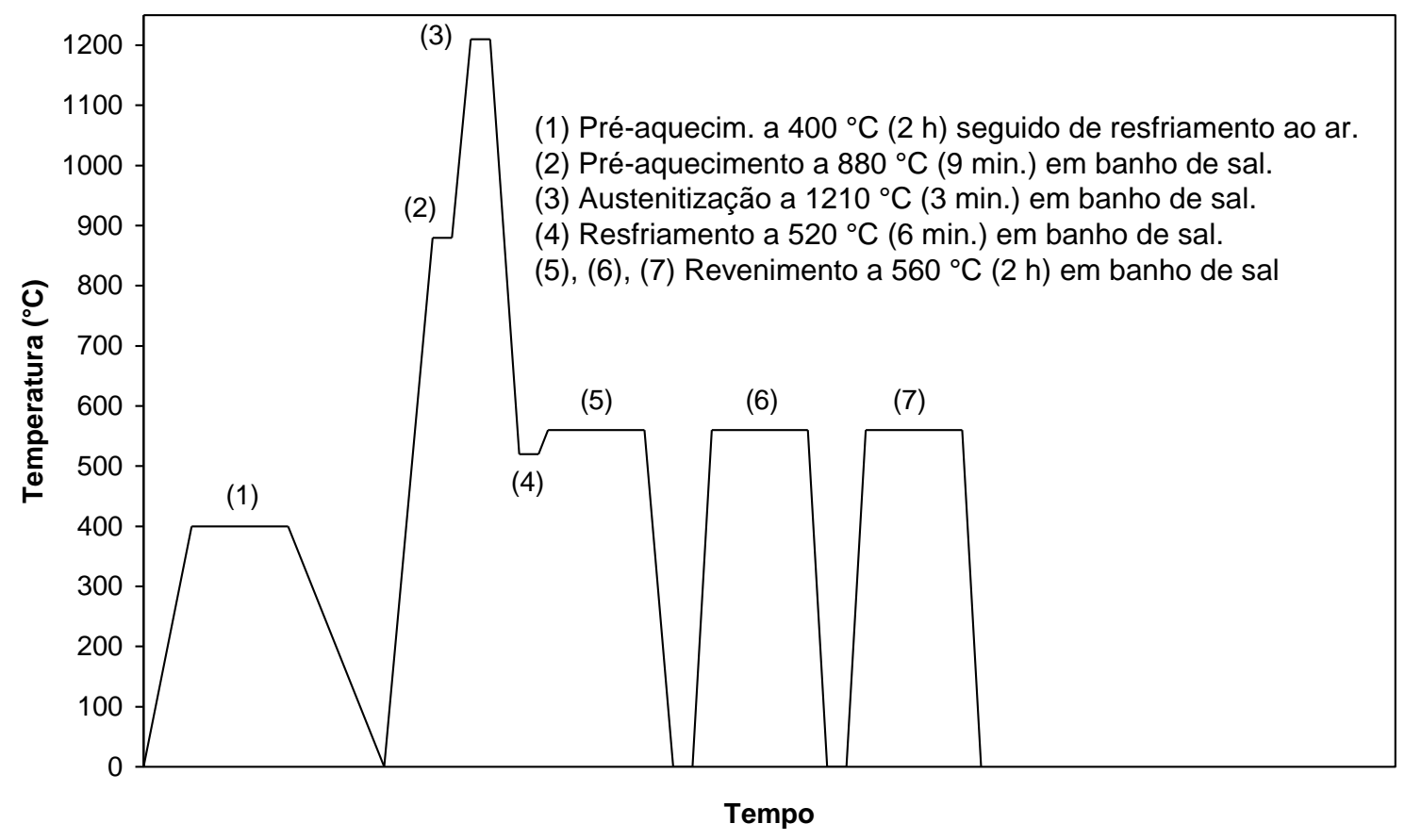

Figura 3.3: Esquema do tratamento térmico realizado nas amostras pela empresa Hurth Infer (adaptada de Jesus, 2004). 
Na TAB. 3.2 são apresentadas as composições químicas dos materiais utilizados neste trabalho e os valores normalizados para a composição química do aço AISI/SAE M2.

Tabela 3.2: Composição química (\% em massa e \% atômica) dos materiais utilizados neste trabalho e valores nominais para o aço AISI/SAE M2.

\begin{tabular}{|c|c|c|c|c|c|c|}
\hline Elemento & & $\begin{array}{c}\text { Norma } \\
\text { (baixo } \\
\text { carbono) }\end{array}$ & $\begin{array}{l}\text { Norma } \\
\text { (alto } \\
\text { carbono) }\end{array}$ & $\begin{array}{c}\text { Convencio- } \\
\text { nal }\end{array}$ & M.P. & $\begin{array}{c}\text { Conformação } \\
\text { por spray }\end{array}$ \\
\hline \multirow{2}{*}{$C$} & $\%$ massa & $0,78-0,88$ & $0,95-1,05$ & 0,90 & 0,85 & $\overline{1,03}$ \\
\hline & $\%$ at. & $3,71-4,21$ & $4,49-4,94$ & 4,29 & 4,07 & 4,88 \\
\hline \multirow{2}{*}{$\boldsymbol{W}$} & $\%$ massa & $5,50-6,75$ & $5,50-6,75$ & 6,28 & 6,38 & 6,19 \\
\hline & $\%$ at. & $1,71-2,11$ & $1,70-2,10$ & 1,95 & 1,99 & 1,92 \\
\hline \multirow{2}{*}{ Mo } & $\%$ massa & $4,50-5,50$ & $4,50-5,50$ & 5,17 & 5,25 & 4,98 \\
\hline & $\%$ at. & $2,68-3,29$ & $2,66-3,27$ & 3,08 & 3,15 & 2,95 \\
\hline \multirow{2}{*}{$\boldsymbol{V}$} & $\%$ massa & $1,75-2,20$ & $1,75-2,20$ & 6,28 & 1,90 & 1,87 \\
\hline & $\%$ at. & $1,96-2,48$ & $1,95-2,46$ & 1,99 & 2,14 & 2,09 \\
\hline \multirow{2}{*}{$\mathrm{Cr}$} & $\%$ massa & $3,75-4,50$ & $3,75-4,50$ & 3,94 & 4,20 & 3,29 \\
\hline & $\%$ at. & $4,12-4,97$ & $4,09-4,94$ & 4,34 & 4,64 & 3,60 \\
\hline \multirow{2}{*}{ Si } & $\%$ massa & $0,20-0,45$ & $0,20-0,45$ & 0,36 & & 0,22 \\
\hline & $\%$ at. & $0,41-0,92$ & $0,40-0,71$ & 0,73 & - & 0,45 \\
\hline \multirow{2}{*}{$M n$} & $\%$ massa & $0,15-0,40$ & $0,15-0,40$ & 0,29 & & 0,18 \\
\hline & $\%$ at. & $0,16-0,42$ & $0,15-0,42$ & 0,30 & - & 0,19 \\
\hline \multirow{2}{*}{$\mathrm{Ni}$} & $\%$ massa & 0,30 máx. & 0,30 máx. & & & 0,29 \\
\hline & $\%$ at. & 0,29 & 0,29 & & & 0,28 \\
\hline $\boldsymbol{P}$ & $\begin{array}{c}\% \text { massa } \\
\% \text { at. }\end{array}$ & $\begin{array}{l}\text { 0,03 máx. } \\
\text { 0,06 }\end{array}$ & $\begin{array}{l}\text { 0,03 máx. } \\
\text { 0,06 }\end{array}$ & $\begin{array}{c}0,018 \\
\mathbf{0 , 0 3}\end{array}$ & - & - \\
\hline \multirow{2}{*}{$S$} & $\%$ massa & 0,03 máx. & 0,03 máx. & 0,001 & 0,27 & \\
\hline & $\%$ at. & 0,05 & 0,05 & 0,001 & 0,48 & \\
\hline$N$ & $\%$ massa & - & - & - & - & 0,0340 \\
\hline \multirow{2}{*}{$\mathrm{Fe}$} & $\%$ massa & $83,04-78,96$ & $82,84-78,99$ & 81,271 & 81,15 & $\begin{array}{c}\mathbf{0 , 1 4} \\
81.916\end{array}$ \\
\hline & $\%$ at. & $84.87-81.20$ & $84.16-80.51$ & 83.28 & 83.52 & 83.50 \\
\hline
\end{tabular}

\subsection{Extração dos precipitados}

A separação de compostos ou fases cristalinas diferentes pode ser realizada por métodos químicos e físicos. No caso de materiais complexos como os aços altamente ligados diversos métodos necessitam ser empregados para a separação de seus constituintes.

Os métodos químicos podem ser divididos em duas categorias: uma puramente química onde utiliza-se uma solução na qual a fase de interesse seja inerte, enquanto que as outras fases reagem com a solução dissolvendo-se, e outra categoria é o emprego da eletrólise. Já no caso dos métodos físicos busca-se uma característica física específica, 
como por exemplo, o magnetismo no caso da análise de materiais formados por fases magnéticas e não-magnéticas.

Neste trabalho foram utilizadas as técnicas de dissolução eletrolítica e química para a separação da fração total de carbonetos e do carboneto do tipo MC, respectivamente.

A célula eletrolítica de citrato de sódio é o meio de extração de carbonetos mais utilizado para o aço AISI/SAE M2. A eficiência desta célula é tão bem determinada que inúmeros arranjos foram realizados para seu aprimoramento, conforme pode ser visto na FIG 3.4. Este método permite a extração de carbonetos do tipo: $\mathrm{MC}, \mathrm{M}_{6} \mathrm{C}$ e $\mathrm{M}_{23} \mathrm{C}_{6}$.

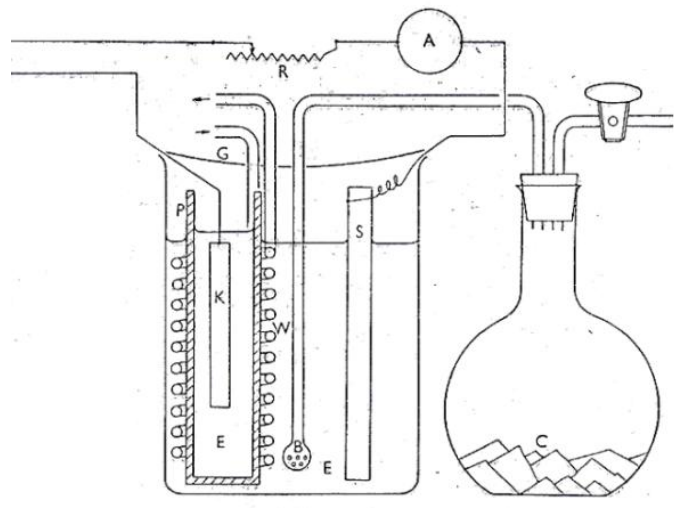

(a)

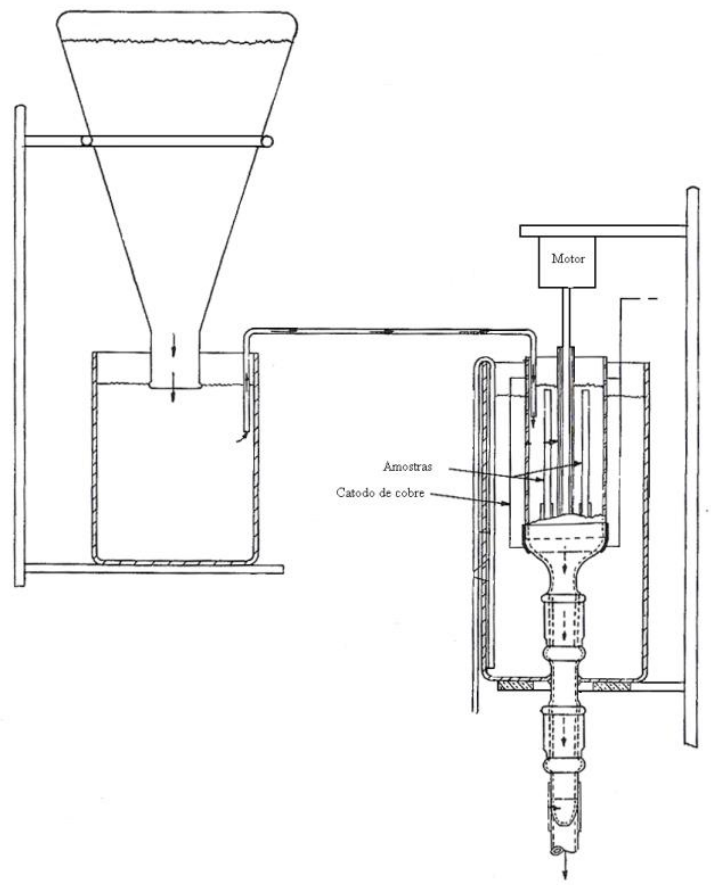

(b)

Figura 3.4: Esquema de célula de citrato de sódio utilizada para extração dos carbonetos nos aços rápidos. Em (a) é apresentada a primeira versão proposta Pemberton (1952) e em (b) a versão proposta por Treje e Benedicks.

Os esquemas apresentados na FIG.3.4 mostram a complexidade da confecção da célula de citrato de sódio, talvez por este motivo sua utilização tenha sido bastante limitada.

Blickwede e Cohen (1949) testaram a célula hidroclorídrica, apresentada esquematicamente na FIG. 3.5, para a extração de carbonetos nos aços rápidos. Um dos problemas observados pelos autores era a escamação das amostras. Na escamação ocorre a 
fragmentação de pequenas partes da amostra que são constituídas por uma camada de carbonetos que recobre a matriz ferrítica e martensítica, FIG. 3.6.

A solução adotada foi a realização de uma separação magnética do resíduo dos carbonetos. Os testes comparando a eficiência da célula hidroclorídrica conjuntamente com a separação magnética, em relação à célula de citrato de sódio obtiveram resultados bastante satisfatórios. Mostrando que este arranjo bastante simples poderia substituir satisfatoriamente a célula de citrato de sódio, para a extração das mesmas fases, embora isto não tenha ocorrido.

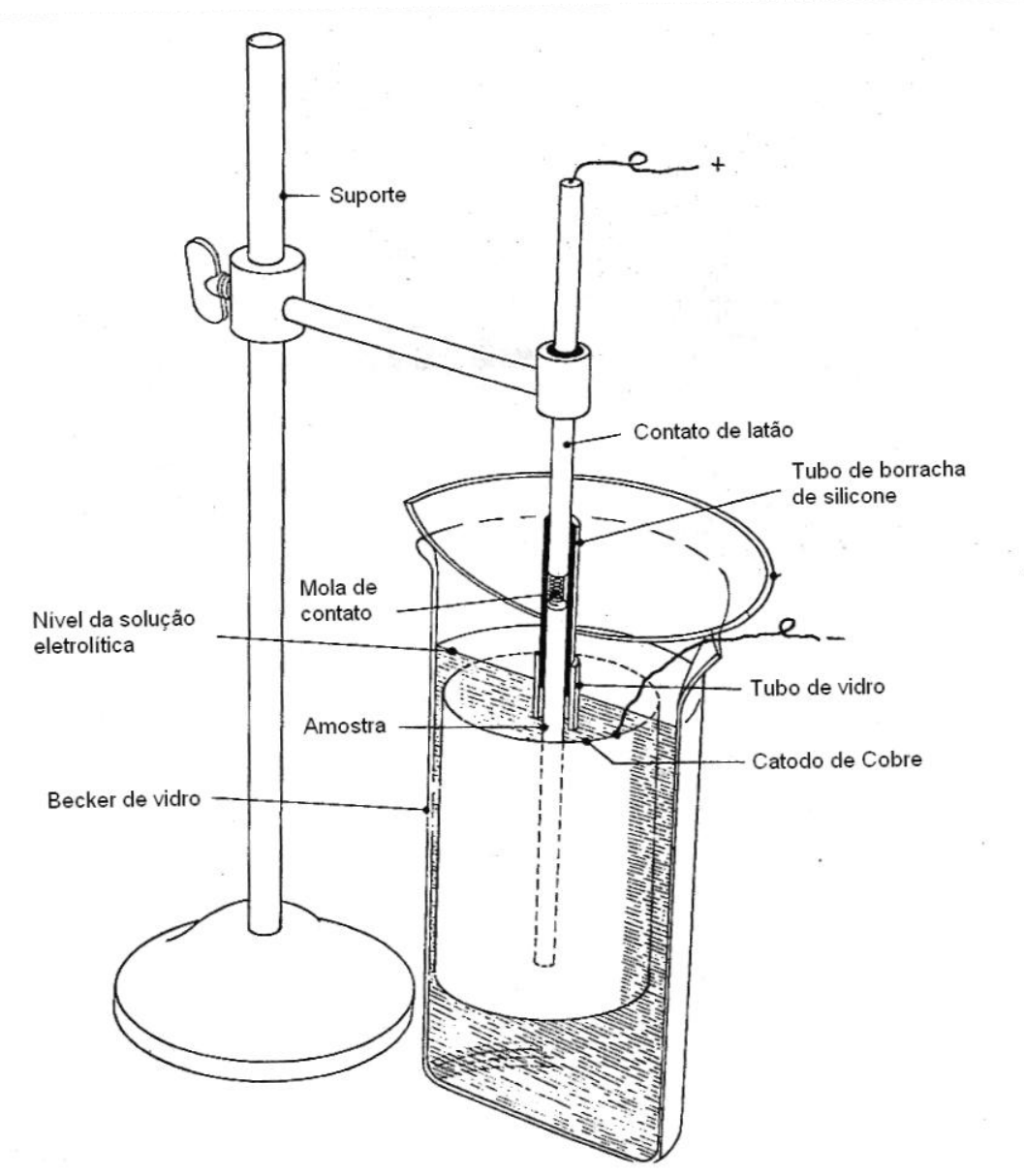

Figura 3.5: Esquema da célula hidro-clorídrica utilizada na dissolução eletrolítica neste trabalho.

As condições experimentais empregadas por Blickwede e Cohen (1949) para a extração de carbonetos de amostras temperadas foram: solução de $\mathrm{HCl}$ a $10 \%$ como eletrólito, densidade de corrente de $4,3 \times 10^{-4} \mathrm{~A} \mathrm{~mm}^{-2}$ e tempo de dissolução de $48 \mathrm{~h}$, com troca da solução eletrolítica após 24 h do início da dissolução. Kaiser e Cohen (1952) utilizaram, também para amostras temperadas, o mesmo tipo de célula eletrolítica. Porém 
como catodo foi utilizado uma chapa de aço inoxidável 18-8. O eletrólito utilizado foi o mesmo e a densidade de corrente foi de $2,3 \times 10^{-4} \mathrm{~A} \mathrm{~mm}^{-2}$ e tempo de extração de 24 horas.

A utilização da célula hidroclorídrica para a extração de carbonetos em amostras revenidas não apresentou eficiência devido ao grande número de fases cristalinas presentes (Blickwede et al.,1950). Porém, neste trabalho, considerando a simplicidade da célula hidroclorídrica e uma vez que inúmeros testes realizados por dissolução química não haviam obtido sucesso para a separação da fração total de carbonetos, realizou-se um estudo com variações da corrente, concentração do eletrólito e do tempo de extração que permitiu determinar as condições experimentais que possibilitaram a extração da fração total dos carbonetos nas amostras revenidas sem a ocorrência do fenômeno de descascamento.

As condições utilizadas foram: catodo de cobre, solução de $\mathrm{HCl}$ a $10 \%$, densidade de corrente de $1,0 \times 10^{-4} \mathrm{~A} \mathrm{~mm}^{-2}$ (limite inferior da fonte disponível) e tempo de dissolução de 16 h sem troca do eletrólito.

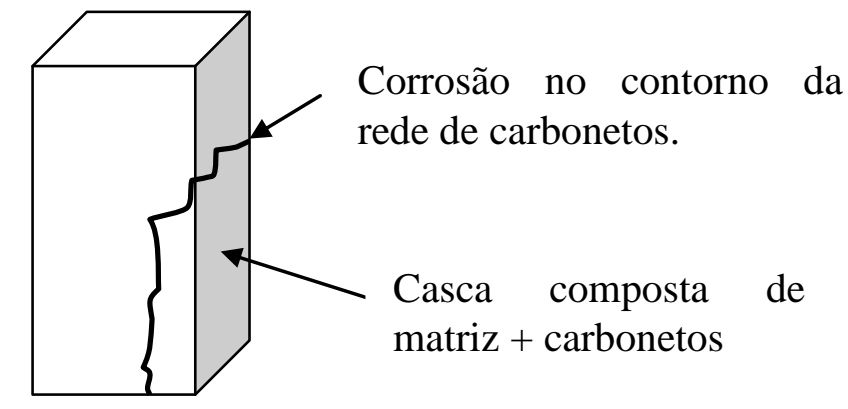

Figura 3.6: Representação esquemática do fenômeno de escamação na dissolução eletrolítica.

A dissolução química do aço AISI/SAE M2 com o reagente de Berzelius (160 $\mathrm{g}$ de cloreto cúprico di-hidratado $\left(\mathrm{CuCl}_{2} .2 \mathrm{H} 2 \mathrm{O}\right), 140 \mathrm{~g}$ de cloreto de potássio $(\mathrm{KCl}), 10 \mathrm{~g}$ de ácido tartárico $\left(\mathrm{C}_{4} \mathrm{H}_{6} \mathrm{O}_{6}\right), 75 \mathrm{ml}$ de ácido clorídrico $(\mathrm{HCl})$ e $925 \mathrm{ml}$ de água (Burke,1975) ) permite a extração de carbonetos do tipo: $\mathrm{MC}, \mathrm{M}_{2} \mathrm{C}, \mathrm{M}_{23} \mathrm{C}_{6}$.

A relação entre a massa de amostra e o volume de solução foi mantida constante, onde o volume de solução foi de $100 \mathrm{~mL}$ para aproximadamente 2 gramas de amostra. A dissolução foi realizada a temperatura ambiente sob agitação constante em placa magnética por aproximadamente 16 horas.

Em ambas as técnicas de extração o resíduo foi filtrado utilizando sistema de filtração e película filtrante, ambos de PFTE (teflon), com tamanho médio de poro de $2 \mathrm{x}$ $10^{-1} \mu \mathrm{m}(200 \mathrm{~nm})$, visto na FIG. 3.7. Na etapa de filtração foi acoplado ao fundo do béquer 
um dispositivo com magneto de Nd-Fe-B com a finalidade de separar magneticamente partículas que pudessem conter a fase matriz.

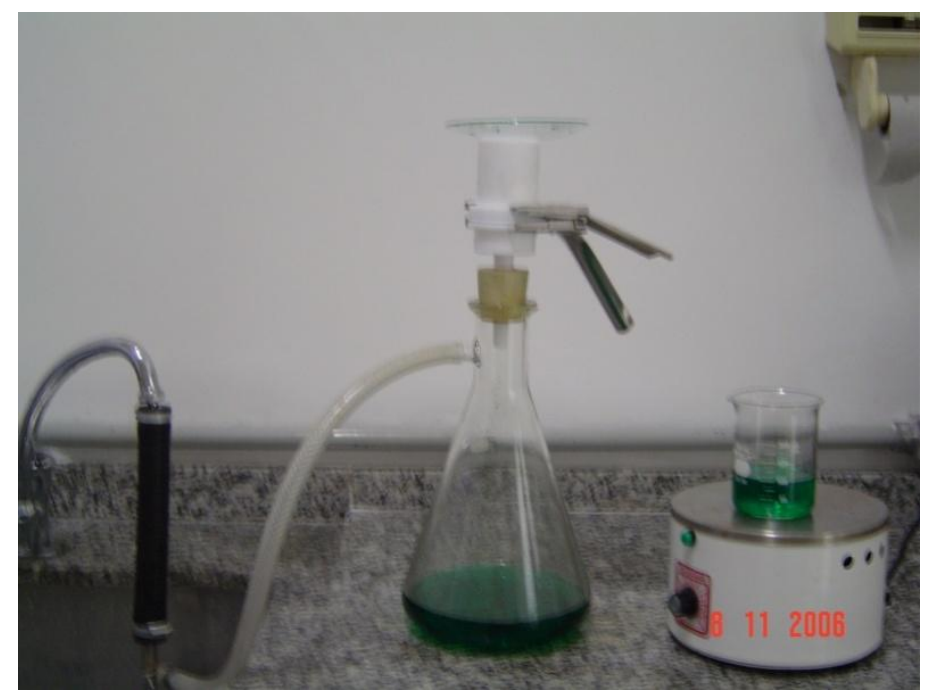

Figura 3.7: Fotografia do sistema utilizado para a filtragem do resíduo da dissolução eletrolítica e da dissolução química.

Tanto o resíduo da dissolução eletrolítica como da dissolução química aderem ao copo de PTFE do sistema de filtração exigindo que o volume adicionado seja o menor possível, tornando esta etapa bastante demorada. Com a finalidade de minimizar que o resíduo pudesse sofrer ataque químico pelo eletrólito ou pelo reagente de Berzelius, mesmo que em taxas insignificantes, os mesmos foram diluídos para o dobro do volume de partida. Desta maneira a etapa de filtragem demorou de 12 a 14 horas.

A TAB. 3.3 apresenta a nomenclatura utilizada para denominar as amostras estudadas neste trabalho.

Tabela 3.3: Nomenclatura das amostras.

\begin{tabular}{ll}
\hline Nome da amostra & \multicolumn{1}{c}{ Descrição } \\
\hline M2COM & Adquirida comercialmente, no estado como recebido. \\
M2CSMH & $\begin{array}{l}\text { Obtida por conformação por spray e retirada da parte } \\
\text { central do pré-formado. }\end{array}$ \\
M2MP & Obtida por metalurgia do pó, no estado sinterizado. \\
M2COMTT & Adquirida comercialmente e tratada termicamente. \\
M2MPTT & Obtida por metalurgia do pó e tratada termicamente. \\
M2CSL50TT & $\begin{array}{l}\text { Obtida por conformação por spray, laminada até } \\
\text { redução de 50\% da espessura e tratada termicamente. }\end{array}$ \\
M2CSL70TT & $\begin{array}{l}\text { Obtida por conformação por spray, laminada até } \\
\text { redução de 72\% da espessura e tratada termicamente. }\end{array}$ \\
\hline
\end{tabular}

\subsection{Análises químicas}


A análise química dos elementos metálicos do resíduo extraído na dissolução química foi realizada pela técnica de fluorescência de raios X por dispersão de energia (EDS) utilizando-se o sistema acoplado ao microscópio eletrônico de varredura para a análise química individual das partículas extraídas, e também, pela técnica de fluorescência de raios $\mathrm{X}$ por dispersão de energia utilizando-se um espectrômetro dedicado, vide esquema na FIG. 3.8, para a análise da massa total do resíduo extraído.

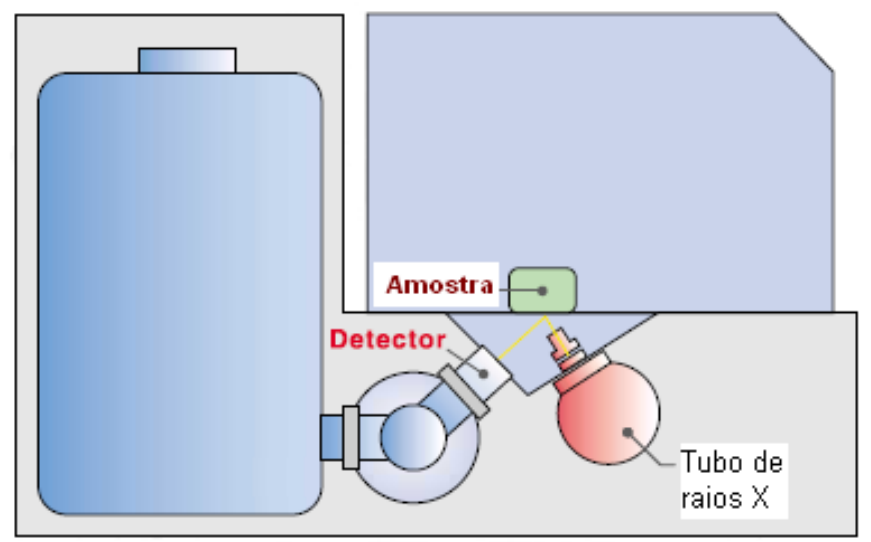

Figura 3.8: Esquema do espectrômetro de fluorescência de raios X.

A análise química quantitativa, nos dois equipamentos utilizados, é realizada com base no método dos parâmetros fundamentais. Este método é baseado na obtenção de curvas de calibração para cada elemento químico individualmente e as correções para o efeito matriz são realizadas por algoritmos desenvolvidos pelos fabricantes de cada equipamento (Karagöz et al., 1989).

A maior confiabilidade dos resultados obtidos no espectrômetro pode ser atribuída a:

1) Possibilidade de dimensionamento da área irradiada permitindo a análise de todo o resíduo extraído;

2) Sintonização da energia do feixe incidente permitindo que a obtenção do espectro dos elementos leves seja realizada em energia mais baixa que a dos elementos pesados;

3) O equipamento possui ainda um conjunto de filtros que possibilitam maior discriminação entre o sinal medido e o ruído.

A obtenção de amostras por metalurgia do pó para o aço AISI/SAE M2 pelo processo descrito no item 3.1 é bastante difícil devido à estreita janela de temperatura de 
sinterização deste aço (comunicação oral Ambrozio Filho, 2004). Portanto, a disponibilidade de amostras obtidas por metalurgia do pó foi limitada.

O material obtido por conformação por spray apresentou problema de contaminação de parte do pré-formado pela evaporação da água do material refratário que recobre o pino do substrato de deposição (vide FIG. 3.9) resultando no descarte da parte do material contaminada.

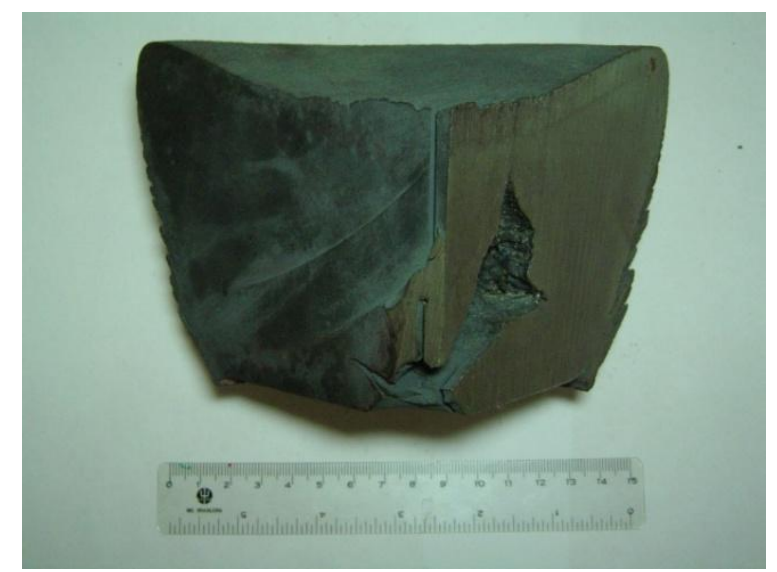

Figura 3.9: Foto do pré-formado de aço AISI/SAE M2 obtido na planta de conformação por spray do IPEN mostrando o defeito decorrente da evaporação da água do material refratário que recobria o pino de suporte do substrato.

Somando-se a estes fatos, parte das amostras tratadas termicamente já haviam sido utilizadas por Jesus (2004) para os ensaios de desgaste sem refrigeração, conseqüentemente foram submetidas a temperaturas e tempos característicos de overtempering e, portanto foram descartadas para este estudo.

Pelos motivos descritos acima, a quantidade de carbonetos extraídos não permitiu a realização da análise quantitativa de carbono pelo método da micro-combustão. Porém a análise qualitativa, realizada por espectrometria de fluorescência de raios $\mathrm{X}$ comprovou a presença de carbono nas amostras.

\subsection{Análise quantitativa das fases}

A quantificação das fases presentes é tradicionalmente realizada pelas técnicas de: metalografia quantitativa, extração seletiva das fases presente e por difração de raios X.

$\mathrm{Na}$ análise por metalografia quantitativa é necessário distinguir as fases presentes na microestrutura. Quando a observação microscópica da superfície polida da amostra não permite a diferenciação das fases presentes empregam-se ataques superficiais que permitam esta distinção. Realizada a distinção das fases pode-se quantificá-las através 
do emprego da contagem de pontos ou se houver diferenciação de tonalidade entre as fases a análise computadorizada da imagem. A utilização da rede de pontos permite a obtenção da fração de pontos enquanto que a análise da imagem fornece a fração em área.

A quantificação através da análise por difração de raios $\mathrm{X}$ parte do princípio que a somatória da intensidade relativa integrada das reflexões das fases cristalinas é proporcional à quantidade de células unitárias difratantes. Portanto, este método fornece a fração volumétrica difratante das fases componentes do material. Para a quantificação com exatidão das fases por esta técnica é necessário o uso de amostras-padrão, isto é, amostras com quantidades conhecidas das fases que se pretende analisar, para a elaboração de uma curva de calibração.

Diferentemente da quantificação por metalografia quantitativa e por difração de raios X a extração de precipitados permite a quantificação em peso. A comparação entre os valores de fração volumétrica e fração em peso depende do conhecimento da densidade real das fases envolvidas. Os aços rápidos por conterem vários tipos de carbonetos e estes apresentarem substituições atômicas nos sítios dos átomos metálicos, esta conversão tornase ainda mais complexa.

Na FIG. 3.10(a) é apresentado o gráfico da fração volumétrica e da fração em massa do total de carbonetos extraídos para amostras de aço AISI/SAE M2 em função da temperatura de austenitização obtidos por Blickwede e Cohen (1949) e por Kaiser e Cohen (1952). Pode-se ver que ocorre um desvio significativo principalmente quando a fração de carbonetos diminui. Posteriormente verificou-se que para os aços rápidos os ataques para revelação das fases presentes, em geral, tendem a enfatizar a área dos carbonetos (Kim et al.,1982).

Kim et al. (1982) propuseram um procedimento para o cálculo da fração de cada tipo de carboneto extraído a partir da análise química das partículas individuais, da análise química do resíduo extraído e da fração de carbonetos extraídos. Os autores descrevem sucintamente o método, porém algumas falhas na definição das variáveis utilizadas no cálculo impedem a reprodução do procedimento. No entanto, os resultados apresentados mostram que os valores de fração volumétrica calculados por metalografia quantitativa podem estar superestimados em até $20 \%$. 


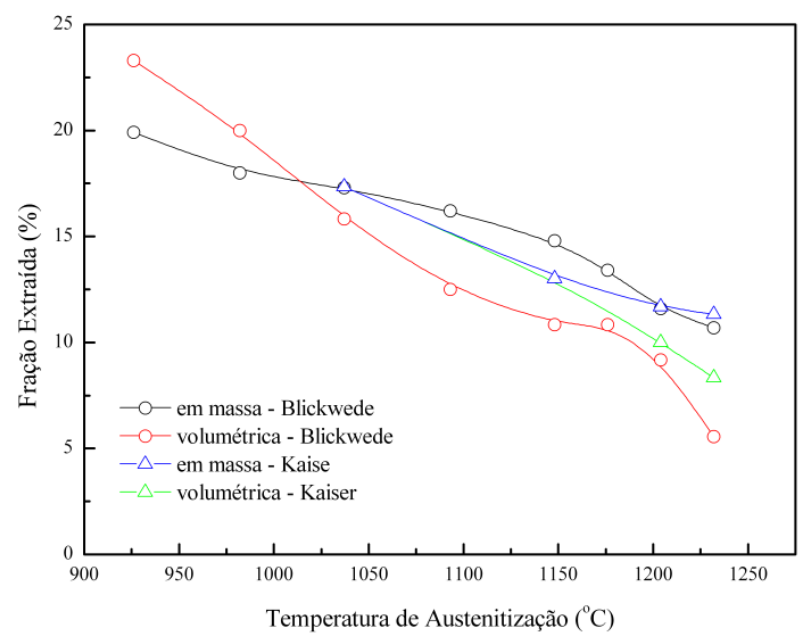

Figura 3.10 - Gráficos de fração volumétrica e da fração em massa de carbonetos extraídos de amostras de aço AISI/SAE M2 em função da temperatura de austenitização.

Kaiser (1991) propôs um método simples baseado no fato que a densidade total de um sistema multi-fásico é a soma do produto da fração em massa pela densidade de cada fase componente do sistema. Os resultados apresentam boa concordância com os resultados apresentados por Kim et al. (1982). Em ambos os trabalhos os autores consideraram que a composição química do carboneto do tipo MC apresentava cerca de $70 \%$ atômico de vanádio.

A estimativa das frações volumétricas neste trabalho foi realizada, utilizandose o método proposto por Kaiser (1991). O cálculo da densidade das fases foi realizado considerando-se:

1) Para o $\mathrm{MC}$ considerou-se a estequiometria $\mathrm{V}_{4} \mathrm{C}_{3}$. $\mathrm{O}$ parâmetro de rede e a composição química foram determinados pelo refinamento desta estrutura pelo método de Rietveld;

2) Para o $\mathrm{M}_{6} \mathrm{C}$ a composição química foi obtida por análise pontual por EDS para partículas embebidas na matriz e o parâmetro de rede foi obtido através do espectro de difração de raios $\mathrm{X}$ da amostra maciça;

3) Para a matriz foi utilizada a densidade teórica da matriz ferrítica.

\subsection{As análises por difração de raios $X$}

As análises por difração de raios X foram realizadas na linha de D10B-XPD do Laboratório Nacional de Luz Síncrotron (LNLS), através da aprovação das propostas 
número: 4193; 4741 e 5722, para as quais foram concedidos um total de 8 turnos de 24 horas.

Na FIG. 3.11 é apresentado um diagrama esquemático da linha de luz utilizada e na FIG. 3.12 uma foto do goniômetro Huber disponível nesta linha.

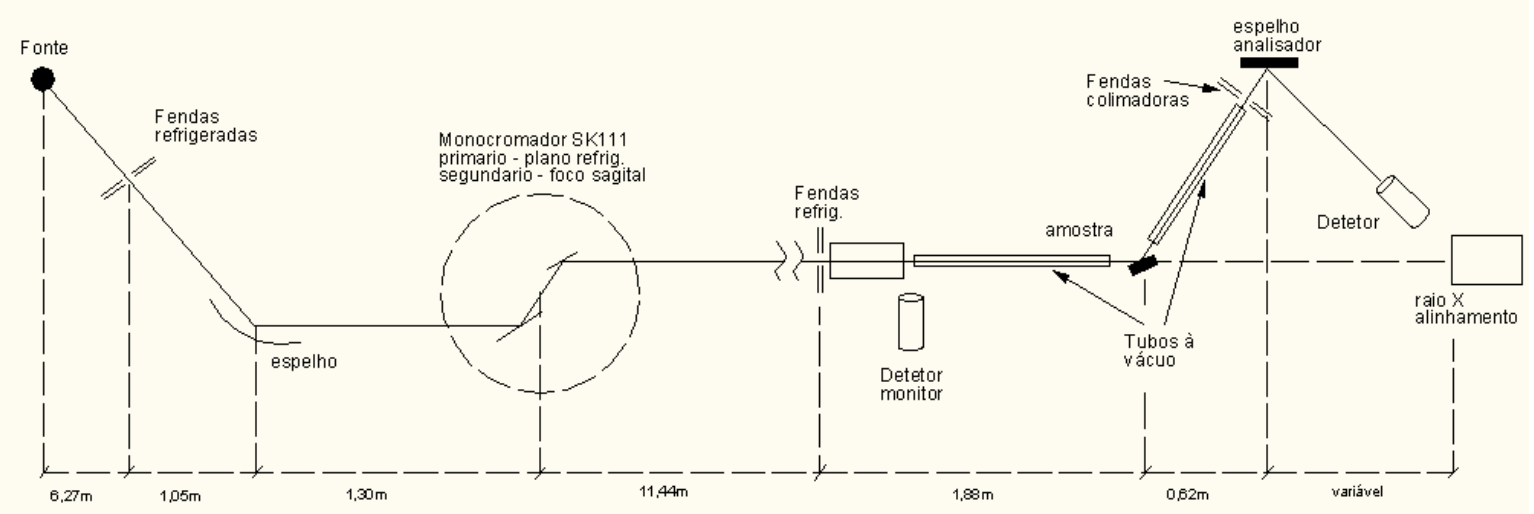

Figura 3.11: Diagrama esquemático da linha da luz D10B-XPD do LNLS.

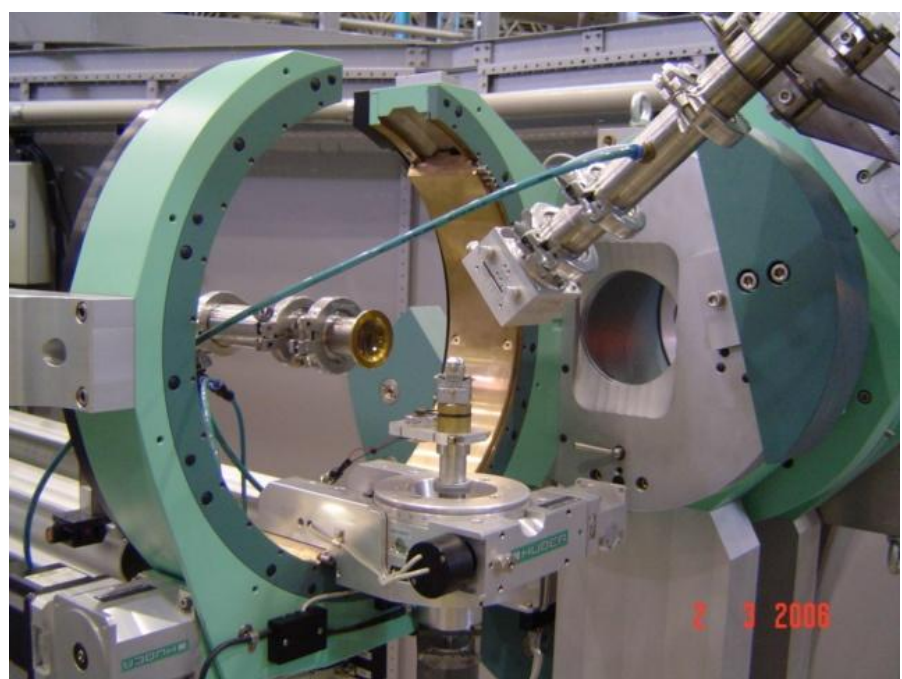

Figura 3.12: Foto do goniômetro Huber de seis círculos com geometria $\theta-2 \theta$ utilizado nas análises deste trabalho.

A grande vantagem da realização de medidas de difração de raios $\mathrm{X}$ utilizando fonte de luz síncrotron é a alta resolução alcançada e a possibilidade de sintonia da energia dos raios X (comprimento de onda). Porém há um preço a se pagar por essa resolução, pois este tipo de arranjo experimental está sujeito a instabilidades na órbita do feixe, aquecimento no monocromador, detecção de harmônicos de segunda e terceira ordens, entre outros. Os dois primeiros efeitos citados implicam em alteração na energia dos fótons 
e conseqüentemente no deslocamento das reflexões, na ocorrência deste tipo de problema os dados não permitirão a convergência do refinamento. $O$ terceiro problema ocorre quando a energia selecionada é baixa e a linha não possui espelhos que permitam filtrar estes harmônicos; neste caso é possível eliminar os harmônicos através de uma pequena defasagem nos espelhos do monocromador, porém com perda significativa de intensidade.

A identificação das fases cristalinas presentes foi realizada através da comparação com padrões de difração de raios $\mathrm{X}$ constantes nas bases de dados: Powder Diffraction File (ICDD) - Release 2003 elaborada pelo International Centre for Diffraction Data, Inorganic Crystal Structure Database (ICSD) elaborada pelos Fachinformationszentrum Karlsruhe (FIZ) na Alemanha e pelo National Institute of Standards and Technology (NIST) nos Estados Unidos e na Crystmet elaborada pela Toth Information Systems. O acesso às bases ICSD e Crystmet é fornecido pelo site www.portaldapesquisa.com.br através de convênio com o Laboratório Nacional de Luz Síncrotron.

Os dados obtidos por difração de raios $\mathrm{X}$ foram utilizados para a determinação dos parâmetros cristalográficos através do método de Rietveld (Young, 1988; McCusker et al., 1999) utilizando o algoritmo implementado no programa GSAS (General Structure Analysis System) desenvolvido por Larson e Von Dreele (2004). As condições experimentais utilizadas e suas justificativas serão descritas nos itens a seguir.

\subsection{As condições experimentais para aplicação do método de Rietveld}

\subsubsection{Os dados experimentais}

O primeiro passo para a realização de um bom refinamento é a obtenção de um espectro de difração de raios $\mathrm{X}$ de um composto padrão, isto é, monofásico, com tamanho médio de cristalito conhecido, livre de microtensões. Estes padrões podem ser adquiridos comercialmente ou produzidos pelo próprio interessado.

A escolha do padrão está relacionada às características da amostra e a configuração do equipamento que está sendo utilizado para a obtenção dos dados. Assim, por exemplo, se a amostra possuir alta cristalinidade (tamanho de cristalito grande) e os dados forem obtidos utilizando um difratômetro de raios $\mathrm{X}$ com fonte de luz síncrotron e cristal analisador, o padrão ideal é o $\mathrm{LaB}_{6}$. Outros padrões são: silício, alumina e mica.

O refinamento do padrão tem a finalidade de determinar os parâmetros instrumentais do equipamento, como, por exemplo, a energia utilizada, no caso do uso de 
radiação de luz síncrotron, e determinar os valores iniciais para as variáveis da função de perfil.

A escolha do tipo de porta amostra e da maneira como a amostra será preparada é ditada pelas características da própria amostra. Amostras hidrofóbicas, ou que tendem a apresentar orientação preferencial, devem preferencialmente ser acondicionadas em capilares. Esta técnica também pode ser utilizada quando o volume de amostra for pequeno. O uso deste arranjo somente é aconselhável para estudos muito específicos, pois a coleta de dados é extremamente demorada e há necessidade da realização de correções dos dados experimentais devido a absorção pelo capilar.

Para se evitar orientação preferencial a condição de preparação das amostras é a que merece maior atenção. Para isto existem diversas técnicas de preparação com a finalidade de minimizar estes problemas. Estas técnicas são: o carregamento lateral e o carregamento inverso (Buhrke et al., 1998).

A rugosidade superficial é outro fator importante que também pode estar relacionado à deposição da amostra no porta-amostra. Este fator pode levar a efeitos de micro-absorção na superfície da amostra. No caso em que não é possível cominuir a amostra para que a rugosidade da mesma seja mínima, este fato deve ser considerado na estratégia do refinamento.

O ponto de partida para qualquer análise referente a estrutura cristalina de um material é a obtenção de um difratograma simples, isto é, realizando-se uma varredura "rápida". A partir dos dados da varredura rápida é possível estabelecer parâmetros como passo de varredura, largura das fendas, tempo de contagem e outras necessidades específicas para o material que está sendo estudado.

O passo de varredura $(\Delta 2 \theta)$ é determinado por:

$$
\Delta 2 \theta=\frac{F W H M}{N}
$$

onde: $F W H M$ é a largura a meia altura do pico de difração e $N$ deve ser um valor entre 5 e 10 passos (McCusker et al., 1999).

As fendas de divergência e espalhamento possuem em geral a mesma largura e são escolhidas em função do ângulo de início da varredura e da área de amostra disponível.

A quantidade de amostra é fator que determinará a escolha de um portaamostra que permita a obtenção de uma camada com espessura suficiente para que a 
penetração do feixe de raios $\mathrm{X}$ ocorra sem que atinja a superfície do porta-amostra, e que ao mesmo tempo proporcione a maior área de amostra possível.

Devido a divergência do feixe a área irradiada pelo feixe de raios $\mathrm{X}$ é inversamente proporcional ao valor do ângulo $2 \theta$. Portanto, a posição angular da primeira reflexão de interesse determina a largura máxima da fenda de divergência.

Atenção especial deve ser dada à questão estatística quando se utiliza fonte de luz síncrotron. Neste tipo de arranjo o feixe é colimado resultando que a área irradiada pelo feixe é muito menor que na difração de raios $\mathrm{X}$ por tubo selado (difratômetro convencional). Portanto, dependendo do tamanho médio dos domínios coerentes o número de cristalitos pode não ser representativo de uma distribuição aleatória para a realização de um bom refinamento, sendo necessário, se possível, cominuir a amostra.

O tempo de contagem em cada passo de varredura deve ser escolhido de maneira a se obter o menor desvio estatístico possível. Na prática este tempo é ditado em função da disponibilidade do equipamento.

\subsubsection{O espalhamento anômalo}

Conjuntamente com o método de Rietveld nestes últimos 40 anos houve o aumento de instalações de luz síncrotron no mundo inteiro. E este fato teve uma importância muito grande para o aumento do campo de aplicação do método de Rietveld, pois forneceu uma das principais ferramentas para se obter refinamentos com dados de difração de raios $\mathrm{X}$ mais precisos que são: a possibilidade da escolha da energia e a alta resolução dos picos. A escolha da energia é a ferramenta que permite colocar em “evidência" determinados átomos através do fenômeno do espalhamento anômalo.

Segundo McCusker et al. (1999), os melhores resultados com o uso do espalhamento anômalo são obtidos quando é possível acessar a energia de absorção das camadas $K$ e $L$ dos átomos de interesse. Neste caso, o experimento deve ser executado com espectros de difração de raios $\mathrm{X}$ obtidos em energia de $10 \mathrm{eV}$ a $20 \mathrm{eV}$ menores que a energia da camada $\mathrm{K}$ dos átomos de interesse e um difratograma obtido com energia de 1 $\mathrm{keV}$ acima da energia de absorção, isto é, num valor de energia em que os fatores de espalhamento dos átomos de interesse não possam ser distinguidos entre si.

A natureza real do espalhamento anômalo é o espalhamento ressonante da radiação. Na realidade o espalhamento normal é uma condição ideal que ocorre apenas quando a freqüência da onda da radiação incidente $\left(\omega_{\mathrm{i}}\right)$ é muito maior quando comparada 
às freqüências de ressonância dos átomos $\left(\omega_{\mathrm{K}}, \omega_{\mathrm{L}}, \omega_{\mathrm{M}}\right.$, etc., onde o sub-índice refere-se a camada eletrônica) que estão associadas a borda de absorção de cada camada eletrônica.

Vários métodos têm sido usados para calcular as correções necessárias devido à radiação ressonante, os três principais métodos são:

- método de Hönl: que usa autofunções do hidrogênio para obter as energias do oscilador e a partir delas calcular o coeficiente de absorção fotoelétrico, o coeficiente de absorção e a seção de choque. Este método originalmente restringiase a contribuição dos elétrons da camada $K$ e foi posteriormente estendido para os elétrons da outras camadas por diversos autores.

- o método de Parrat e Hempstead: que usa uma relação semi-empírica para o efeito fotoelétrico, a absorção e a secção de choque a partir do qual $f$ e $f^{\prime \prime}$ são obtidos.

- o método de Cromer e Liberman: que utiliza as funções de onda relativísticas de Slater-Dirac.

Nas FIG. 3.13 a 3.16 são apresentados os gráficos do fator de espalhamento atômico em função de $\operatorname{sen} \theta / \lambda$, onde $\theta$ representa o ângulo de difração e $\lambda$ o comprimento de onda. Na TAB.3.4 são apresentadas as energias e os correspondentes comprimentos de onda utilizados nas análises de difração de raios X realizadas no LNLS. A seleção das energias foi realizada para que se obtivesse contraste entre os fatores de espalhamento atômicos dos átomos de vanádio, cromo, ferro, molibdênio e tungstênio.

Tabela 3.4: Energias $\left(\mathrm{E}_{\mathrm{f}}\right)$ e respectivo comprimento de onda utilizados nas análises por difração de raios $\mathrm{X}$ com fonte de luz síncrotron.

\begin{tabular}{lc}
\hline Energia $(\mathrm{keV})$ & $\lambda(\mathrm{nm})$ \\
\hline $\mathbf{5 , 4 1 0 3}$ & $0,22912(2)$ \\
$\mathbf{5 , 4 4 3 3}$ & $0,22773(6)$ \\
$\mathbf{7 , 0 9 0 3}$ & $0,17483(2)$ \\
$\mathbf{8 , 0 0 0 5}$ & $0,15494(1)$ \\
$\mathbf{1 0 , 2 7 3 0}$ & $0,12070(5)$ \\
\hline
\end{tabular}




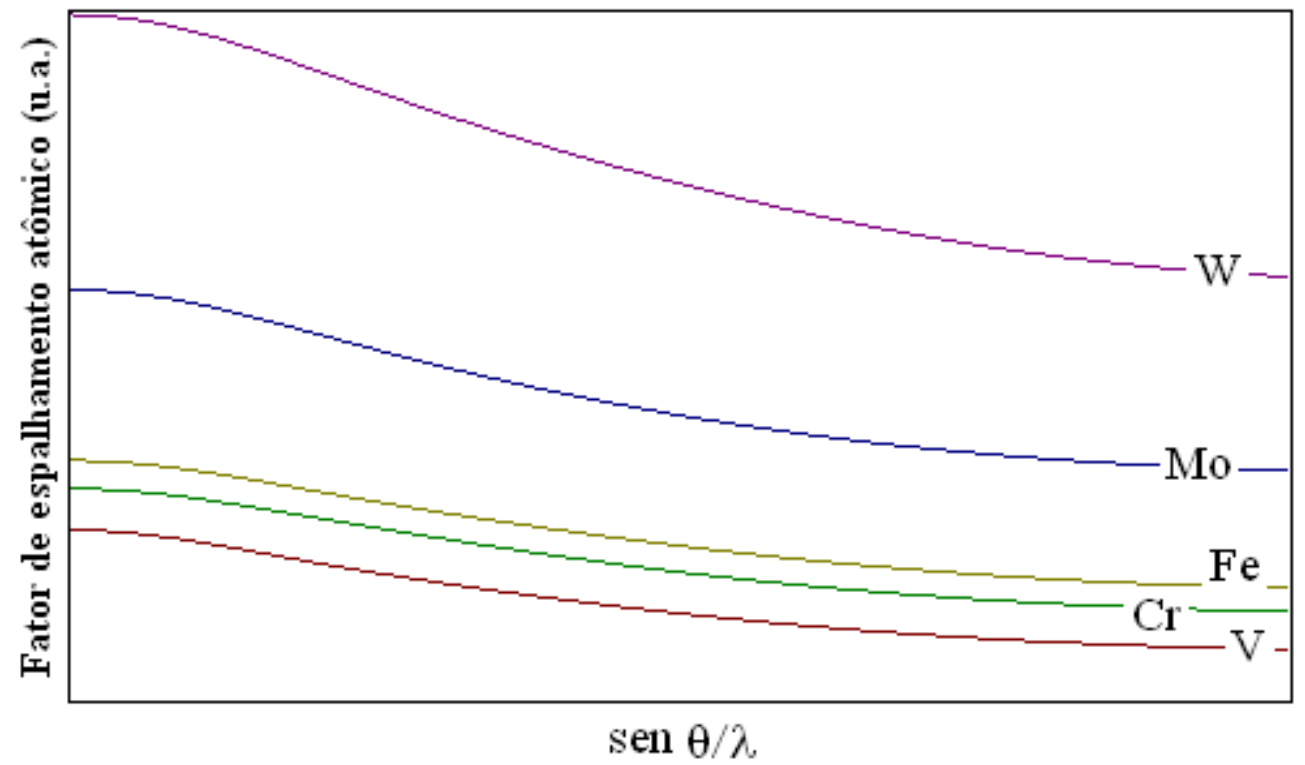

Figura 3.13: Gráfico do fator de espalhamento atômico dos átomos de vanádio, cromo, ferro, molibdênio e tungstênio para $\mathrm{E}_{\mathrm{f}}=5,4433 \mathrm{keV}$ (Cromer, 1980).

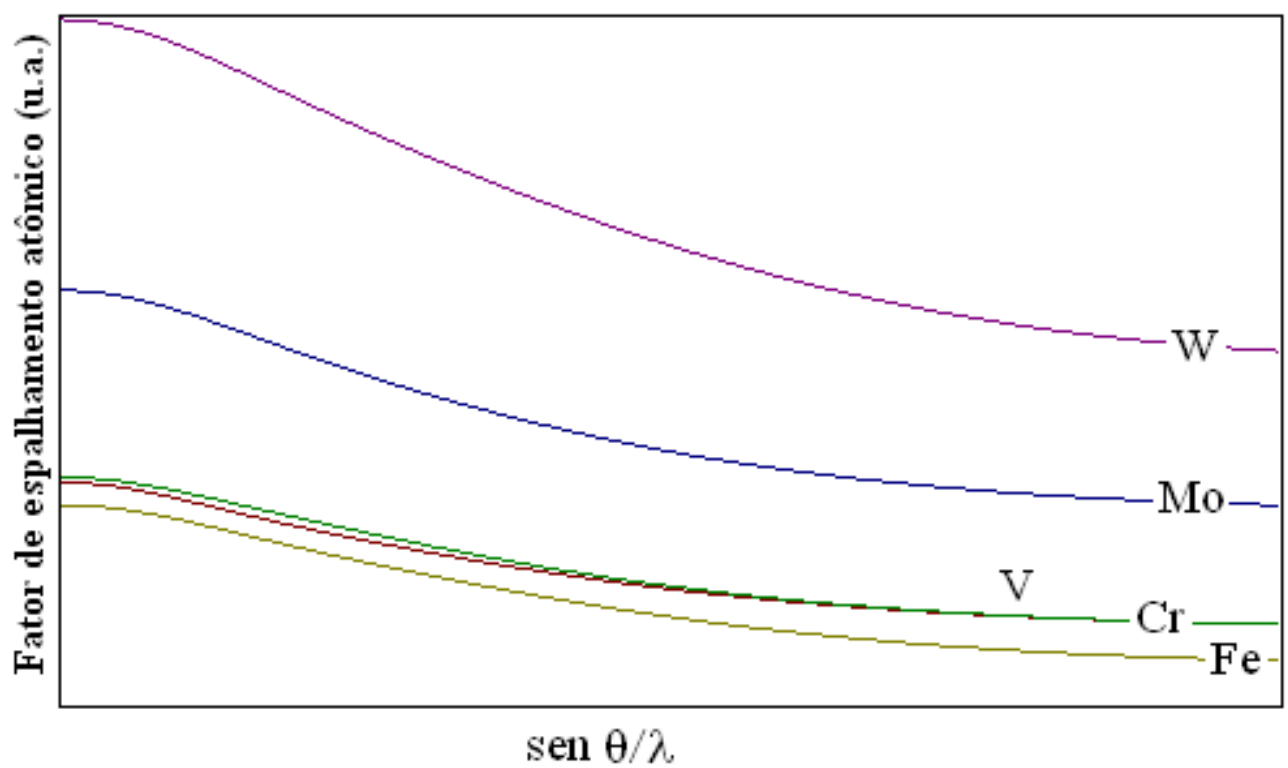

Figura 3.14: Gráfico do fator de espalhamento atômico dos átomos de vanádio, cromo, ferro, molibdênio e tungstênio para $\mathrm{E}_{\mathrm{f}}=7,0903 \mathrm{keV}$ (Cromer, 1980). 


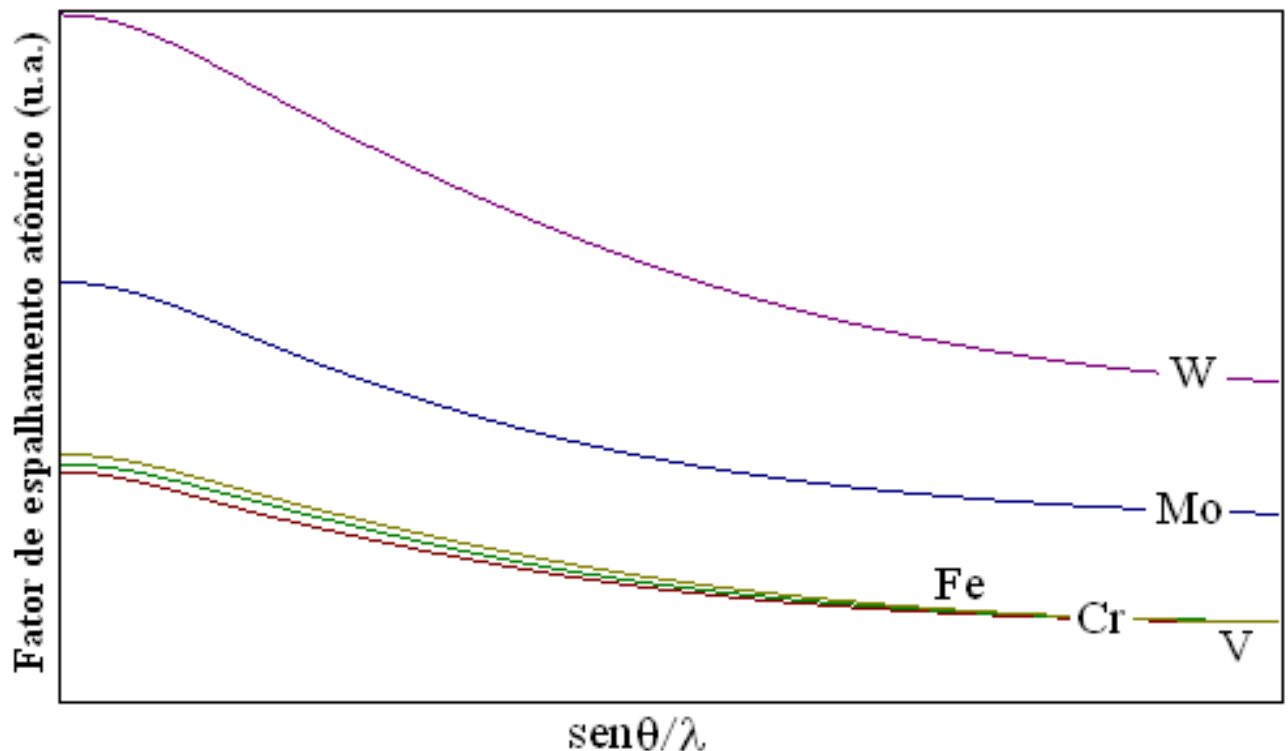

Figura 3.15: Gráfico do fator de espalhamento atômico dos átomos de vanádio, cromo, ferro, molibdênio e tungstênio para $\mathrm{E}_{\mathrm{f}}=8,0005 \mathrm{keV}$ (Cromer, 1980).

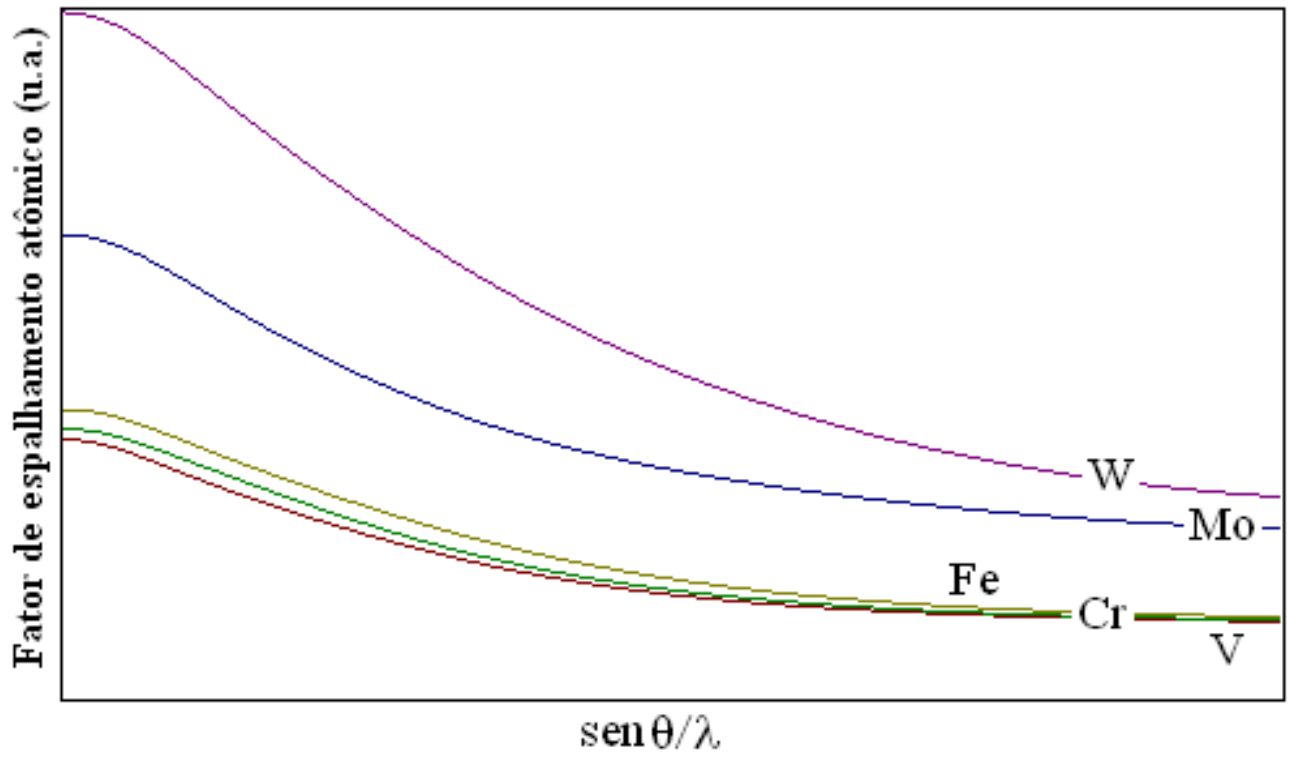

Figura 3.16: Gráfico do fator de espalhamento atômico dos átomos de vanádio, cromo, ferro, molibdênio e tungstênio para $\mathrm{E}_{\mathrm{f}}=10,2730 \mathrm{keV}$ (Cromer, 1980).

\subsubsection{A obtenção dos parâmetros cristalográficos}

Os métodos de determinação do grupo espacial de um material pela análise do espectro de difração de raios $\mathrm{X}$ de um material policristalino estão bem estabelecidos (Cullity e Stock, 2001; Glusker e Trueblood,1985; Stout e Jensen, 1989). No entanto, em todos os métodos propostos a determinação das posições atômicas somente pode ser realizada por tentativa e erro. 
Até por volta de 1960, considerava-se que a estrutura cristalina de um composto somente poderia ser determinada usando-se a técnica de difração de raios $\mathrm{X}$ ou nêutrons com o emprego de amostras monocristalinas do composto.

A partir desta época, o avanço da tecnologia computacional permitiu o cálculo minimizando-se as aproximações e com relativa rapidez. Aliando-se a este fato o grande desenvolvimento de novos materiais, que nem sempre apresentava facilidade de obtenção de monocristais, proporcionaram o ambiente perfeito para a aceitação do refinamento de estrutura utilizando dados obtidos por difratometria do pó de policristais. Conseqüentemente, o método de Rietveld despertou o interesse de inúmeros pesquisadores, proporcionando o aperfeiçoamento do método.

A definição mais clara para o método de Rietveld foi dada por Paiva-Santos (2005) "É um método de refinamento de estruturas cristalinas, fazendo uso de dados de difração de raios $\mathrm{X}$ ou nêutrons, por pó. A estrutura cristalina é refinada, de forma a fazer com que o difratograma calculado com base na estrutura cristalina, se aproxime - o melhor possível - do difratograma observado".

Desta definição é possível estabelecer que para a utilização do método de Rietveld o usuário necessitará de conhecimentos de cristalografia estrutural e de difração de raios $\mathrm{X}$ por pó que permitam a interpretação dos resultados. $\mathrm{O}$ desenvolvimento de inúmeros programas de computador utilizando o método de Rietveld permitiu a popularização do método nas diversas áreas de estudos de materiais.

\subsubsection{A estrutura modelo}

A eleição da estrutura cristalina modelo é o parâmetro de maior relevância para o refinamento. A primeira pergunta do iniciante no estudo do método de Rietveld é: se é preciso conhecer a estrutura cristalina, para que serve o método? Esta resposta está contida na própria definição do método. O objetivo do método é refinar um modelo estrutural e não determinar a estrutura cristalina. Por refinar entende-se: estudar parâmetros estruturais como posição atômica, fator de ocupação, fator de temperatura entre outros. Portanto para se iniciar os cálculos é necessário o conhecimento de pelo menos o grupo espacial desta estrutura, a partir do qual é possível obter-se as posições atômicas, que poderão ser confirmadas através de outras técnicas de caracterização, isto é, o mais próximo possível que se pode chegar da idéia de determinação da estrutura cristalina. 
A eleição da estrutura cristalina pode ser feita de diversas maneiras:

- em muitos casos a estrutura é conhecida, e neste caso o método será empregado para verificar alterações decorrentes da adição de átomos que entram em substituição ou nos interstícios da estrutura e para a quantificação das fases presentes;

- através da utilização das bases de dados cristalográficos é possível eleger uma estrutura isomorfa como modelo para a estrutura desconhecida;

- realizar a determinação do grupo espacial por difração de elétrons utilizando microscopia eletrônica de transmissão ou difração de raios $\mathrm{X}$ no caso de grupos espaciais com alta simetria.

\subsubsection{Princípio matemático}

O método de Rietveld parte de um equacionamento matemático que descreve a intensidade em cada ponto do espectro pela equação (Young, 1996):

$$
y_{i}=S \sum_{h k l} M_{h k l} L_{h k l}\left|F_{h k l}^{2}\right| \phi_{h k l} P_{h k l} A+y_{b i}
$$

onde: $\quad S$ é o fator de escala

$h k l$ são os índices de Miller

$M_{h k l}$ é o fator de multiplicidade

$L_{h k l}$ é o fator de Lorentz-Polarização

$F_{h k l}$ é o fator de estrutura

$\phi_{h k l}$ é a função do perfil

$A$ é o fator de absorção

$P_{h k l}$ é a função de orientação preferencial

$y_{b i}$ é a intensidade da radiação de fundo no i-ésimo ponto.

sendo que a definição do fator de estrutura é:

$$
F_{h k l}=\sum_{n}^{N} O_{n} f_{n} e^{2 \pi i\left(h u_{n}+k v_{n}+l w_{n}\right)}
$$

onde: $N$ são todos os átomos da célula unitária, $u v w$ são as coordenadas fracionárias do enésimo átomo da célula unitária, $O_{n}$ o fator de ocupação de cada sítio equivalente, $f_{n} \mathrm{o}$ fator de espalhamento do átomo que é dado por: 


$$
f_{n}=f_{n r} e^{\left[-U_{n}\left(\frac{\operatorname{sen} \theta}{\lambda}\right)^{2}\right]}
$$

onde: $f_{n r}$ é o fator de espalhamento para o átomo em repouso e $U_{n} \mathrm{o}$ deslocamento quadrático médio, ou no caso de deslocamentos isotrópicos:

$$
f_{n}=f_{n r} e^{\left[-\frac{1}{4}\left(U_{11 n r} h^{2} a^{* 2}+\cdots+2 U_{23 n r} k l b^{*} c^{*}\right)\right]}
$$

onde: os asterísticos indicam os eixos da célula no espaço recíproco.

Por fim o fator de espalhamento para o átomo em repouso é dado em função do espalhamento anômalo por:

$$
f_{n r}=\sum_{s} a_{n s} e^{\left(-b_{n s}\left(\frac{\operatorname{sen} \theta}{\lambda}\right)^{2}\right)}+c_{n}+d f^{\prime}+i d f^{\prime \prime}
$$

onde: $a_{n s}, b_{n s} e c_{n}$ são os coeficientes para o fator de espalhamento do enésimo átomo e $d f^{\prime}, e d f^{\prime \prime}$ são a parte real e imaginária devido a correção do espalhamento anômalo.

O fator de ocupação, $O_{n}$, é definido por:

$$
O_{n}=\frac{m_{n}}{M}
$$

onde: $m_{n}$ é a multiplicidade da posição atômica do enésino átomo e $M$ representa o total das posições equivalentes, de maneira que $0<F O_{n} \leq 1$. Este fator permite a correção do fator de estrutura para o caso de ligas substitucionais e de compostos sub-estequiométricos.

A leitura atenta da equação 3.2 mostra que há dois tipos de parâmetros refináveis no método de Rietveld: os parâmetros estruturais e os parâmetros do perfil.

O método foi originalmente proposto para dados experimentais obtidos por difração de nêutrons. O perfil de um pico de difração de nêutrons é descrito satisfatoriamente por uma função gaussiana. Esta foi a primeira função implementada nos algoritmos utilizando o método proposto por Rietveld foram necessários 10 anos para que fosse implementada uma função que modelasse os picos de difração de raios X.

A forma dos perfis de difração depende: (a) da contribuição espectral da fonte de raios X; (b) dos parâmetros geométricos do arranjo experimental e (c) das 
características microestruturais do material (tamanho de cristalito e efeitos de microtensões). A influência dos dois primeiros fatores no alargamento dos picos de difração pode ser minimizada através da utilização de geradores de raios $\mathrm{X}$ altamente estabilizados ou pelo uso da radiação síncrotron e pela adoção de goniômetros de alta precisão. Portanto, minimizados os efeitos instrumentais o alargamento passa a ser predominantemente função das características microestruturais do material.

O trabalho de Lebrun e Sprauel (1990) mostrando que os parâmetros do perfil do pico de difração têm uma forte correlação com as propriedades mecânicas, tais como, dureza, taxa de deformação, densidade de discordâncias e tamanho médio do domínio coerente, foi um forte indicativo que os métodos de ajuste de todo o perfil, como é o caso do método de Rietveld, poderiam ser utilizados na caracterização quantitativa da microestrutura (Sahu et al., 2002).

A função de Voigt, que é a convolução de uma função de Gauss com uma função de Cauchy tem se mostrado a mais adequada para a descrição do perfil obtido por difração de raios X. Desde sua adoção inúmeras modificações têm sido incorporadas com o objetivo de corrigir a influência dos diversos fatores microestruturais que afetam a forma do perfil do pico. Infelizmente, elas são implementadas em diferentes programas do método de Rietveld. Isto ocorre também para as inúmeras funções propostas para modelar a radiação de fundo baseadas em ajuste polinomiais, transformadas de Fourier e série de senos.

\subsubsection{A estratégia de refinamento}

A análise cuidadosa do espectro de difração de raios $\mathrm{X}$ e o conhecimento das condições experimentais utilizadas na sua obtenção são fundamentais para a escolha dos parâmetros que serão refinados e para a interpretação correta dos resultados obtidos. Os pontos mais importantes na análise preliminar são:

- Identificação de todas as fases presentes: a identificação correta das fases cristalinas presentes em um material exige o conhecimento não só da composição química como também dos processos envolvidos em sua obtenção são estes conhecimentos que permitem se ter uma idéia das possíveis fases cristalinas presentes no material;

- O alargamento dos picos de difração é devido a fatores como: tamanho dos cristalitos, microtensões presentes na rede cristalina, sobreposição de picos de diversas fases. Estes fatores, também, podem ser previstos pelo conhecimento dos processos de obtenção do material; 
- A análise do perfil do pico pode ainda indicar a presença de uma distribuição bimodal de tamanho de cristalitos.

- O deslocamento dos picos pode estar relacionado a substituições atômicas que ocorre na célula cristalina alterando os parâmetros de rede.

- Alterações na intensidade relativa dos picos são decorrentes de substituições atômicas que alteram o fator de espalhamento ou de orientações preferenciais. A presença de orientação preferencial pode ser avaliada conhecendo-se o hábito cristalino, uma vez que a geometria externa dos cristais guarda relação com a estrutura cristalina interna e que os processos de fabricação favorecem a formação de determinada geometria externa.

A correção para a presença de orientação preferencial tem sido uma questão que tem gerado controvérsias entre os pesquisadores que utilizam o método de Rietveld. Esta controvérsia pode ser vista como composta por duas vertentes, uma delas formada por pesquisadores mais puristas que defendem ser melhor eliminar a orientação preferencial na preparação da amostra. Enquanto, que a outra vertente considera que desde que a intensidade da reflexão seja menor de 2 vezes a intensidade aleatória é possível realizar esta correção por algoritmo matemático sem que haja perda de informações estruturais.

O algoritmo desenvolvido por Larson e Von Dreele (2004) não permite a adoção de uma restrição para o fator de ocupação (F.O.) quando a ocupação do sitio é disputada por mais de dois átomos. De maneira que o refinamento foi realizado conforme o fluxograma apresentado na FIG. 3.17. Adotou-se como valores iniciais para o fator de ocupação a composição química do resíduo da dissolução química. Após a obtenção da convergência do refinamento, os valores obtidos para o fator de ocupação foram utilizados no refinamento de cada um dos espectros separadamente. 


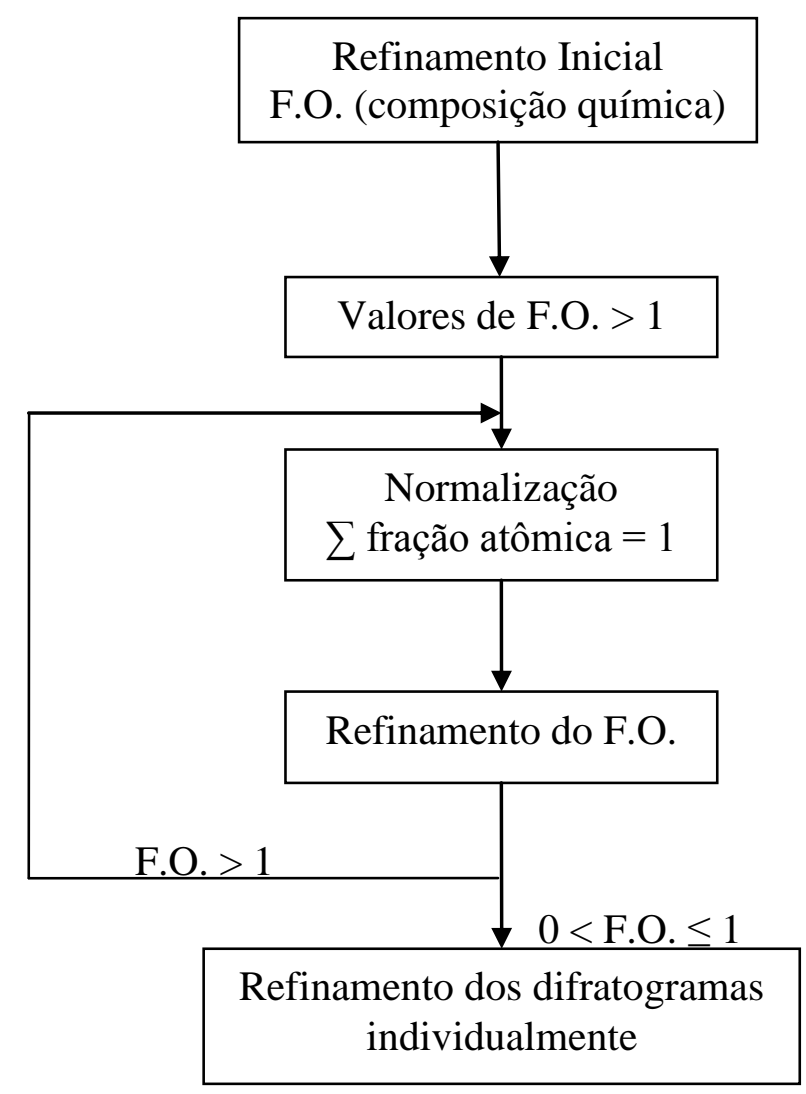

Figura 3.17: Fluxograma do esquema de refinamento da estrutura cristalina pelo método de Rietveld.

O fator de absorção no caso do uso de dados de difração de raios $\mathrm{X}$ obtidos por amostras planas na geometria de Bragg-Brentrano está ligado à rugosidade superficial da amostra. Uma importante consideração sobre esta questão esta relacionada à obtenção de deslocamentos quadráticos médios negativos fato que indica a existência de uma rugosidade superficial relevante.

\subsection{Análises microscópicas}

De acordo com a literatura as seguintes soluções foram utilizadas no ataque superficial para a revelação da microestrutura e dos carbonetos $\mathrm{MC}, \mathrm{M}_{6} \mathrm{C}$ e $\mathrm{M}_{23} \mathrm{C}_{6}$ nos aços AISI/SAE M2:

1) Nital de $1 \%$ a $5 \%$ (Zanoni, 2006, Nogueira, 2006);

2) Picral a $4 \%$ (Kim, 1979);

3) Nital a 2\% contendo cloreto de benzalcônio(Kim, 1979); 
4) Reagente de Murakami: uma parte de água), uma parte de ferricianeto de potássio $\left(\mathrm{K}_{3} \mathrm{Fe}\left(\mathrm{CN}_{6}\right)\right)$ e uma parte de hidróxido de potássio $(\mathrm{KOH})$ (Kim, 1979);

5) Reagente de Vilella: $1 \mathrm{~g}$ de ácido pícrico, $5 \mathrm{~mL}$ de ácido clorídrico $(\mathrm{HCl})$ e $100 \mathrm{~mL}$ de etanol (Kim, 1979);

6) Solução de ácido oxálico (Kim, 1979);

7) Solução de uma parte de ácido nítrico $\left(\mathrm{HNO}_{3}\right)$, três partes de ácido clorídrico $(\mathrm{HCl})$ e duas partes de glicerina (McHarguer, 1954).

8) Solução de $100 \mathrm{~mL}$ de peróxido de hidrogênio a $30 \%$ e $5 \mathrm{~mL}$ de ácido fluorídrico a $42 \%$ (Ding, 1992);

$\mathrm{O}$ carboneto $\mathrm{M}_{6} \mathrm{C}$ pode ser atacado seletivamente com solução de hidróxido de sódio a $4 \%$ saturada com permanganato de potássio, adquirindo coloração marrom em quatro ou cinco segundos. Enquanto que o MC é revelado, tornando-se cinza ou preto, por ataque eletrolítico com solução de ácido crômico a 1 \% utilizando-se uma diferença de potencial em torno de 2,5 V (Blickwede e Cohen, 1949; Kaiser e Cohen, 1952; LeckieEwing, 1952).

As soluções descritas acima e outras preparadas variando-se as concentrações dos reagentes foram testadas para o ataque das amostras revenidas, porém não se obteve sucesso para a diferenciação das fases. Os ataques, para revelação da microestrutura neste trabalho, foram feitos com solução de Nital a 3\% e com solução de Berzelius diluída. O microscópio eletrônico de varredura com sistema de análise química por dispersão de energia acoplado foi utilizado para a análises dos precipitados na amostra maciça e para a análise química das partículas dos carbonetos extraídos.

No estudo de materiais com presença de fases formadas por elementos químicos com seção de choque de espalhamento de raios $\mathrm{X}$ muito distintas a identificação das fases por microscopia é uma ferramenta complementar importante, uma vez que nestes casos o limite de detecção da difração de raios X é da ordem de 5\% a 10\% em volume. Além da seção de choque de espalhamento de raios $\mathrm{X}$ este limite depende da estrutura cristalina e das composições químicas das fases constituintes do material.

No caso específico do aço AISI M2 pode ocorrer um falso negativo, por difração de raios $\mathrm{X}$, para o carboneto do tipo $\mathrm{M}_{23} \mathrm{C}_{6}$ quando o material também possui carbonetos do tipo $\mathrm{M}_{6} \mathrm{C}$. Este resultado pode ser explicado pelas seguintes considerações:

1) $\mathrm{O} \mathrm{M}_{23} \mathrm{C}_{6}$ é basicamente um carboneto de cromo e possui uma secção de choque de raios $\mathrm{X}$ bem menor que o $\mathrm{M}_{6} \mathrm{C}$, que é um carboneto formado por ferro, molibdênio e tungstênio. 
2) As reflexões do $\mathrm{M}_{23} \mathrm{C}_{6}$ estão muito próximas das reflexões do $\mathrm{M}_{6} \mathrm{C}$ e dependendo do alargamento destes picos pode ocorrer uma sobreposição dos dois espectros.

$\mathrm{O}$ ataque superficial também é muito útil para revelar a morfologia dos carbonetos. O conhecimento da morfologia dos carbonetos fornece importante informação sobre os mecanismos que ativaram sua formação, principalmente no uso de técnicas de microscopia eletrônica com alto potencial de aumento. Na tese de doutoramento de Boccalini (1996) é apresentada uma revisão pormenorizada sobre a identificação de carbonetos a partir de suas morfologias. 


\section{Resultados e discussão}

Inicialmente neste capítulo é apresentada a caracterização das amostras no estado inicial, isto é, antes da realização de qualquer tratamento mecanotérmico com o objetivo de mostrar as diferenças na microestrutura e nos tipos de carbonetos observados. Em seguida apresenta-se os resultados das análises químicas e as micrografias dos resíduos obtidos após as dissoluções da matriz e de parte dos precipitados, que permitiram caracterizar a obtenção de um carboneto do tipo MC ainda não reportado na literatura. $\mathrm{O}$ capítulo encerra-se com os resultados dos refinamentos pelo método de Rietveld que possibilitaram determinar a estequiometria do carboneto $\mathrm{MC}$ formado após o tratamento de revenimento.

\subsection{Caracterização das amostras no estado inicial}

A microestrutura de carbonetos do material adquirido comercialmente no estado como recebido (M2COM) está apresentada na FIG. 4.1. Observa-se que a distribuição de carbonetos é bastante heterogênea na amostra, característica esperada para o material produzido por metalurgia convencional.

A análise química pontual realizada por EDS mostrou que a fase mais clara é composta principalmente por átomos de ferro, molibdênio e tungstênio. A quantificação dos elementos metálicos está próxima da composição reportada na literatura e apresentada na TAB. 2.8 para o carboneto do tipo $\mathrm{M}_{6} \mathrm{C}$.

A presença de carbonetos com composição química rica em vanádio, característica do carboneto MC, foi observada em pontos muito esparsos. A dificuldade de realizar um número estatisticamente confiável de identificações torna difícil afirmar que a presença deste tipo de carboneto seja quantitativamente significativa nesta amostra através da análise por metalografia quantitativa. 
No espectro de difração de raios $\mathrm{X}$ obtido para a amostra M2COM, apresentado na FIG 4.2, foi possível identificar as fases: ferrita/martensita através da comparação com a microficha da estrutura cúbica de corpo centrado do ferro (PDF 6-696) e o carboneto do tipo $\mathrm{M}_{6} \mathrm{C}$ por comparação com as microfichas dos carbonetos duplos de $\mathrm{Fe}_{3} \mathrm{~W}_{3} \mathrm{C}$ (PDF 78-1990) e de $\mathrm{Fe}_{3} \mathrm{Mo}_{3} \mathrm{C}$ (PDF 47-1191), apresentado melhor coincidência com as reflexões do $\mathrm{Fe}_{3} \mathrm{~W}_{3} \mathrm{C}$ (menor parâmetro de rede).

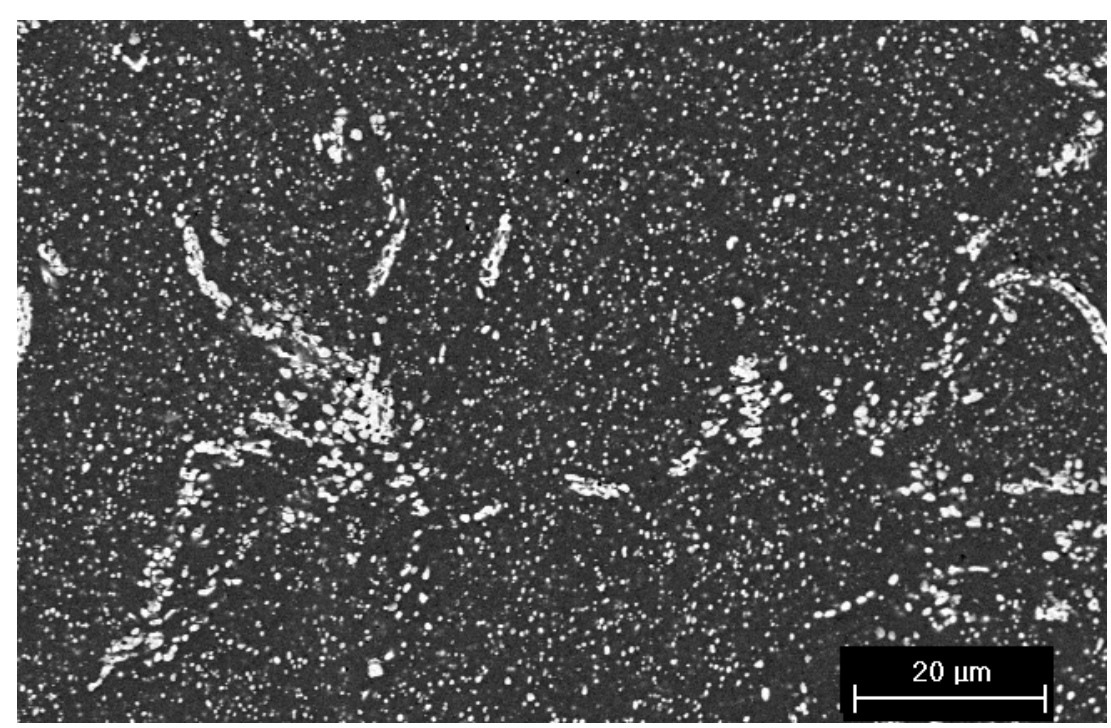

Figura 4.1: Micrografia obtida por microscopia eletrônica de varredura, utilizando elétrons retro-espalhados, mostrando a microestrutura de carbonetos da amostra $\mathrm{M} 2 \mathrm{COM}$.

O carboneto do tipo MC foi identificado pela presença de dois picos de baixa intensidade pela comparação com a microficha do carboneto de vanádio estequiométrico (PDF 73-476). Apesar da intensidade do fundo de escala ser baixa, comprometendo deste modo os picos de baixa intensidade, não foram observadas variações significativas no espectro da radiação de fundo indicando uma baixa probabilidade de existência de outras fases cristalinas. 


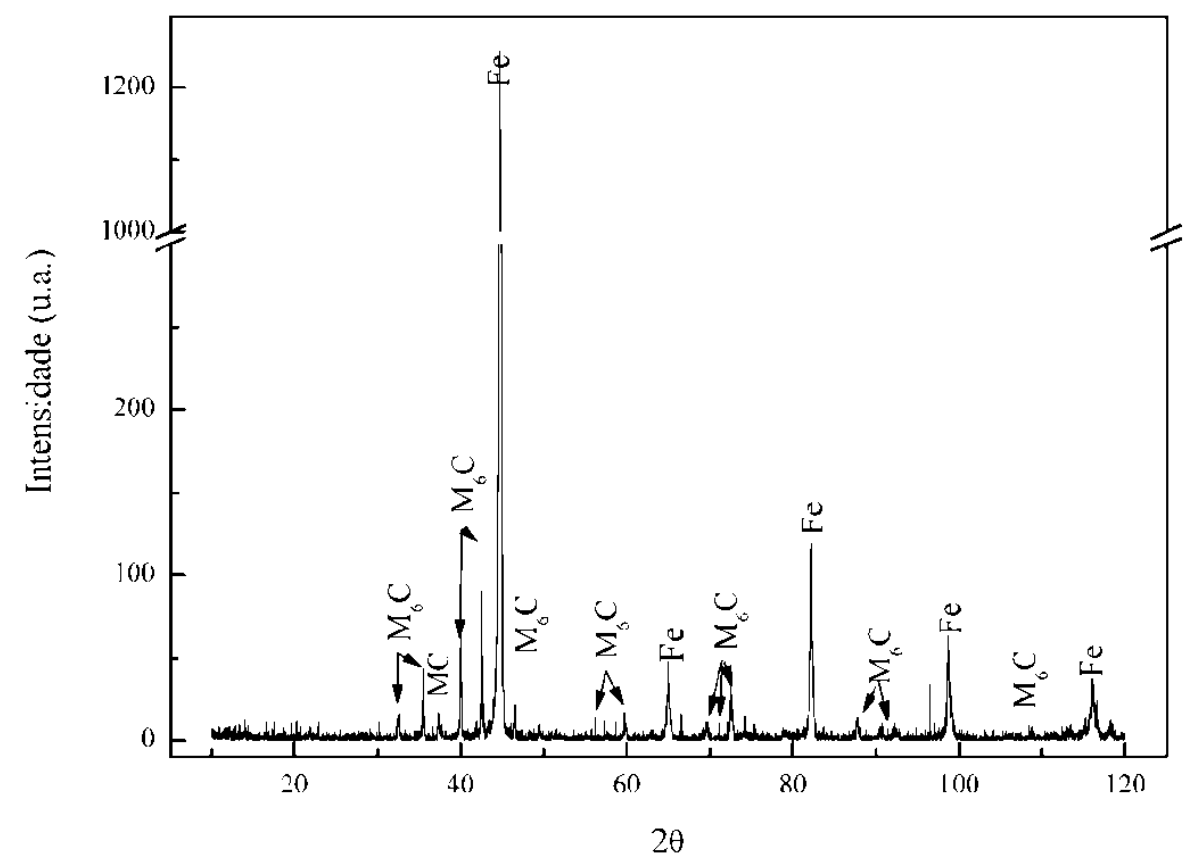

Figura 4.2: Espectro de difração de raios $\mathrm{X}$ obtido para a amostra de aço AISI M2 do material adquirido comercialmente $\left(\mathrm{E}_{\mathrm{f}}=8,0492 \mathrm{keV}\right)$.

$\mathrm{Na}$ literatura tem-se verificado a identificação do carboneto do tipo MC por comparação com a microficha referente ao carboneto $\mathrm{V}_{8} \mathrm{C}_{7}$ (PDF 35-786) (Jesus, 2004 e Wießner, 2008). Do ponto de vista de uma identificação qualitativa da fase este procedimento não acarreta nenhum erro significativo.

As características dos carbonetos $\mathrm{V}_{8} \mathrm{C}_{7}, \mathrm{VC}$ e $\mathrm{V}_{4} \mathrm{C}_{3}$ são apresentadas na $\mathrm{TAB}$. 4.1 (Rafaja et al. 1998). Apesar das diferenças cristalográficas entre o $\mathrm{V}_{8} \mathrm{C}_{7} \mathrm{e} \mathrm{VC}$ serem marcantes estas estruturas geram espectros de difração de raios $\mathrm{X}$ bastante semelhantes entre si a primeira vista, quando considera-se que o $\mathrm{V}_{8} \mathrm{C}_{7}$ é uma estrutura ordenada. $\mathrm{O}$ espectro de difração de raios $\mathrm{X}$ do $\mathrm{V}_{8} \mathrm{C}_{7}$ é composto por reflexões de alta intensidade $\mathrm{e}$ outras com intensidade relativa muito baixa devido às reflexões da super-rede. Uma vez que o parâmetro de rede do $\mathrm{V}_{8} \mathrm{C}_{7}$ é quase o dobro do $\mathrm{VC}$ resulta que as reflexões de alta intensidade do $\mathrm{V}_{8} \mathrm{C}_{7}$ estão em posição angular semelhante às reflexões do $\mathrm{VC}$. No refinamento da estrutura pelo método de Rietveld a escolha da estrutura $\mathrm{V}_{8} \mathrm{C}_{7}$ resultará em erro, dependendo dos parâmetros refinados. 
Tabela 4.1: Características cristalográficas dos carbonetos de vanádio.

\begin{tabular}{|c|c|c|c|c|c|c|c|}
\hline \multirow{2}{*}{ Carboneto } & \multirow{2}{*}{$\begin{array}{c}\text { Grupo } \\
\text { espacial }\end{array}$} & \multirow{2}{*}{$\begin{array}{l}\text { Parâmetro } \\
\text { de rede }(\AA ̊)\end{array}$} & \multicolumn{4}{|c|}{ Posições atômicas } & \multirow{2}{*}{$\begin{array}{l}\text { Fator de } \\
\text { ocupação }\end{array}$} \\
\hline & & & Sítio & $\mathbf{x}$ & $\mathbf{y}$ & $\mathbf{z}$ & \\
\hline \multirow{5}{*}{$\mathrm{V}_{8} \mathrm{C}_{7}$} & \multirow{5}{*}{$\mathrm{P}_{3} 42$} & \multirow{5}{*}{8,34027} & $\bar{C} \mathrm{C}: 4 \mathrm{a}$ & 0,125 & 0,125 & 0,125 & 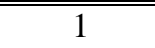 \\
\hline & & & $\mathrm{C}: 12 \mathrm{~d}$ & 0,125 & $0,6296(6)$ & $0,6204(6)$ & 1 \\
\hline & & & $\mathrm{C}: 12 \mathrm{~d}$ & 0,125 & $0,3254(8)$ & $0,9246(8)$ & 1 \\
\hline & & & $\mathrm{V}: 8 \mathrm{c}$ & $0,3705(4)$ & $0,3705(4)$ & $0,3705(4)$ & 1 \\
\hline & & & $\mathrm{V}: 24 \mathrm{e}$ & $0,1216(4)$ & $0,3811(6)$ & $0,1326(4)$ & 1 \\
\hline \multirow{2}{*}{$\mathrm{VC}$} & \multirow{2}{*}{ Fm-3m } & \multirow{2}{*}{4,172} & $\mathrm{~V}: 4 \mathrm{~b}$ & 0,5 & 0,5 & 0,5 & 1 \\
\hline & & & $\mathrm{C}: 4 \mathrm{a}$ & 0 & 0 & 0 & 1 \\
\hline \multirow{2}{*}{$\mathrm{V}_{4} \mathrm{C}_{3}$} & \multirow{2}{*}{ Fm-3m } & \multirow{2}{*}{4,15} & $\mathrm{~V}: 4 \mathrm{a}$ & 0 & 0 & 0 & 1 \\
\hline & & & $\mathrm{C}: 4 \mathrm{~b}$ & 0,5 & 0,5 & 0,5 & 0,845 \\
\hline
\end{tabular}

O espectro de difração de raios X obtido para o pó (FIG. 4.3), utilizado na confecção da amostra pelo processo de metalurgia do pó, permitiu a identificação de estruturas compatíveis com os carbonetos $\mathrm{M}_{6} \mathrm{C}\left(\mathrm{Fe}_{3} \mathrm{Mo}_{3} \mathrm{C}-\mathrm{PDF}\right.$ 47-1191 e $\mathrm{Fe}_{3} \mathrm{~W}_{3} \mathrm{C}$ - PDF 78-1990), MC (VC - PDF 73-476) e Fe (PDF 6-696). Para este material observou-se que o parâmetro de rede das reflexões identificadas para o carboneto do tipo $\mathrm{M}_{6} \mathrm{C}$ está mais próximo do $\mathrm{Fe}_{3} \mathrm{Mo}_{3} \mathrm{C}$.

A substituição de parte do tungstênio por molibdênio nos aços rápidos parte do conceito que o molibdênio, assim como o tungstênio, atua como formador de carbonetos do tipo $\mathrm{M}_{6} \mathrm{C}$. Portanto, espera-se que os carbonetos encontrados nos aços rápidos ao molibdênio apresentem a composição $\mathrm{Fe}_{3}(\mathrm{~W}, \mathrm{Mo})_{3} \mathrm{C}$. A identificação do $\mathrm{M}_{6} \mathrm{C}$ nos espectros de difração de raios $\mathrm{X}$ da amostra adquirida comercialmente e do pó de AISI/SAE M2 mostra que a substituição ocorre e que o parâmetro de rede é função do teor de cada um dos elementos. As identificações sugerem que o processo de produção pode ativar o tungstênio ou o molibdênio como elemento formador do $\mathrm{M}_{6} \mathrm{C}$. 


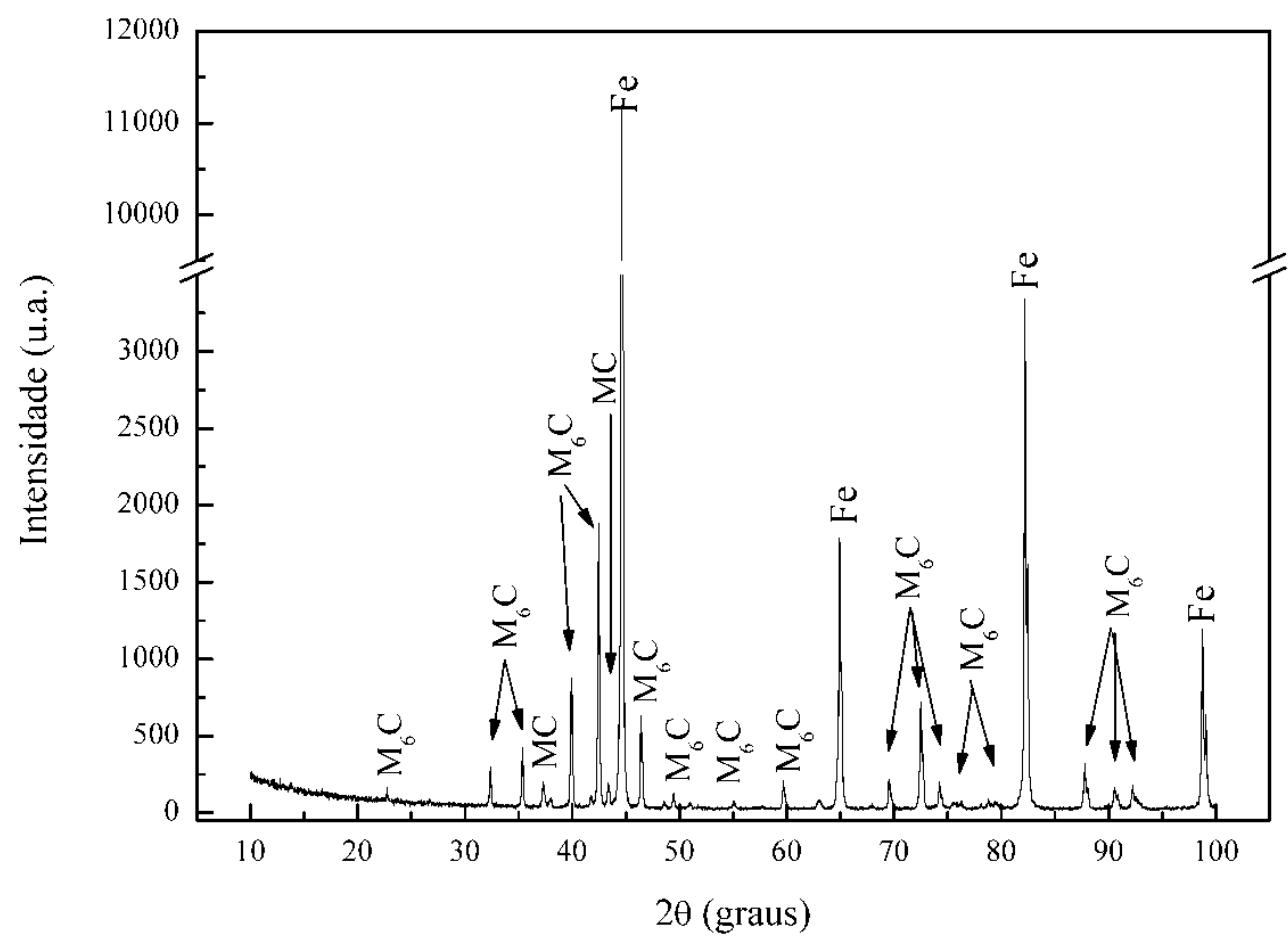

Figura 4.3: Espectro de difração de raios $X$ obtido para o pó do aço AISI M2 utilizado na confecção da amostra M2MP $\left(\mathrm{E}_{\mathrm{f}}=8,0492 \mathrm{keV}\right)$.

Na FIG. 4.4 está apresentada a microestrutura desta amostra após a sinterização. Assim como na amostra comercial a fase clara foi identificada como carboneto do tipo $\mathrm{M}_{6} \mathrm{C}$ através da análise química por EDS. A microestrutura mostra uma distribuição homogênea dos carbonetos na matriz. Não foram observadas diferenças significativas na composição química das partículas mais grosseiras em relação as mais finas possíveis de serem analisadas. Na FIG. 4.5 é apresentado o espectro de difração de raios $\mathrm{X}$ obtido para a amostra após a sinterização.

Após a prensagem e sinterização além das fases identificadas no pó observouse no difratograma (FIG. 4.5) a presença de austenita retida e a presença de uma reflexão pertencente a outra fase que não foi possível identificar. Interessante notar também o alargamento dos picos referentes a fase matriz. $\mathrm{O}$ alargamento dos perfis de difração de raios X são um forte indicativo da presença de domínios coerentes de difração pequenos, presença de micro-tensões e alta densidade de discordâncias (Ji et al., 1990; Sahu et al., 2002). Este resultado é deveras interessante, pois espera-se que na sinterização haja crescimento de grão com conseqüente diminuição da densidade de discordâncias e alívio das micro-tensões. $\mathrm{O}$ alargamento observado neste caso pode estar relacionado ao aumento de micro-tensões decorrentes da solubilização de elementos de liga na matriz. 


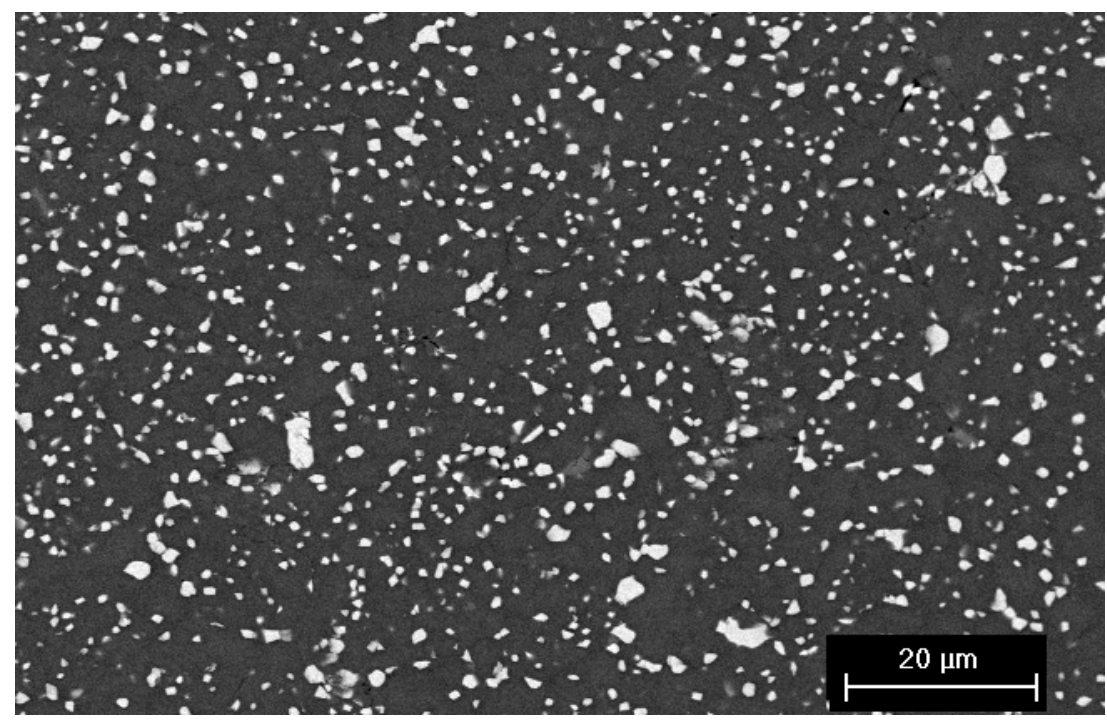

Figura 4.4: Micrografia obtida por microscopia eletrônica de varredura, utilizando elétrons retro-espalhados, mostrando a microestrutura de carbonetos da amostra obtida por metalurgia do pó após a sinterização.

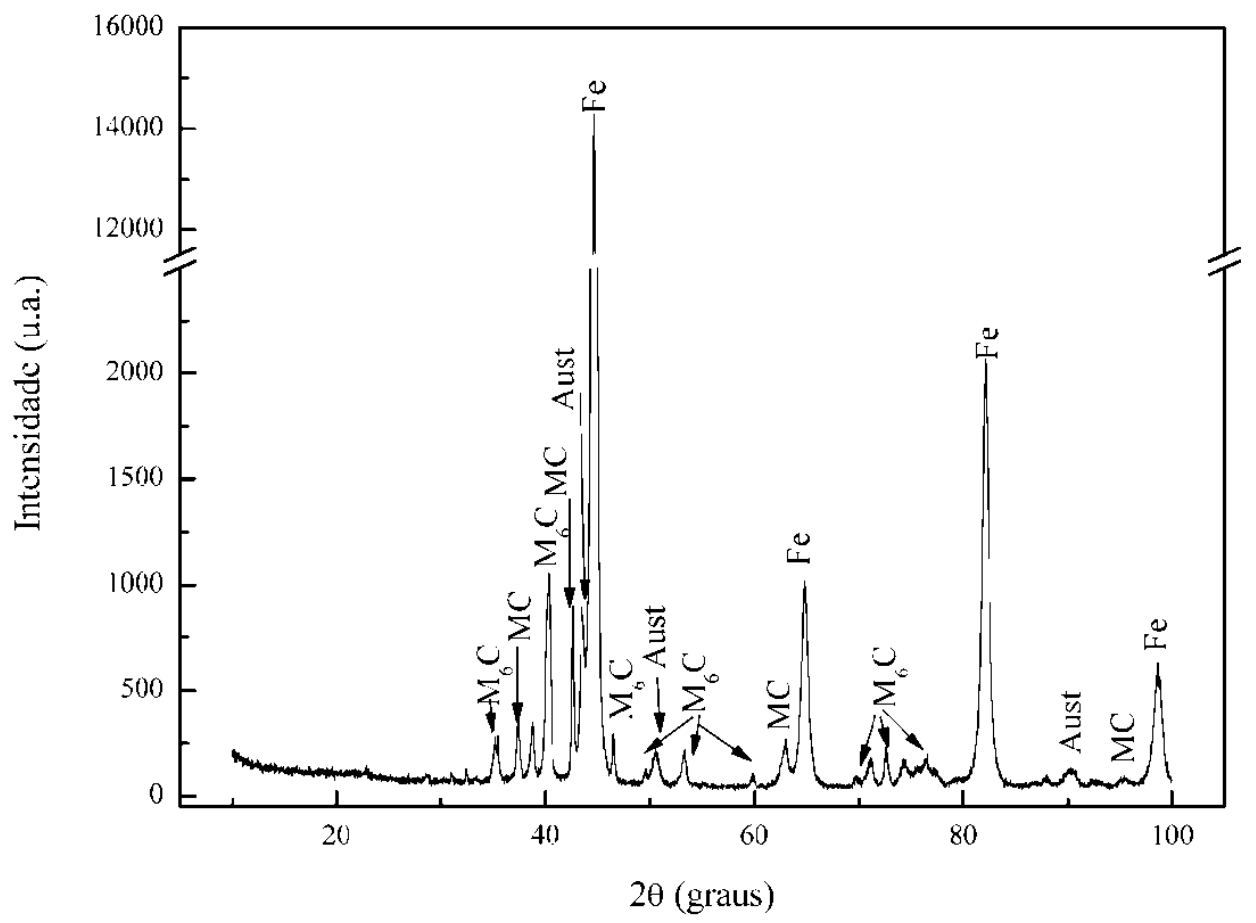

Figura 4.5: Espectro de difração de raios X obtido para a amostra M2MP, produzida por metalurgia do pó, após a sinterização $\left(\mathrm{E}_{\mathrm{f}}=8,04923 \mathrm{keV}\right)$.

No processo de caracterização do material obtido por conformação por spray observou-se que a microestrutura, conforme pode ser visto na FIG.4.6, depende da altura axial do pré-formado. As amostras utilizadas neste trabalho foram retiradas da parte central 
do pré-formado, portanto somente é apresentada a caracterização da amostra retirada nesta região. A análise por EDS pontual das fases distinguíveis na rede de carbonetos e no interior das células permitiu apenas a identificação do carboneto do tipo $\mathrm{M}_{6} \mathrm{C}$.

A identificação das fases cristalinas do espectro de difração de raios X, FIG.4.7, da amostra retirada na meia altura do pré-formado $(\mathrm{M} 2 \mathrm{CSMH})$ apresentou as fases: $\mathrm{M}_{6} \mathrm{C}$ (PDF 78-1990), MC (PDF 73-476), $\mathrm{M}_{23} \mathrm{C}_{6}$ (PDF 78-1502) e Fe (PDF 6-696) e picos referente a uma fase cristalina não coincidente com os padrões disponíveis nas bases de dados PDF, ICSD e Crystmet.

Neste estágio do trabalho a célula hidro-clorídrica para extração eletrolítica ainda não estava implementada, então com o objetivo de realizar a identificação das fases minoritárias da amostra M2CSMH procedeu-se a extração dos precipitados por dissolução química da matriz utilizando o reagente de Berzelius.

O resíduo extraído, espectro de difração de raios X apresentado na FIG. 4.8, consistiu de uma mistura de carbonetos do tipo $\mathrm{MC}, \mathrm{M}_{23} \mathrm{C}_{6}$ e mais uma fase, agora com picos de alta intensidade (representados por *), ainda não identificada por comparação com os padrões disponíveis nas bases de dados: PDF, ICSD e Crystmet.

Segundo Lee et al. (1998b) durante a solidificação dos aços da série com alto teor de molibdênio, obtidos por conformação por spray, tem sido observado o carboneto do tipo $\mathrm{M}_{2} \mathrm{C}$, onde $\mathrm{M}$ representa 23,4 \%at. de vanádio, 26,8 \%at. de molibdênio, 17,3\% at. de tungstênio, $11,5 \%$ at. de cromo, 4,7 \%at. de cobalto e 16,3\% at. de ferro, no préformado. Pelo difratograma apresentado pelos autores foi possível verificar que o carboneto foi identificado por comparação com o espectro da estrutura hexagonal do $\mathrm{Mo}_{2} \mathrm{C}$. Considerando que os autores utilizaram na produção do material estudado uma planta Osprey semelhante à disponível no IPEN, os resultados despertaram interesse especial. O espectro de difração de raios $\mathrm{X}$ do pó recolhido no ciclone da planta utilizada pelos autores apresentou boa cristalinidade possibilitando a identificação das fases: $\mathrm{Fe}-\gamma$, $\mathrm{Fe}-\alpha, \mathrm{MC}$ e $\mathrm{M}_{2} \mathrm{C}$. No entanto, o pó recolhido no ciclone da planta do IPEN apresentou cristalitos muito pequenos, implicando no alargamento dos picos do ferro que impediu a identificação de outras fases presente. 


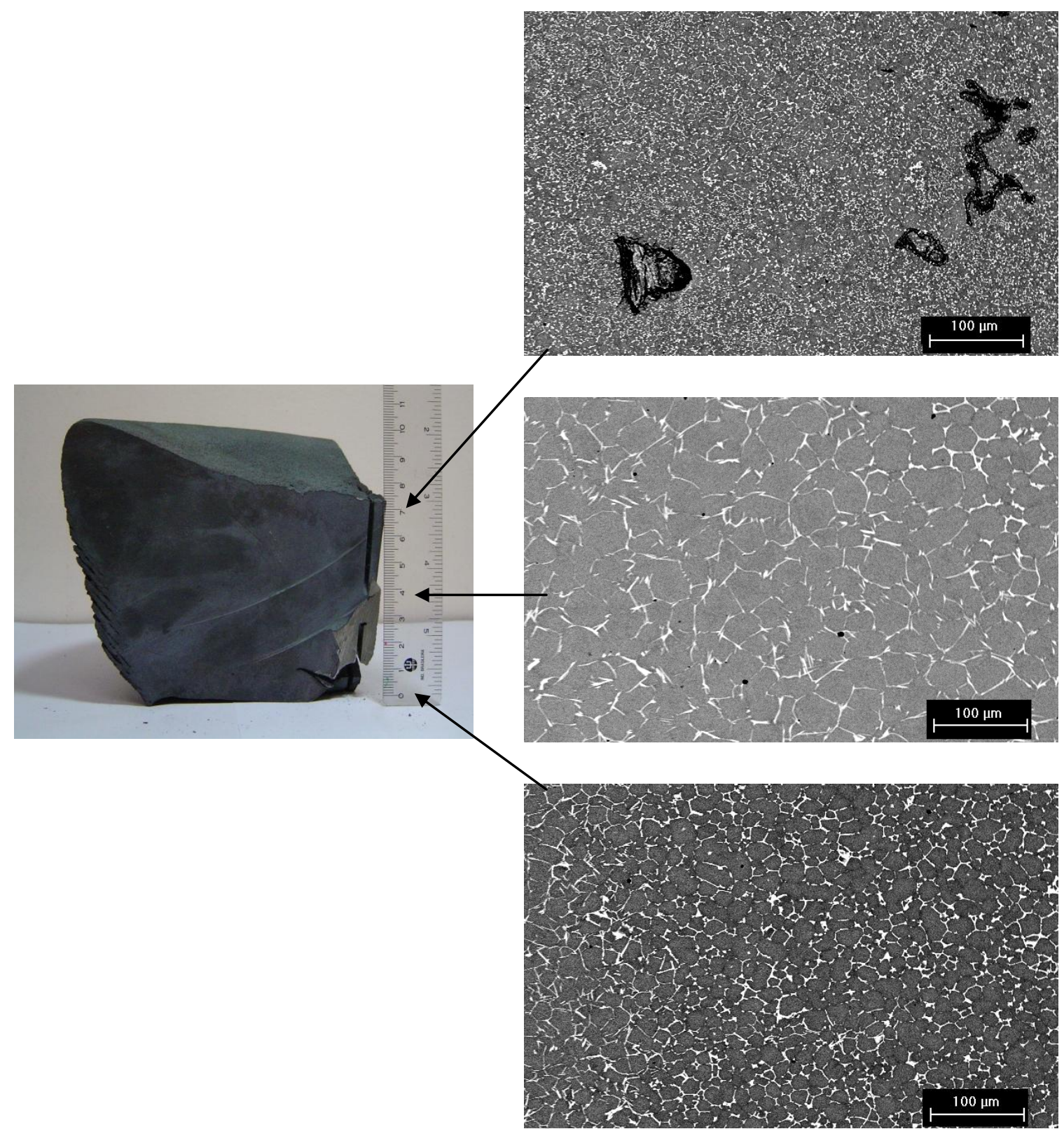

Figura 4.6: Micrografias obtidas por microscopia eletrônica de varredura com elétrons retro-espalhados mostrando as diferenças microestruturais ao longo da direção axial do pré-formado.

Inicialmente considerando a informação obtida do trabalho de Lee et al. (1998b) tentou-se identificar a fase desconhecida como um carboneto do tipo $\mathrm{M}_{2} \mathrm{C}$, com alterações nos parâmetros de rede devido a substituições atômicas. Como na composição química não foi observada a predominância de nenhum dos elementos de liga a comparação foi realizada com os carbonetos de todos os elementos. Neste processo observou-se que o espectro possuia as características dos padrões dos carbonetos $\mathrm{V}_{2} \mathrm{C}$ (PDF 73-1320), $\mathrm{Mo}_{2} \mathrm{C}$ (PDF 35-787) com estrutura hexagonal do grupo espacial P63/mmc e o $\mathrm{W}_{2} \mathrm{C}$ (PDF 35-776) também hexagonal com estrutura do grupo espacial $P$-3 $1 \mathrm{~m}$. Além 
destas estruturas os três carbonetos também apresentam estrutura ortorrômbica do grupo espacial Pbcn (PDFs 71-1258, 71-242 e 20-1315, respectivamente) cujos espectros também possuem características semelhantes aos espectros da estrutura hexagonal.

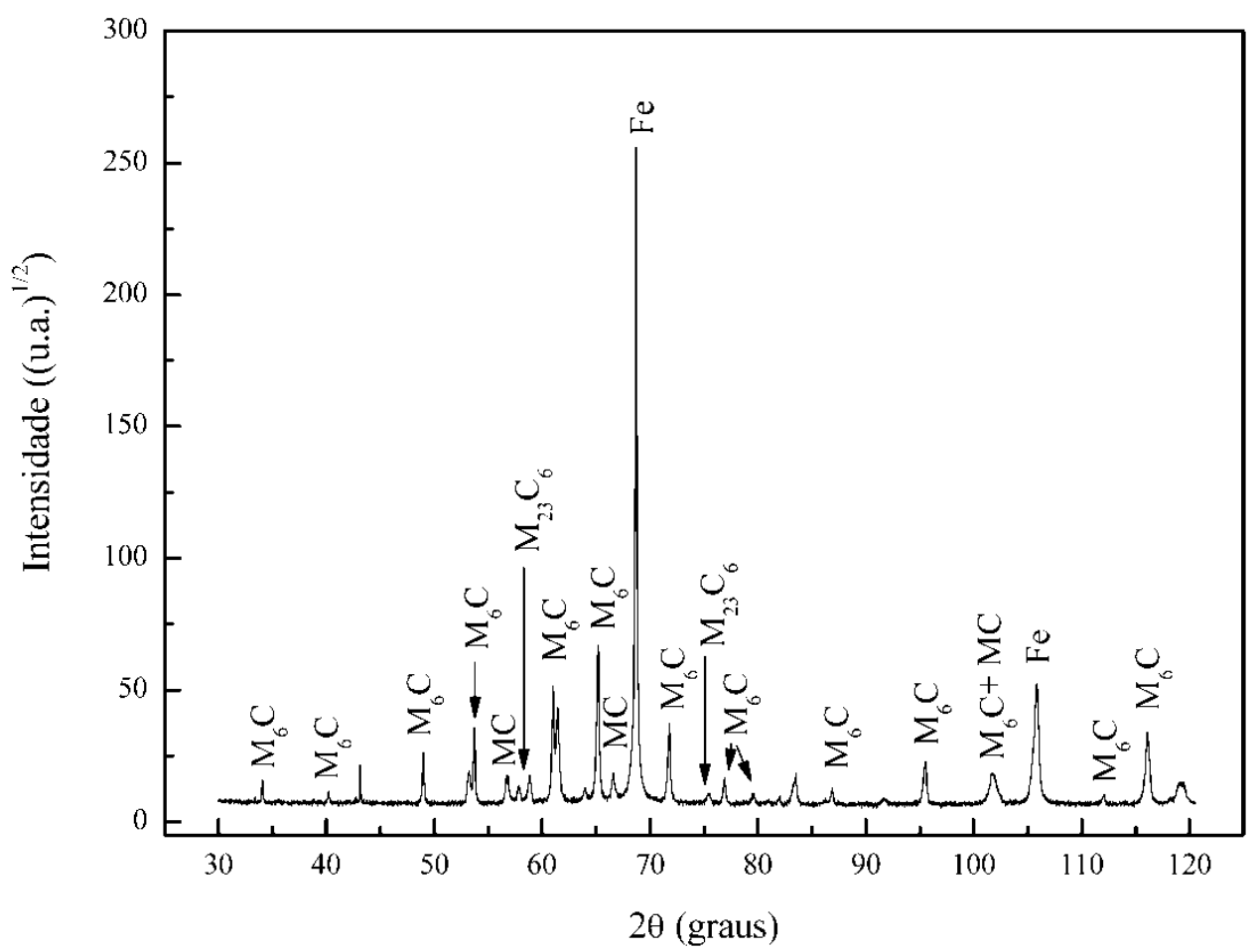

Figura 4.7: Espectro de difração de raios $\mathrm{X}$ obtido para a amostra $\mathrm{M} 2 \mathrm{CSMH}\left(\mathrm{E}_{\mathrm{f}}=\right.$ $5,41177 \mathrm{keV})$.

A partir da análise descrita anteriormente o espectro de difração de raios $\mathrm{X}$, obtido para o resíduo extraído da amostra M2CSMH, foi refinado supondo-se a estrutura hexagonal do grupo espacial $P-31 \mathrm{~m}$ isomorfa às estruturas apresentadas pelas fases $\mathrm{V}_{2} \mathrm{C}$ e $\mathrm{W}_{2} \mathrm{C}$. Porém este modelo não apresentou convergência. Adotou-se então como modelo a estrutura ortorrômbica isomorfa à estrutura apresentada para a fase $\mathrm{Mo}_{2} \mathrm{C}$ catalogada na base de dados ICSD sob número 71-242.

Na FIG. 4.9 é apresentado o gráfico que mostra a concordância entre os dados experimentais e calculados para este modelo. No campo superior os pontos referem-se aos dados experimentas e a linha sólida ao espectro calculado. A linha abaixo do eixo representa a diferença entre o valor observado e o valor calculado. Acredita-se que estas diferenças são devidas à forte orientação preferencial presente na amostra. 


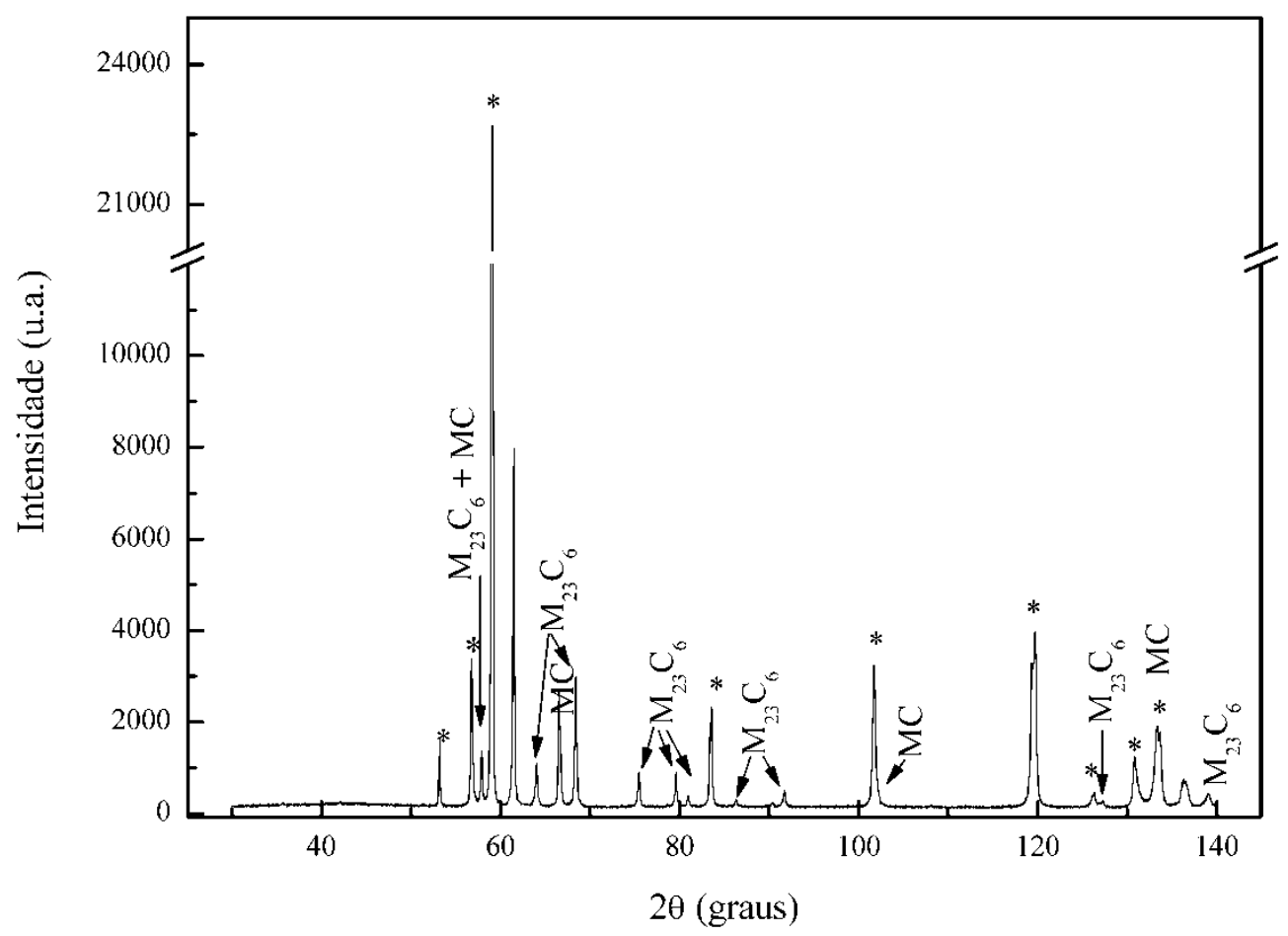

Figura 4.8: Espectro de difração de raios $\mathrm{X}$ obtido para o resíduo da extração de precipitados da amostra M2CSMH $\left(\mathrm{E}_{\mathrm{f}}=5,41177 \mathrm{keV}\right)$.

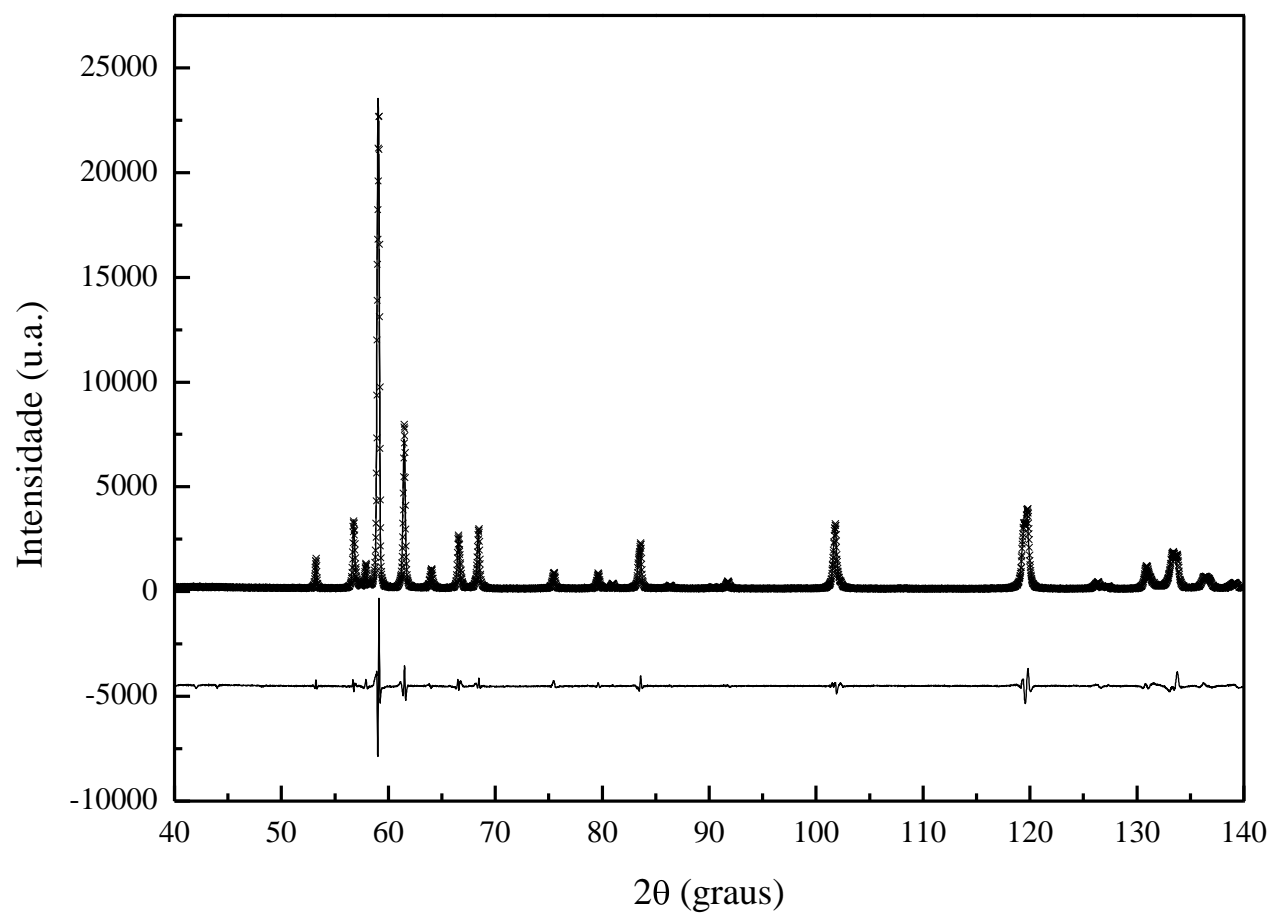

Figura 4.9: Gráfico do refinamento do espectro de difração obtido para os carbonetos extraídos da amostra M2CSMH. 
A partir do refinamento foi possível estabelecer que a estrutura cristalina da fase de maior intensidade do espectro de difração de raios $\mathrm{X}$ obtida na extração dos carbonetos da amostra M2CSMH pertence ao grupo espacial $P b c n$, com parâmetros de rede: $\mathrm{a}=0,4649636 \mathrm{~nm}, \mathrm{~b}=0,674553 \mathrm{~nm}$ and $\mathrm{c}=0,5116704 \mathrm{~nm}$.

A forte orientação preferencial indicou que o crescimento deste carboneto ocorre em hábito cristalino específico, fato que foi observado nas micrografias apresentadas na FIG. 4.10. Observou-se que parte dos carbonetos extraídos apresentou morfologia de plaquetas, hábito cristalino comum para estruturas hexagonais e ortorrômbicas (Lee et al., 1998; Ding et al., 1993).

A micrografia do material no estado maciço, apresentada na FIG. 4.11, mostrou que estas plaquetas formam a rede de carbonetos. Devido à fina espessura destas placas as análises químicas realizadas por EDS não apresentaram resultados consistentes.
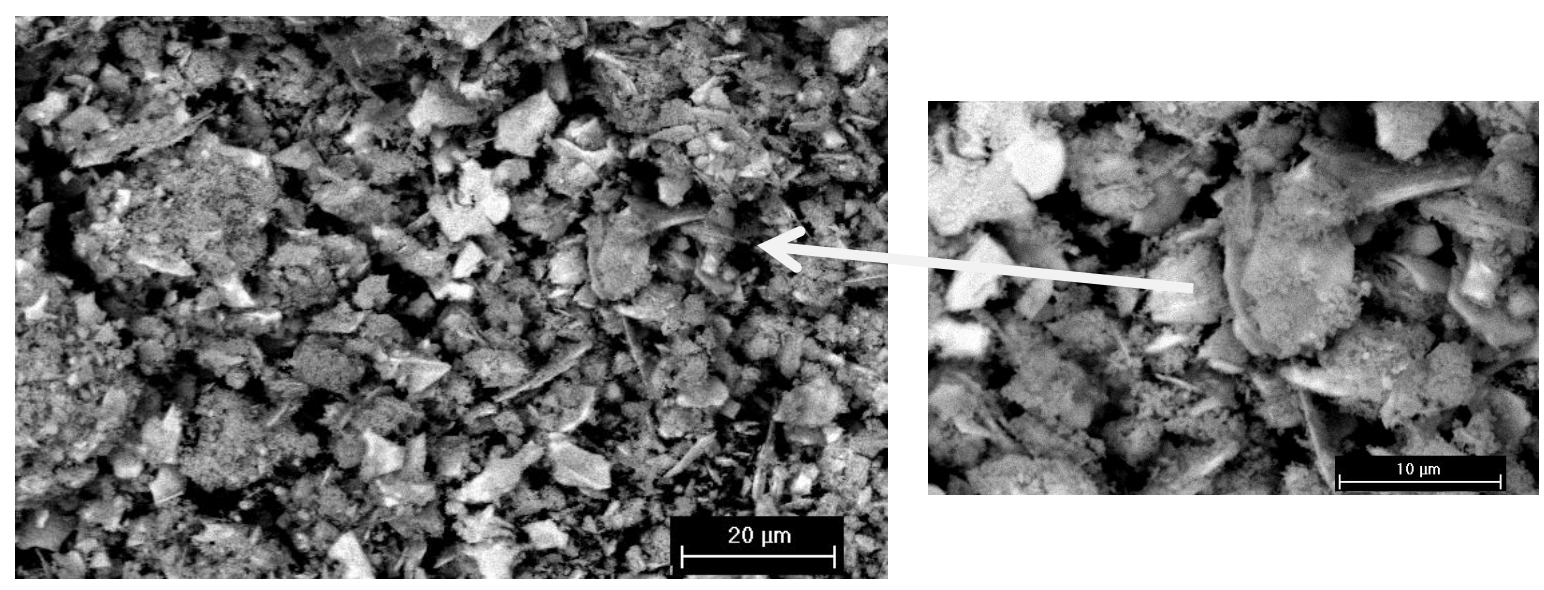

Figura 4.10: Micrografias obtidas por microscopia eletrônica de varredura, com elétrons retro-espalhados dos carbonetos extraídos da amostra M2CSMH.

Os resultados mostraram que inicialmente as amostras possuíam microestruturas e composição de carbonetos diferentes quando comparadas entre si. As amostras M2COM e M2MP apresentam a microestrutura esperada para os processos de produção utilizados. Segundo a literatura na conformação por spray obtêm-se uma distribuição mais homogênea de carbonetos, o que não foi verificado neste caso. A presença do carboneto do tipo $\mathrm{M}_{2} \mathrm{C}$ na meia altura do pré-formado indica que a temperatura de super-aquecimento do sistema foi elevada, o que pode explicar a microestrutura observada e a presença dos carbonetos identificados. 


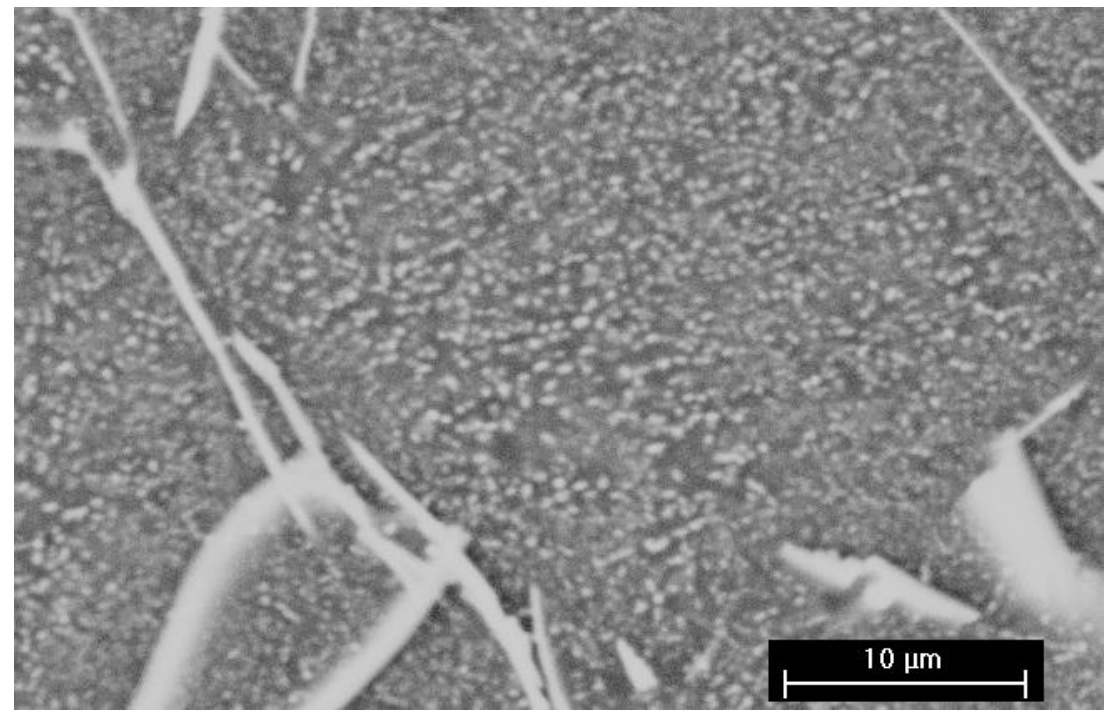

Figura 4.11: Micrografia obtida por microscopia eletrônica de varredura, com elétrons retroespalhados, dos carbonetos embebidos na matriz da amostra M2CSMH.

\subsection{Caracterização das amostras após tratamento térmico}

Os tratamentos térmicos de austenitização e revenimento aplicados aos aços ferramenta tem por objetivo promover a melhora das propriedades mecânicas através do refino da microestrutura devido ao alívio de microtensões internas, a solubilização de parte dos carbonetos primários e principalmente à precipitação de carbonetos secundários que promovem o endurecimento da matriz.

Após os tratamentos de austenitização e revenimento as amostras utilizadas neste estudo foram preparadas metalograficamente e as diversas soluções de ataque descritas no item 3.7 foram testadas para a revelação da microestrutura. $O$ ataque superficial ocorre por reação química da solução com as fases presentes na superfície da amostra e este ataque é dependente da composição química das fases e da estrutura cristalina, já que é esta que determina os tipos de ligações químicas envolvidas. Infelizmente nenhuma das soluções testadas forneceu uma imagem microscópica clara da microestrutura destes materiais.

Conforme já mencionado, o melhor resultado foi obtido com o ataque com solução de Berzelius diluída e está apresentado nas micrografias, figuras de 4.12 a 4.15, obtidas por microscopia óptica. Nas figuras estão incluídas as micrografias obtidas para as amostras após o ataque com solução de Nital a 3\% que é um ataque clássico utilizado para os mais diversos materiais ferrosos. 


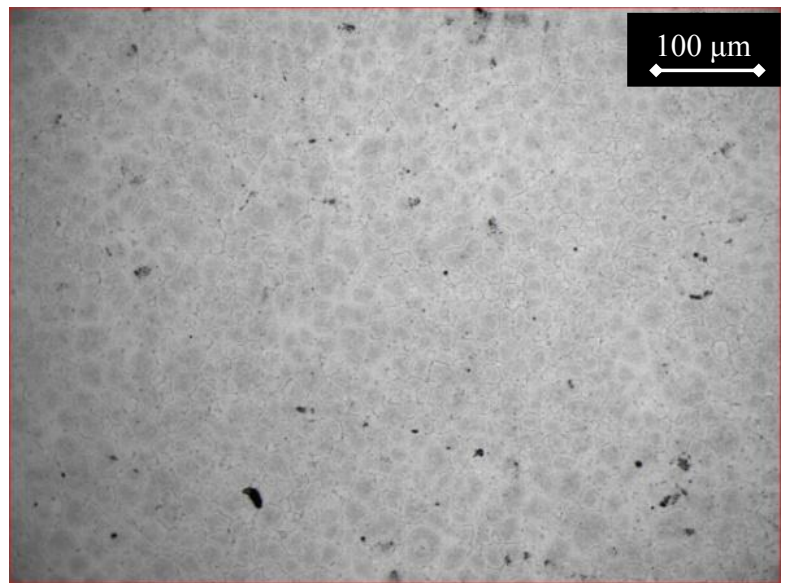

(a)

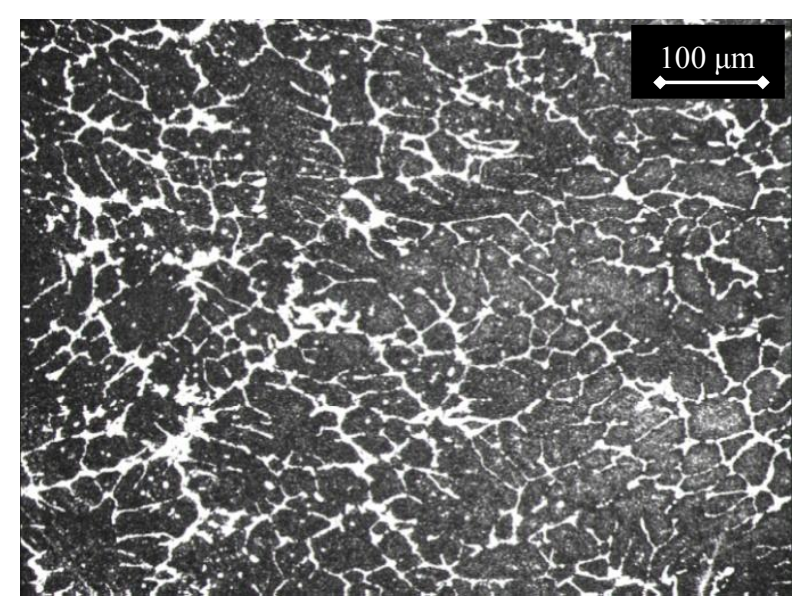

(b)

Figura 4.12: Micrografia ótica da amostra M2COMTT após ataque: (a) solução de Nital a 3\% para revelação do contorno de grão; (b) solução de Berzelius.

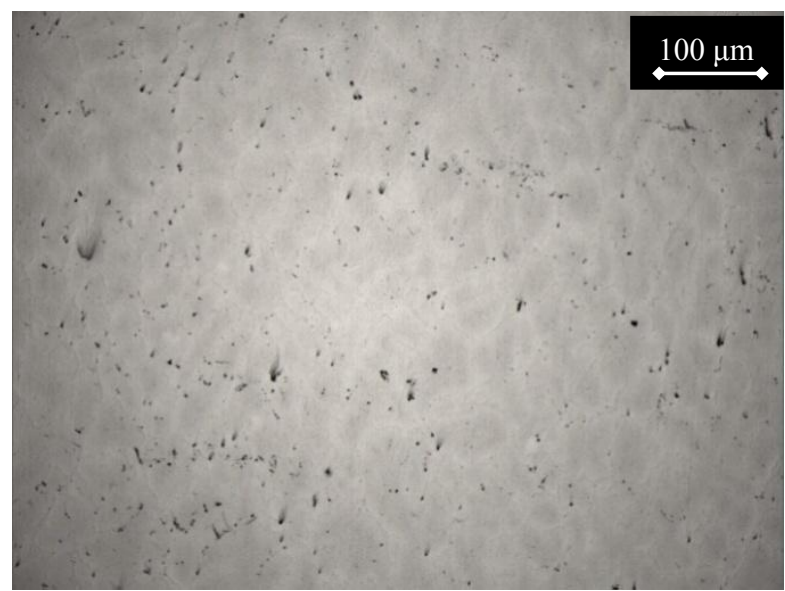

(a)

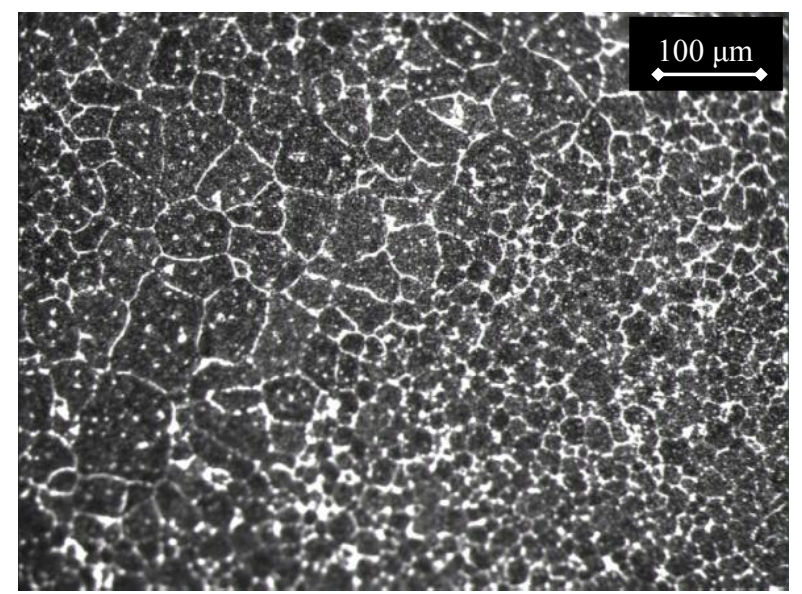

(b)

Figura 4.13: Micrografia ótica da amostra M2MPTT após ataque: (a) solução de Nital a 3\% para revelação do contorno de grão; (b) solução de Berzelius.

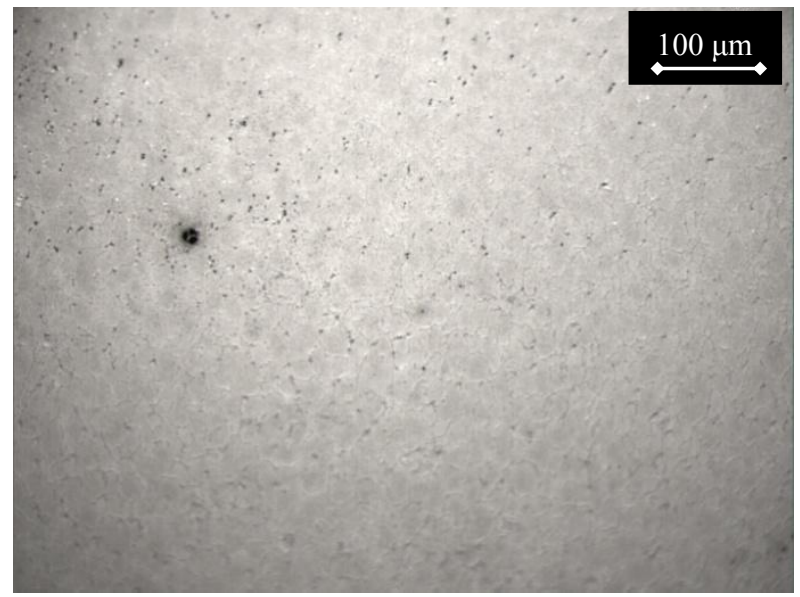

(a)

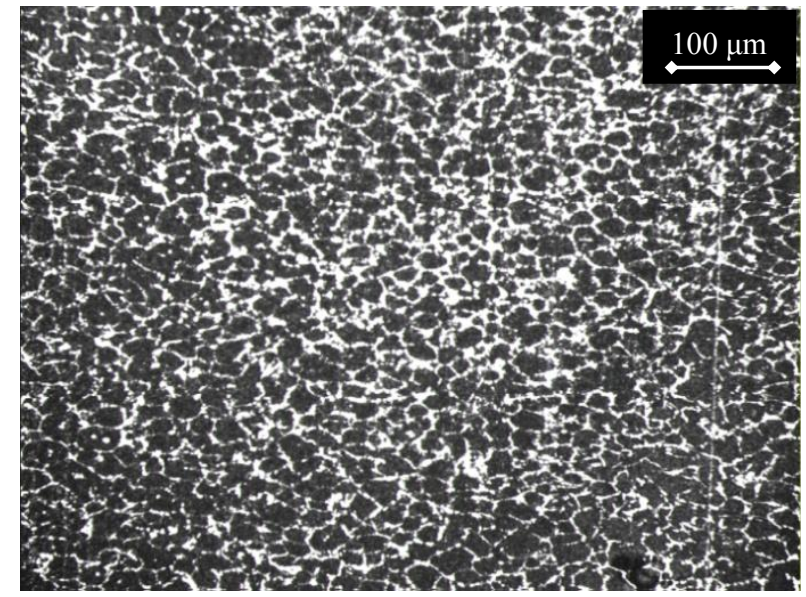

(b)

Figura 4.14: Micrografia ótica da amostra M2CSL50TT após ataque: (a) solução de Nital a 3\% para revelação do contorno de grão; (b) solução de Berzelius. 


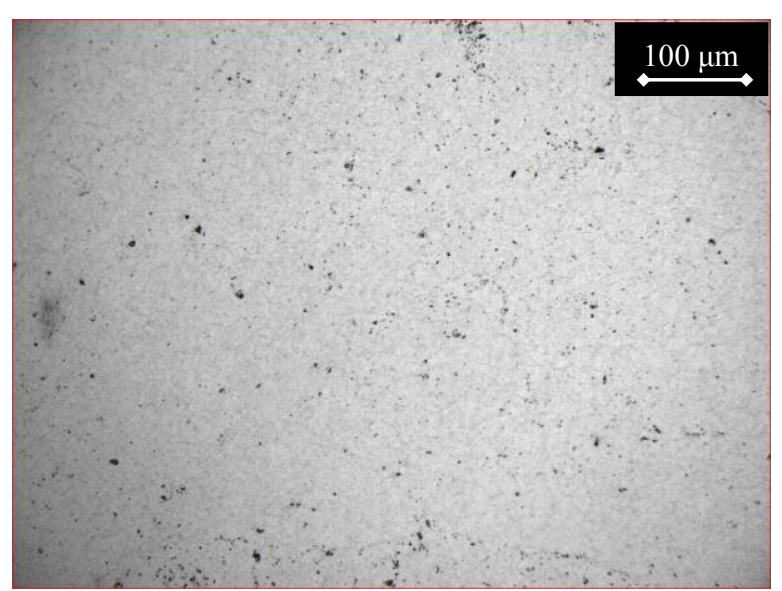

(a)

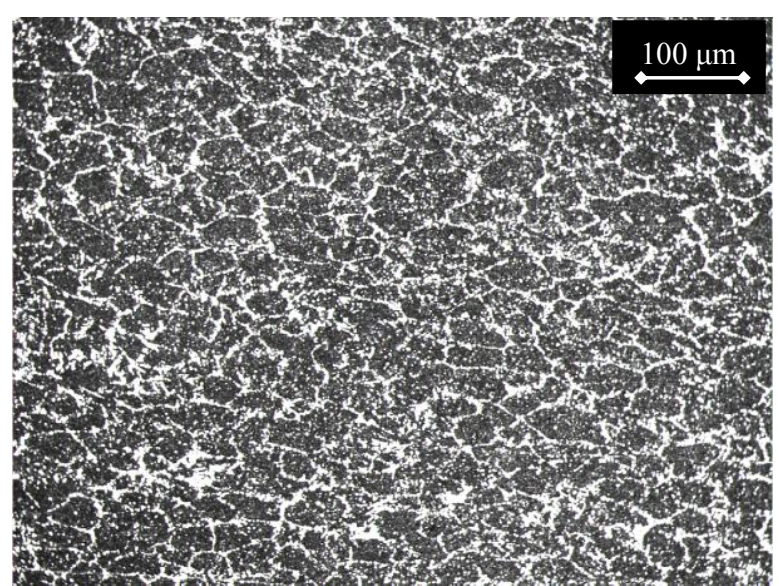

(b)

Figura 4.15: Micrografia ótica da amostra M2CSL70TT após ataque: (a) solução de Nital a $3 \%$ para revelação do contorno de grão; (b) solução de Berzelius.

As micrografias obtidas por microscopia óptica mostraram microestruturas distintas para cada amostra. Aumentos maiores, por microscopia óptica, não forneceram maiores informações. Portanto, foram obtidas micrografias por microscopia eletrônica de varredura, que são apresentadas nas figuras de 4.16 a 4.19 .

A microestrutura do material produzido por metalurgia convencional (M2COMTT) (FIG. 4.12 e 4.16) apresentou heterogeneidade de tamanho de células da rede de carbonetos, assim como na espessura dos contornos da rede. A observação por microscopia eletrônica de varredura mostra que os contornos mais espessos possuem uma morfologia própria. A micrografia obtida por elétrons retro-espalhados mostra que os precipitados dos contornos da rede de carbonetos podem apresentar uma estrutura sólida ou uma estrutura de agregados. Tanto os precipitados sólidos com os formados por agregados de pequenos precipitados apresentam composição química semelhante como pode ser visto na micrografia obtida por elétrons retroespalhados. A região mais escura entre as duas placas sólidas de precipitados foi identificada como uma região rica em vanádio através da análise química por EDS, conforme pode ser visto no gráfico apresentado na FIG. 4.20. 


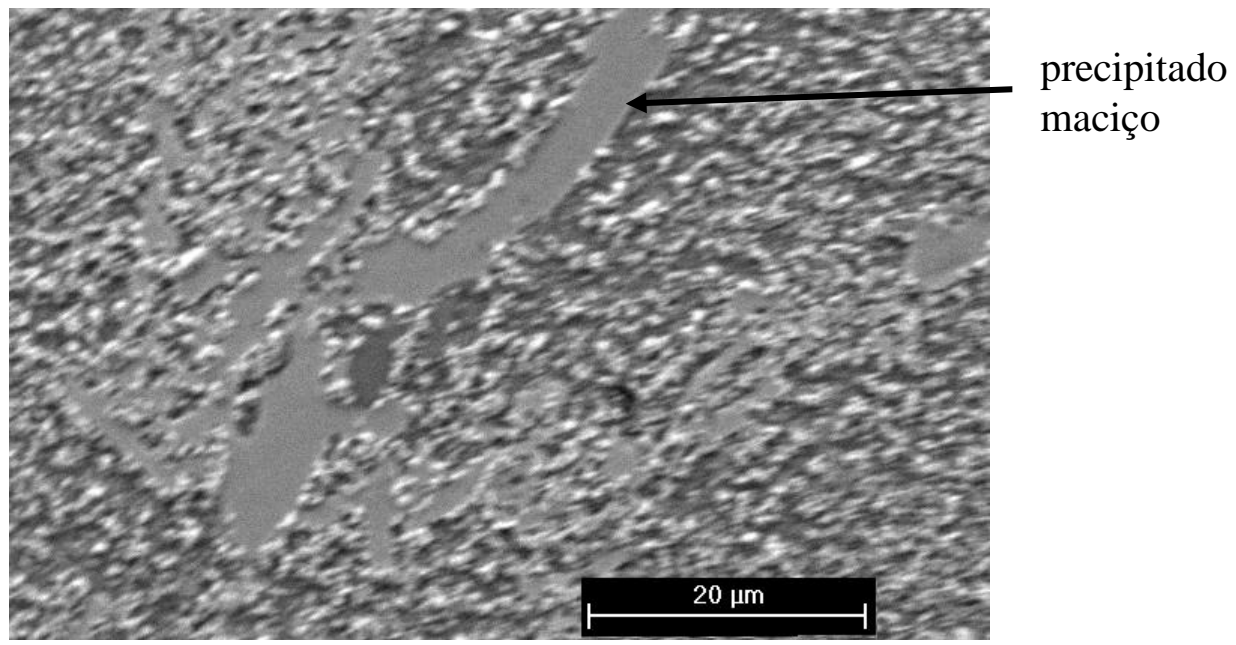

(a)

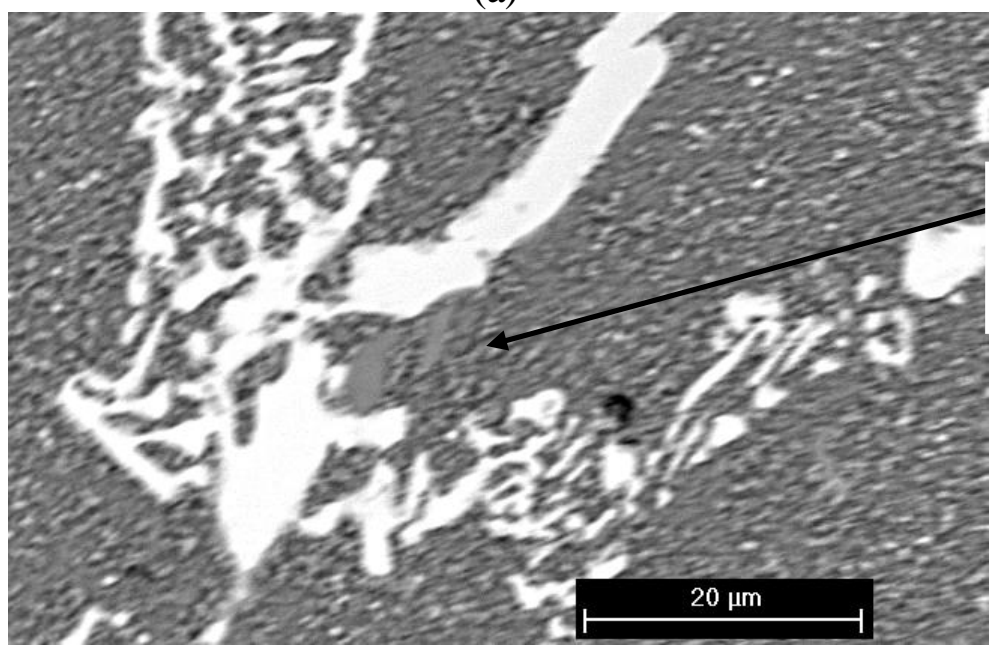

região rica em vanádio

(b)

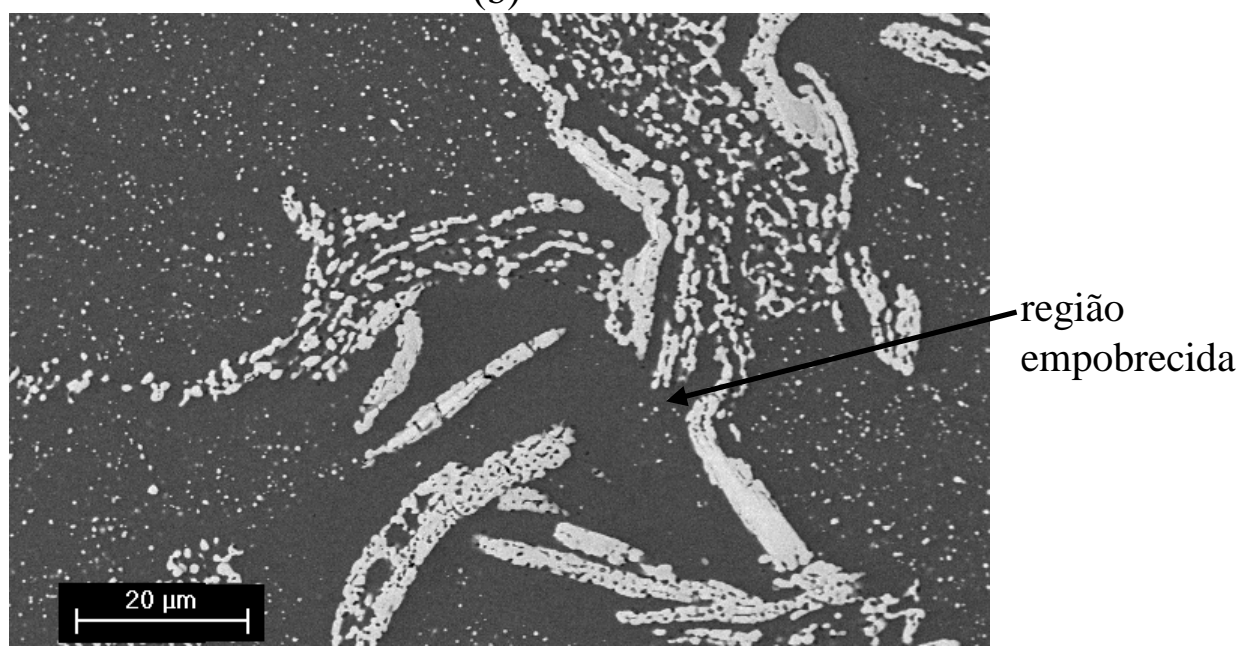

(c)

Figura 4.16: Micrografia da amostra M2COMTT obtida por microscopia eletrônica de varredura, com elétrons secundários (a), retro-espalhados após ataque com solução de Berzelius (b) e sem ataque (c), mostrando a microestrutura no estado revenido. 


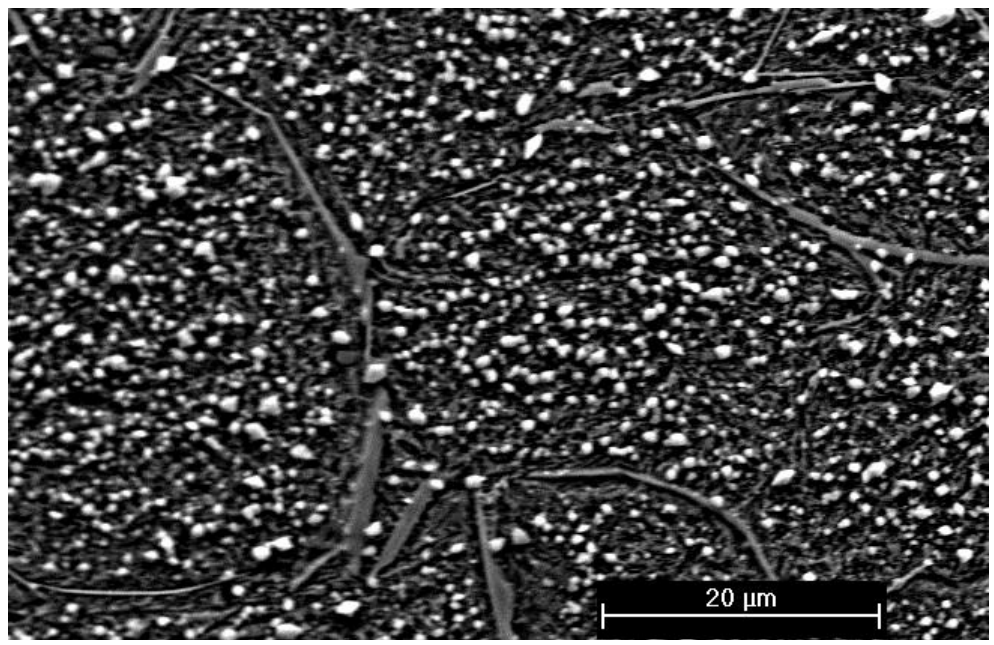

(a)

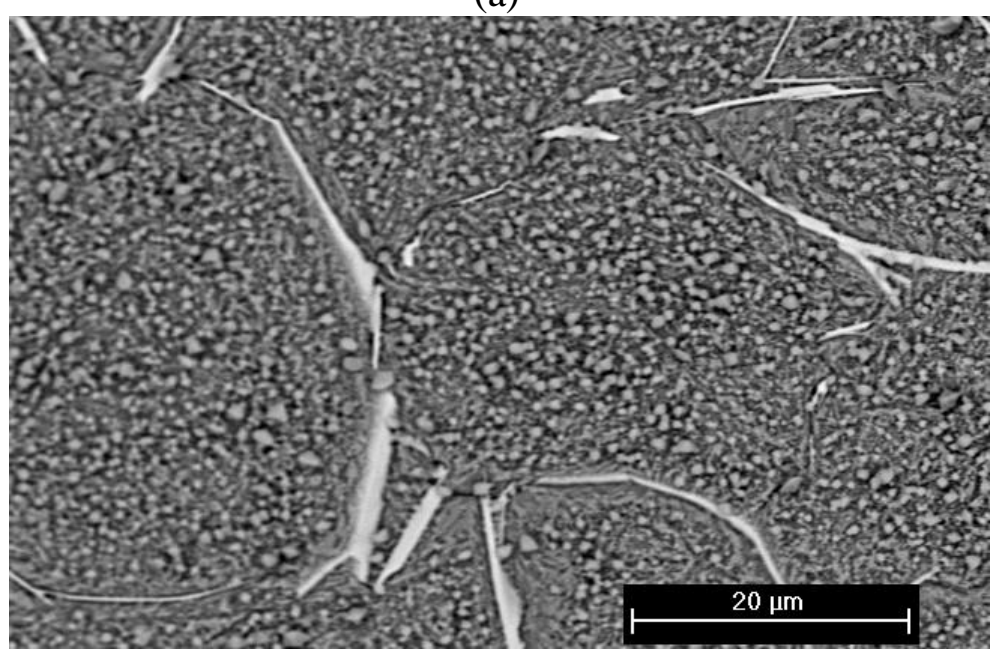

(b)

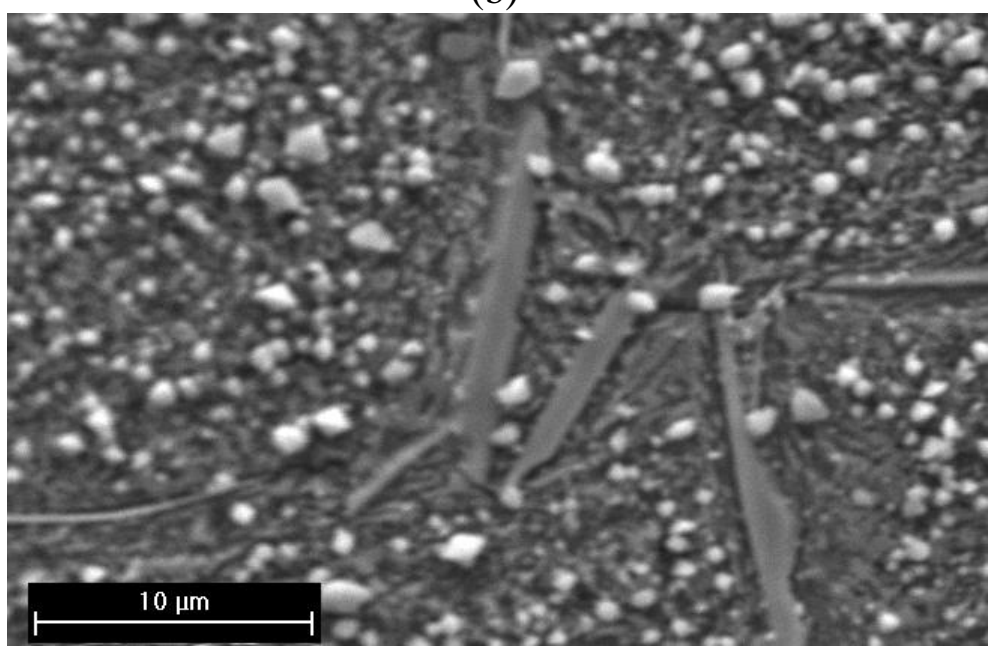

(c)

Figura 4.17: Micrografia da amostra M2MPTT obtida por microscopia eletrônica de varredura, com elétrons secundários (a), retro-espalhados após ataque com solução de Berzelius (b) e detalhe com elétrons secundários e ataque (c), mostrando a microestrutura no estado revenido. 


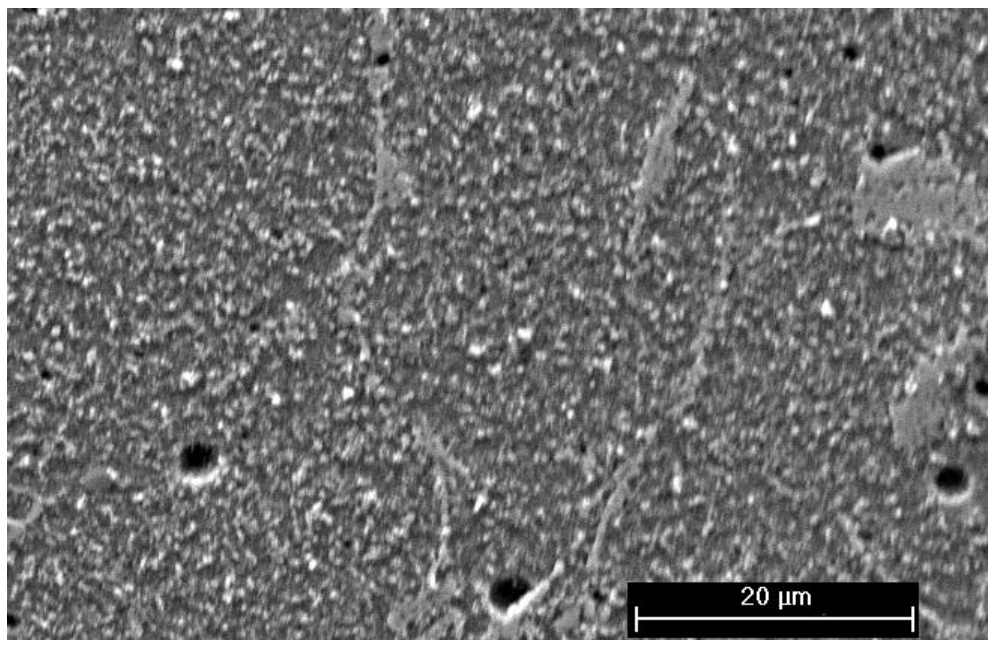

(a)

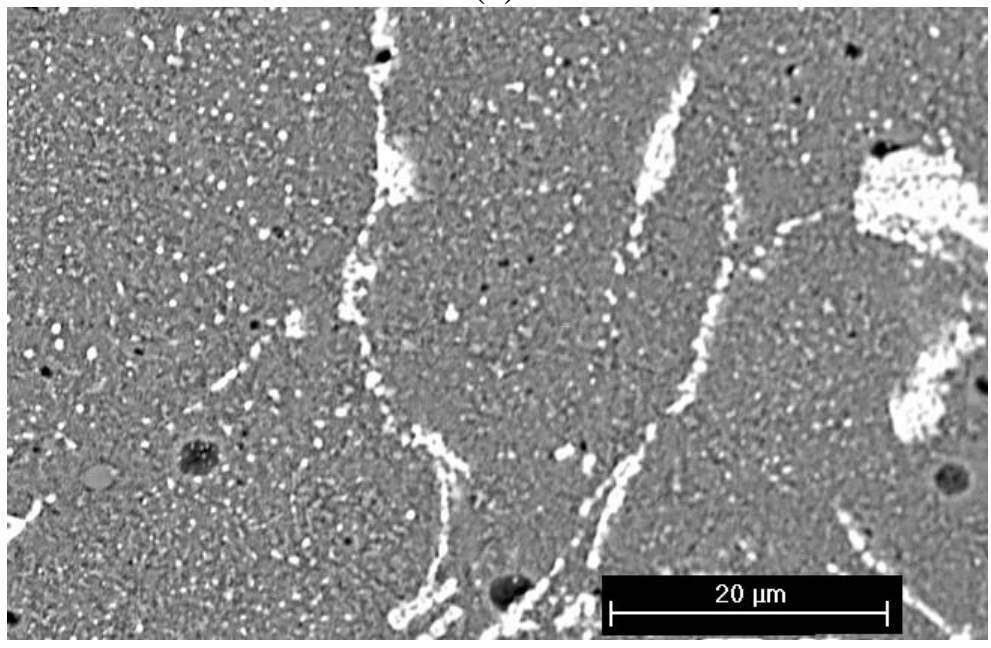

(b)

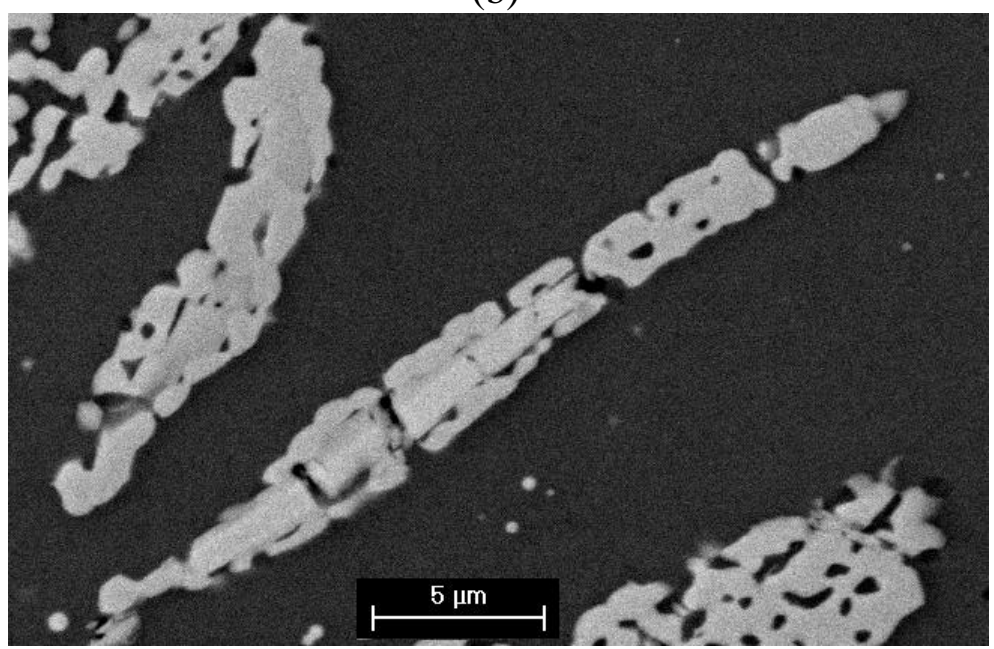

(c)

Figura 4.18: Micrografia da amostra M2CSL50TT obtida por microscopia eletrônica de varredura, com elétrons secundários (a), retro-espalhados após ataque com solução de Berzelius (b) e sem ataque (c), mostrando a microestrutura no estado revenido. 


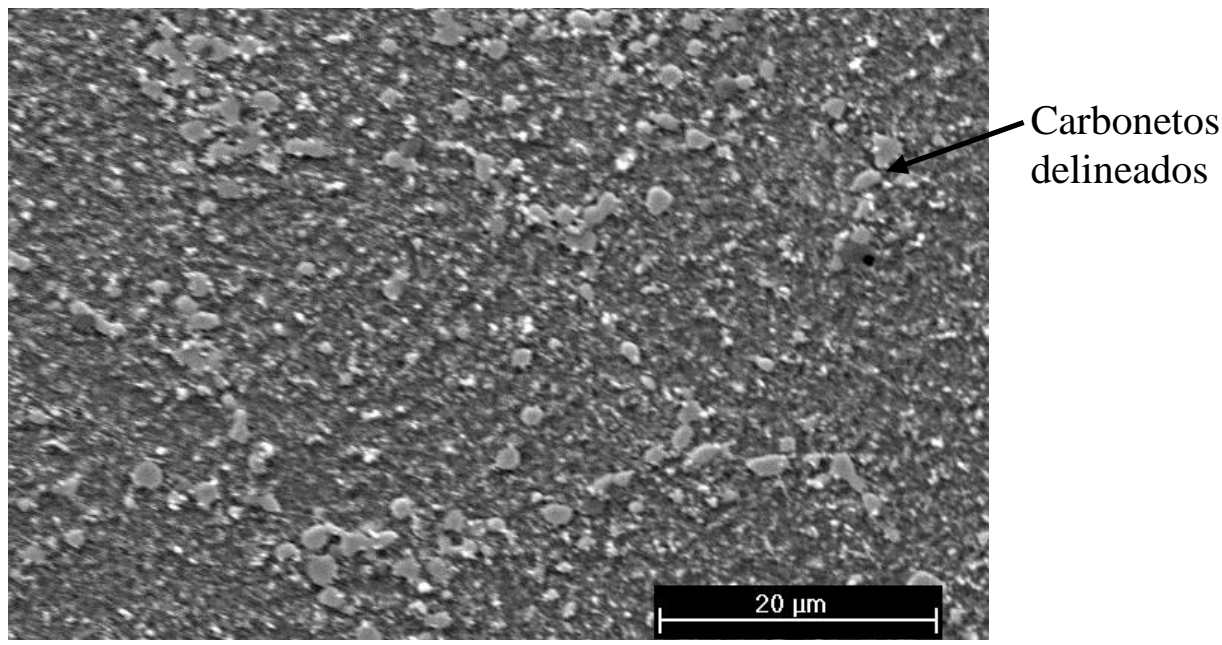

(a)

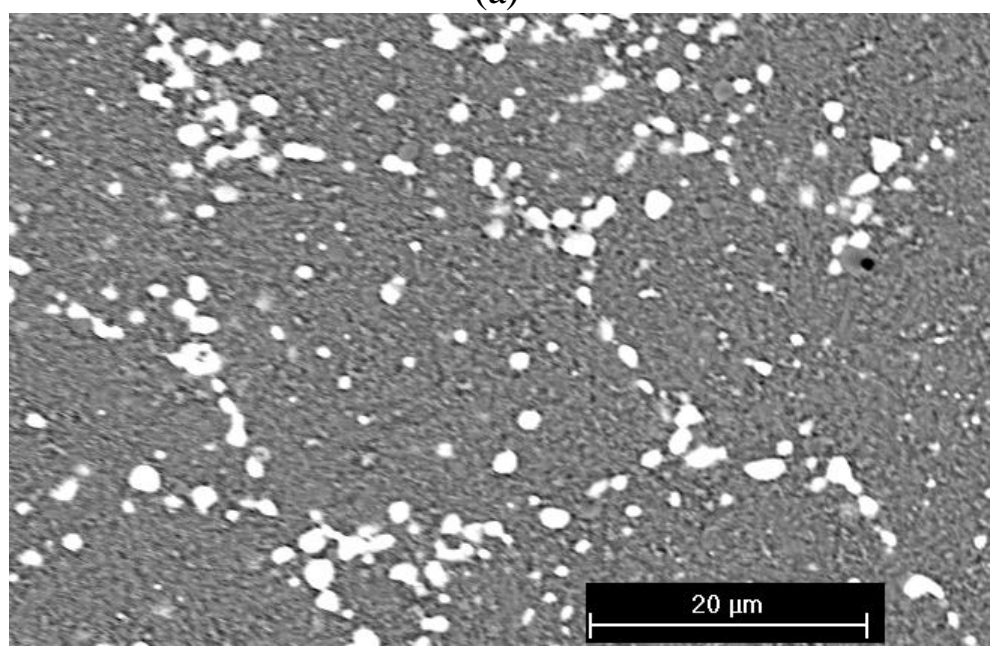

(b)

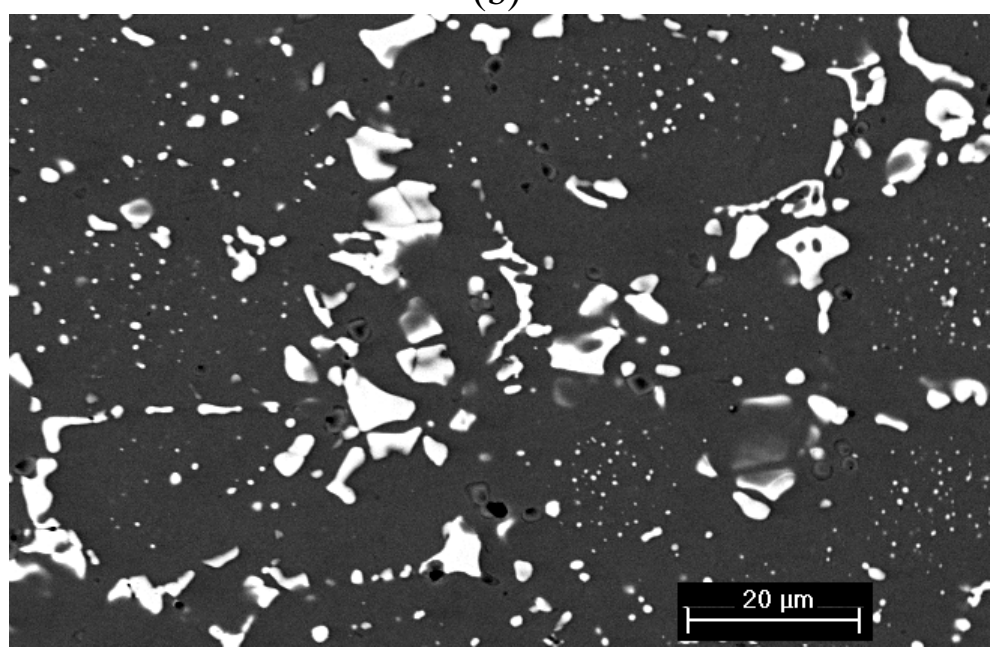

(c)

Figura 4.19: Micrografia da amostra M2CSL70TT obtida por microscopia eletrônica de varredura, com elétrons secundários (a), retro-espalhados após ataque com solução de Berzelius (b) e sem ataque (c), mostrando a microestrutura no estado revenido. 


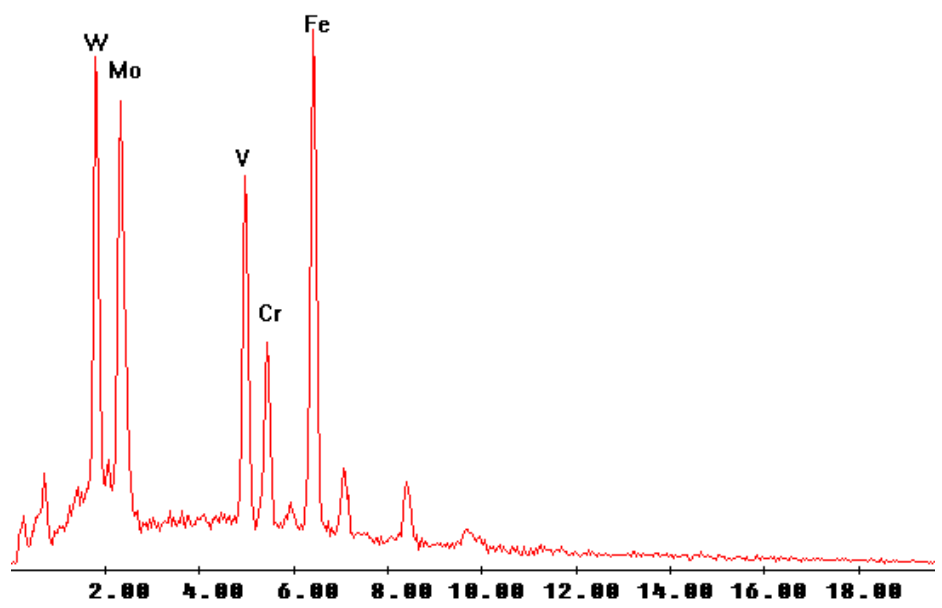

Figura 4.20: Espectro obtido na análise por fluorescência de raios $X$ por dispersão de energia para a região escura entre os precipitados claros que pode ser vista na micrografia apresentada na FIG. 4.16.

O material obtido por metalurgia do pó (M2MPTT) apresentou uma distribuição homogênea de carbonetos dentro das células de carbonetos e uma rede de carbonetos com espessura homogênea FIG. 4.16. O tamanho das células de carbonetos é influenciado pela distribuição granulométrica do pó atomizado. Este pó possui uma granulometria com distribuição gaussiana de partículas, o que permite obter o maior preenchimento possível do material, parte destes contornos foram formados pela sinterização das partículas, de maneira que o tamanho das células apresenta também uma distribuição característica. Apesar da rede de carbonetos tão bem definida, como vista neste caso, não ser comumente vista em aços obtidos por metalurgia do pó esta rede já foi observada no tratamento de partículas grosseiras tratadas em temperaturas da ordem de $1100{ }^{\circ} \mathrm{C}$ (Jurči, 1998).

As micrografias do material conformado por spray apresentadas nas figuras 4.18 e 4.19 mostraram que a laminação com redução de $50 \%$ da espessura provocou uma estiramento nos carbonetos localizados nos contorno da rede de carbonetos sem que ocorresse uma fragmentação total (FIG. 4.18(c)). A laminação para redução de $72 \%$ da espessura provocou a fragmentação total dos contornos de menor espessura (FIG. 4.19 (b)) e uma fragmentação parcial dos contornos mais espessos (FIG.4.19 (c)).

Nas micrografias de todas as amostras obtidas, após o ataque com solução de Berzelius, por elétrons secundários observou-se uma grande quantidade de precipitados delineados pelo ataque quando comparadas com as micrografias obtidas por elétrons retro-espalhados, onde o contraste é devido ao número atômico. Este delineamento permitiu verificar que há 
uma distribuição homogênea dos elementos pesados no interior da célula e com contraste ligeiramente menor que dos carbonetos dos contornos da rede, ricos em elementos pesados (Mo e W).

Na FIG. 4.21 são apresentados os espectros de difração de raios $\mathrm{X}$ para as amostras após os tratamentos de austenitização e revenimento. Foram identificadas as fases: $\mathrm{M}_{6} \mathrm{C}\left(\mathrm{Fe}_{3} \mathrm{Mo}_{3} \mathrm{C}\right.$ - PDF: 47-1191 e $\mathrm{Fe}_{3} \mathrm{~W}_{3} \mathrm{C}$ PDF 78-1990), MC (VC PDF 73-476), ferrita / martensita, em todas as amostras. Além destas fases foram observadas reflexões da fase austenítica na amostra M2MPTT.

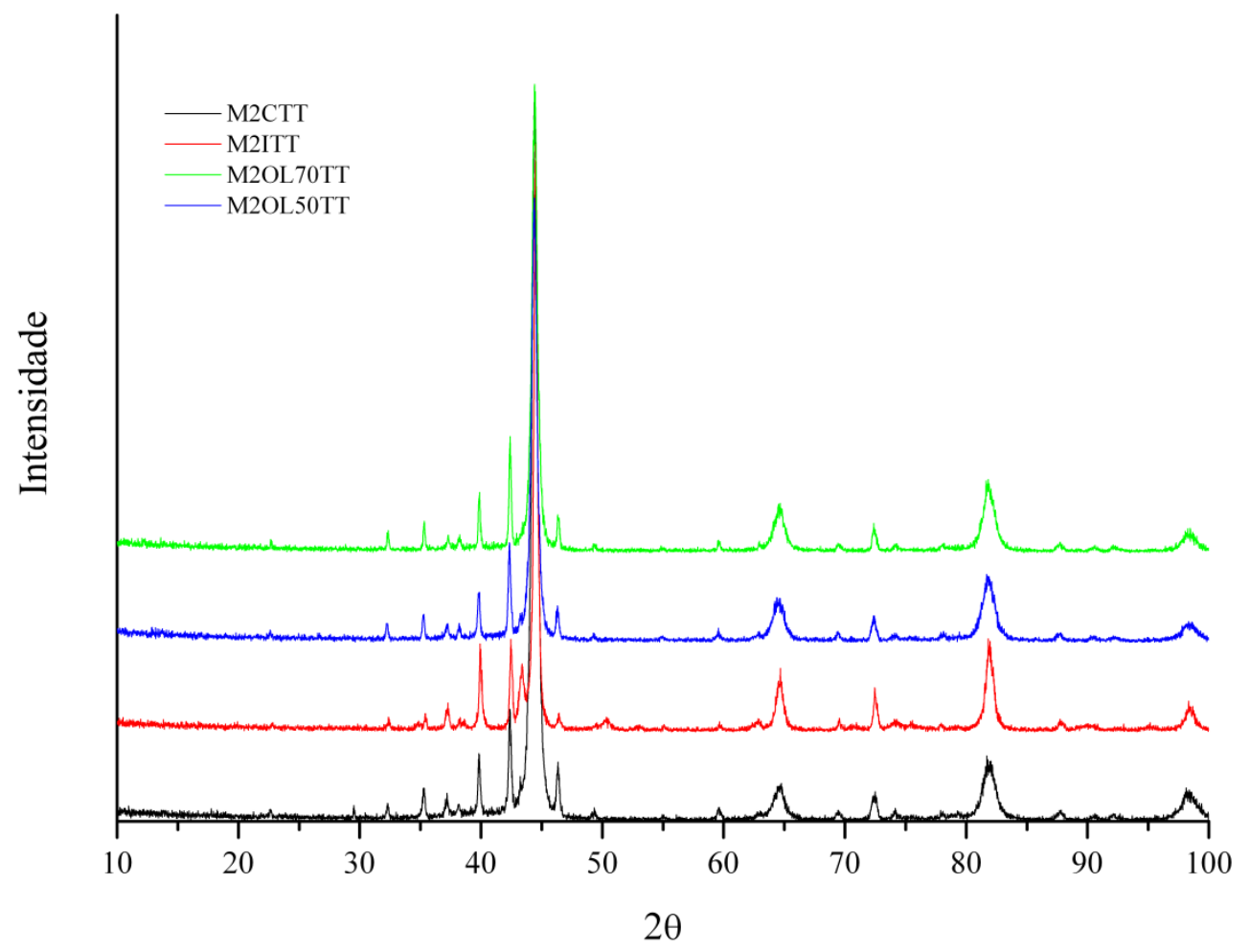

Figura 4.21: Espectro de difração de raios $\mathrm{X}$ das amostras: M2COMTT, M2MPTT, M2CSL50TT e M2CSL70TT $\left(\mathrm{E}_{\mathrm{f}}=8,04923 \mathrm{keV}\right)$.

\subsection{A extração dos precipitados}

O extenso estudo para extração dos precipitados teve como objetivo a separação de cada fase cristalina para a determinação dos parâmetros cristalográficos e subseqüentemente a quantificação pelo método de Rietveld. Porém, os resultados destes esforços foram lentos, pois a maioria dos métodos estudados mostrou uma forte dependência com a microestrutrura do material (Blickwede e Cohen, 1949). 
A determinação dos parâmetros, tais como concentração do eletrólito, densidade de corrente, da célula eletrolítica hidro-clorídrica permitiu a extração de carbonetos do tipo $\mathrm{M}_{6} \mathrm{C}$ e $\mathrm{MC}$ conforme apresentado no espectro de difração de raios $\mathrm{X}$ mostrado na FIG. 4. 22. Este espectro foi obtido em um difratômetro convencional de raios $\mathrm{X}$, utilizando radiação característica do cobre e que não possui o monocromador para eliminação da radiação fluorescente proveniente dos átomos de ferro constituinte do carboneto do tipo $\mathrm{M}_{6} \mathrm{C}$. Desta maneira, não foi possível determinar a existência ou não de fases minoritárias.

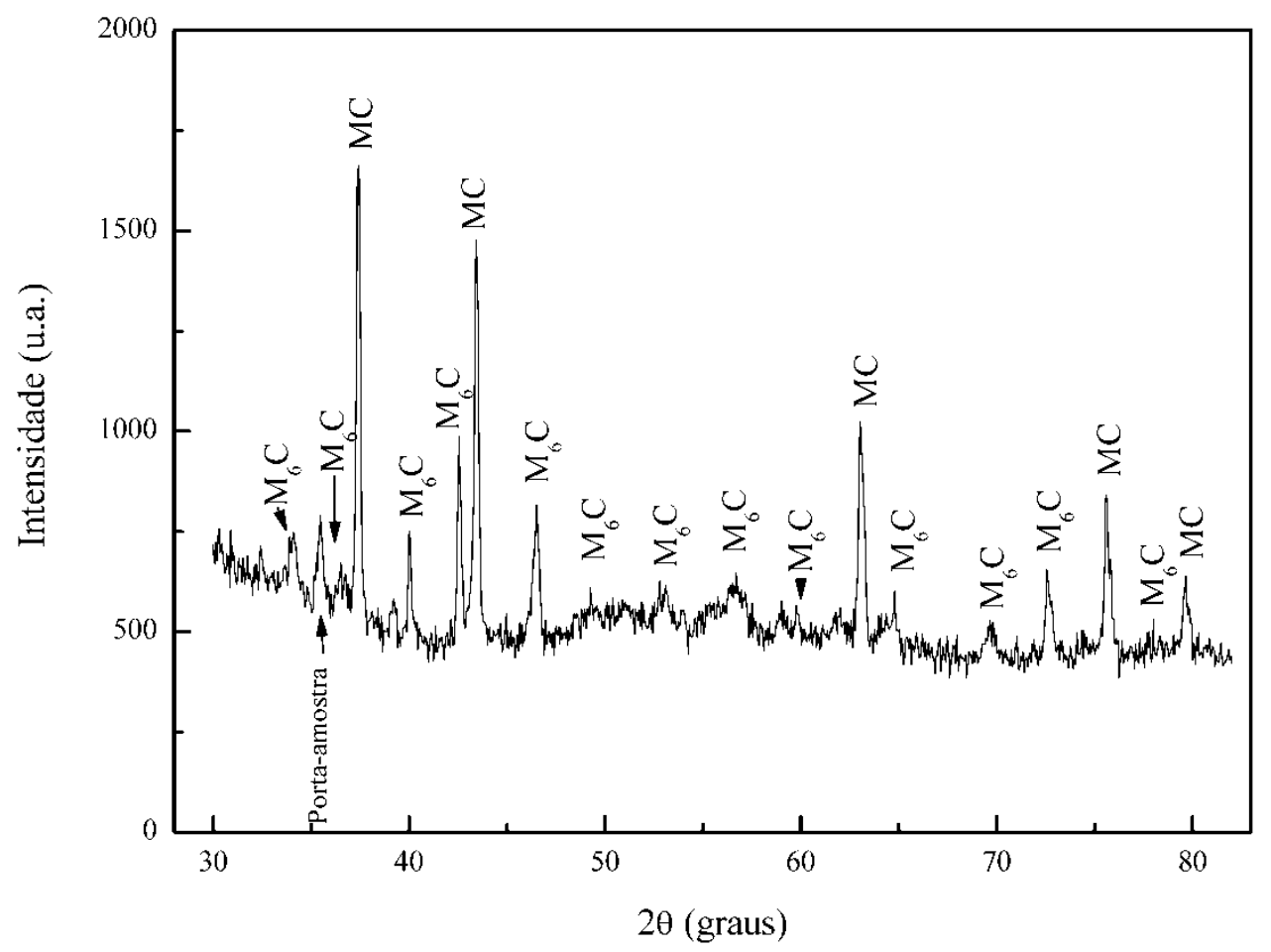

Figura 4.22: Espectro de difração de raios $X$ do resíduo obtido a partir da extração eletrolítica utilizando a célula hidro-clorídrica.

Quando da dissolução eletrolítica observou-se a presença de resíduo em forma de placa com dimensões da ordem de vários milímetros quadrados e com formas geométricas definidas, porém extremamente frágeis. Estes resíduos estão apresentados nas micrografias mostradas nas figuras de 4.23 a 4.26 . 


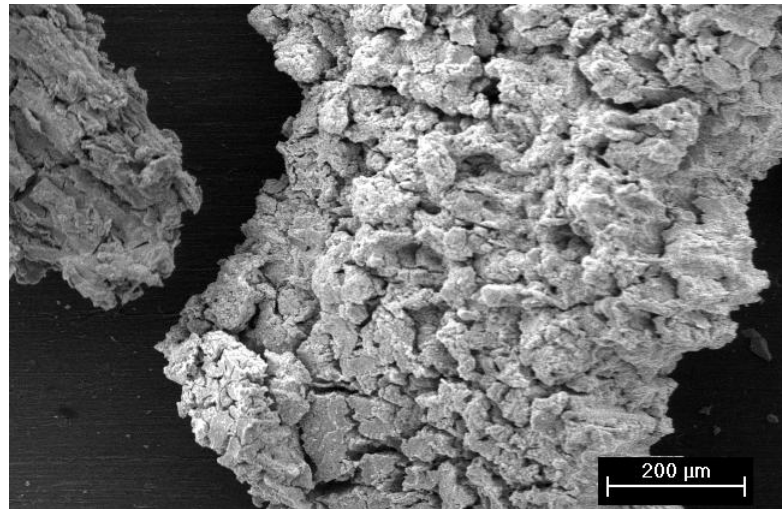

(a)

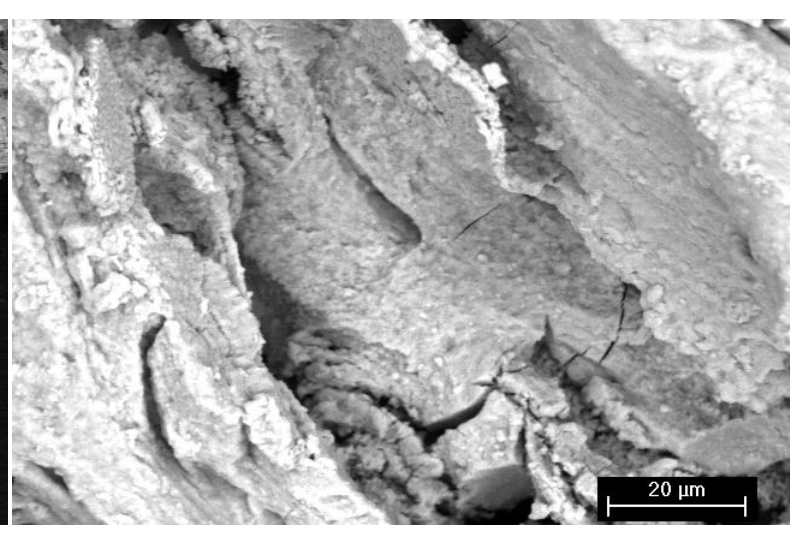

(b)

Figura 4.23: Micrografia obtida por microscopia eletrônica de varredura utilizando elétrons secundários (a) e retro-espalhados (b) dos precipitados e carbonetos extraídos por dissolução eletrolítica da amostra M2COMTT.

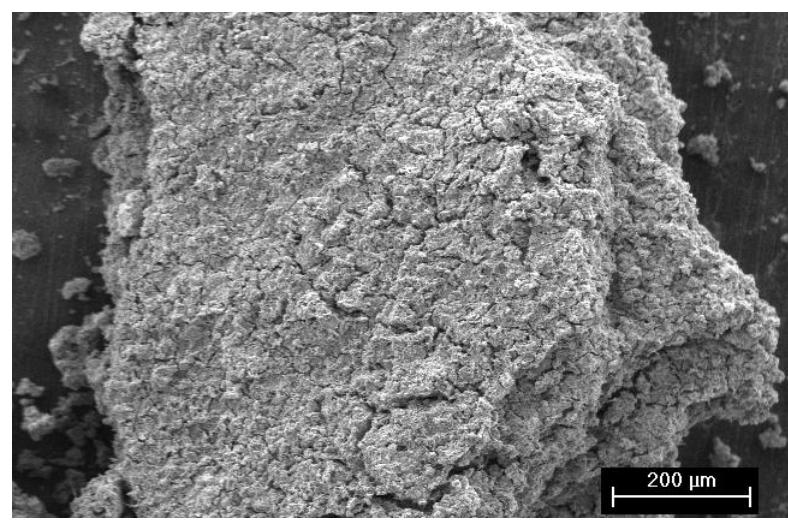

(a)

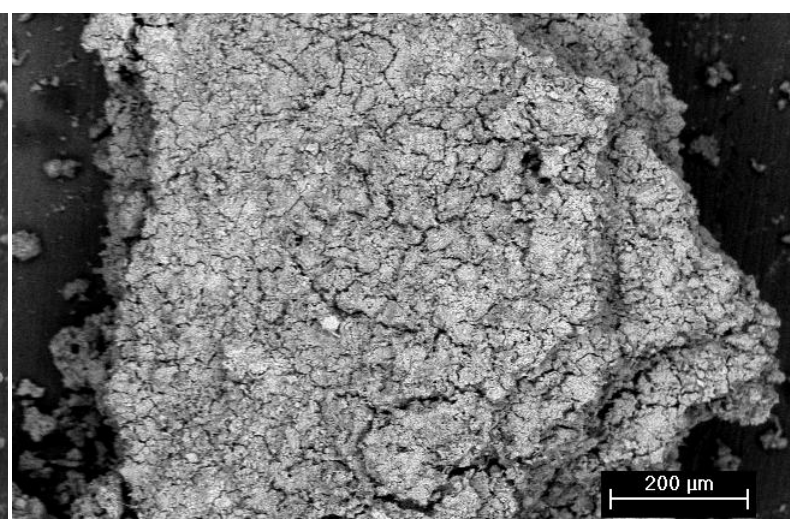

(b)

Figura 4.24: Micrografia obtida por microscopia eletrônica de varredura utilizando elétrons secundários (a) e retro-espalhados (b) dos precipitados e carbonetos extraídos por dissolução eletrolítica da amostra M2MPTT.

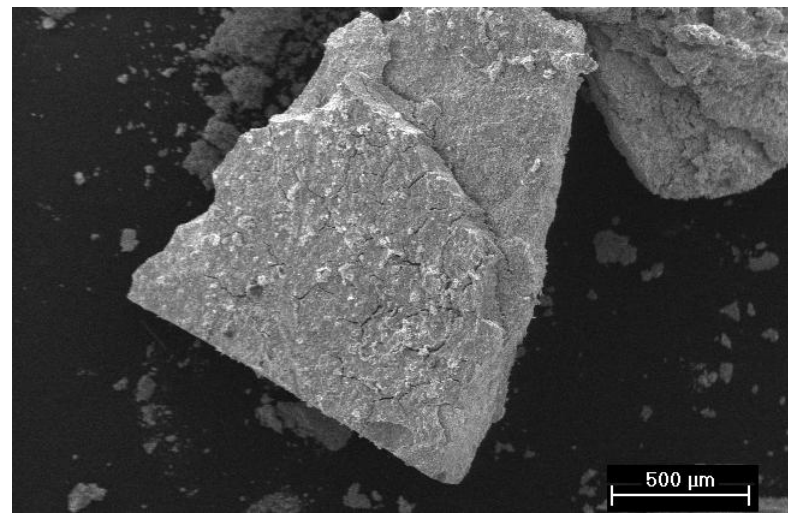

(a)

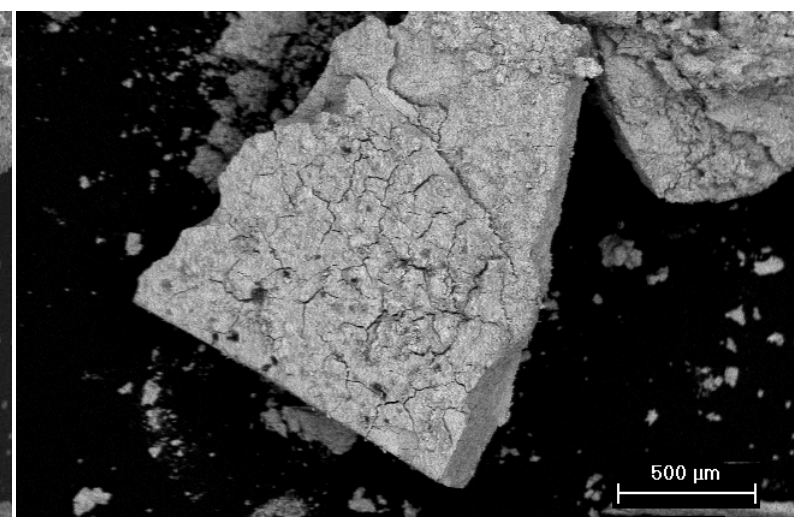

(b)

Figura 4.25: Micrografia obtida por microscopia eletrônica de varredura utilizando elétrons secundários (a) e retro-espalhados (b) dos precipitados e carbonetos extraídos por dissolução eletrolítica da amostra M2CSL50TT 


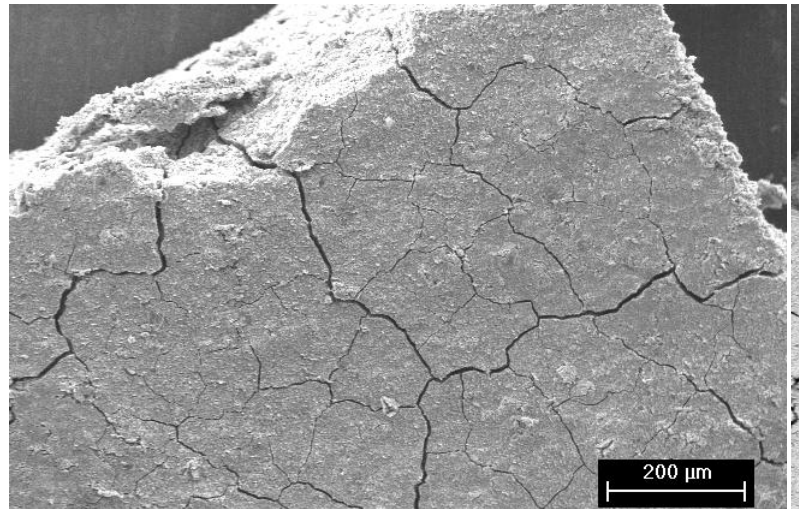

(a)

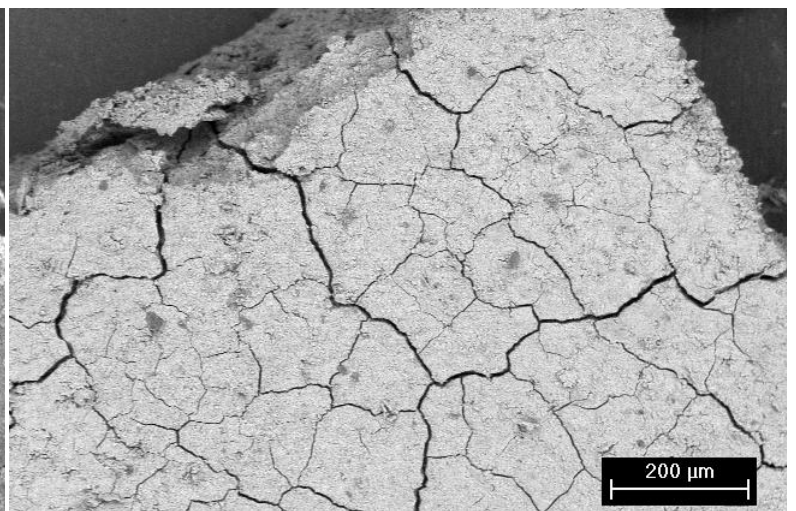

(b)

Figura 4.26: Micrografia obtida por microscopia eletrônica de varredura utilizando elétrons secundários (a) e retro-espalhados (b) dos precipitados e carbonetos extraídos por dissolução eletrolítica da amostra M2CSL70TT.

A análise da interação destes resíduos sob a ação de um campo magnético mostrou que os mesmos não apresentam caráter magnético macroscópico. A ausência de interação magnética comprova que a dissolução da matriz ferrítica foi completa.

As análises químicas realizadas por EDS pontual nos resíduos apresentados nas figuras de 4.23 a 4.26 identificaram uma distribuição levemente heterogênea do vanádio nestas superfícies. No entanto, não se observaram diferenças significativas no contraste das imagens obtidas por elétrons retro-espalhados. Estes fatos sugerem que a rede de carbonetos é extensa e compacta o suficiente para permitir que o resíduo mantenha a forma geométrica da amostra, e que estas estruturas são formadas pelo entrelaçamento dos carbonetos do tipo $\mathrm{M}_{6} \mathrm{C}$ e $\mathrm{MC}$.

A dissolução eletrolítica promove a extração da fração total dos carbonetos e fases intermetálicas, quando presentes (Blickwede et al., 1950). Já a dissolução química com o reagente de Berzelius promove a dissolução da fase matriz e do carboneto $\mathrm{M}_{6} \mathrm{C}$, porém com uma velocidade de reação menor (vide FIG. 4.27) que a matriz, sem a dissolução dos carbonetos do tipo $\mathrm{MC}, \mathrm{M}_{2} \mathrm{C}$ e $\mathrm{M}_{23} \mathrm{C}_{6}$. Portanto, a utilização conjunta destas técnicas, tomando-se o cuidado de garantir que toda a fração de $\mathrm{M}_{6} \mathrm{C}$ seja dissolvida, permite a quantificação em massa da fração de carbonetos do tipo $\mathrm{M}_{6} \mathrm{C}$, da fração de carbonetos total e da fração de carbonetos do tipo MC. 


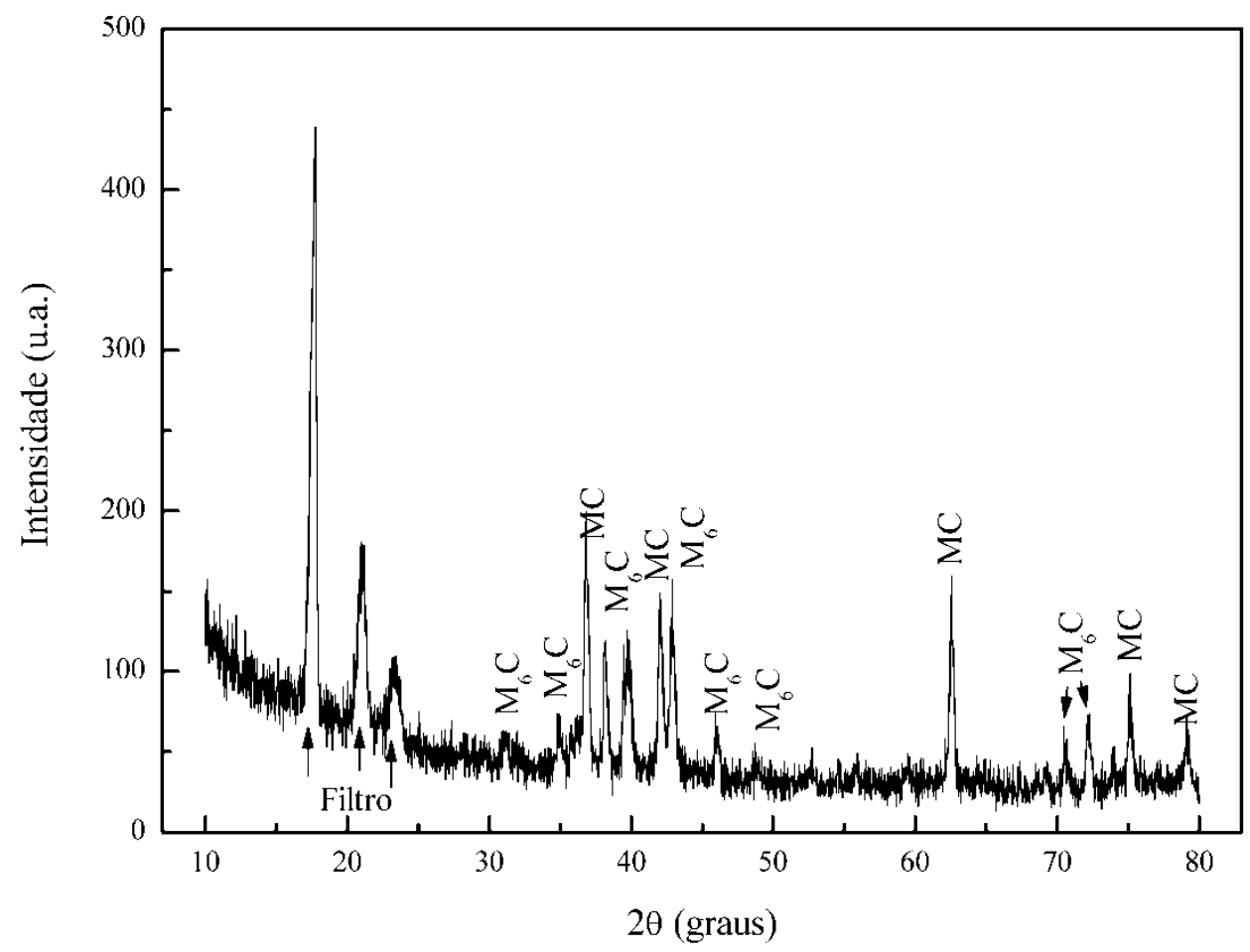

Figura 4.27: Espectro de difração dos carbonetos extraídos após dissolução química, com reagente de Berzelius, por 2,5 horas.

Na FIG. 4.28 são apresentadas as micrografias obtidas por microscopia eletrônica de varredura dos carbonetos extraídos pela dissolução química. Durante a investigação microscópica foram realizadas análises químicas pontuais por EDS que permitiram a determinação da composição média dos carbonetos por este método, vide TAB. 4.2. A análise química no espectrômetro de fluorescência de raios $\mathrm{X}$, da massa total do resíduo, obtida na extração química é apresentada na TAB. 4.3.

A microestrutura do material obtido por metalurgia convencional, após o tratamento térmico, era composta por carbonetos dos contornos da rede de carbonetos que apresentavam com uma estrutura de carbonetos agregados e regiões com carbonetos de aspecto mais maciço (FIG. 4.15). O resíduo obtido da extração eletrolítica da amostra deste material foi o que apresentou as menores regiões agregadas em comparação com os materiais obtidos por metalurgia do pó e conformação por spray. O restante do resíduo (FIG. 4.28 (a)) é formado por partículas mais finas fato condizente quanto se considera que este material foi submetido a deformações plásticas mais severas que promovem uma maior fragmentação dos carbonetos primários 


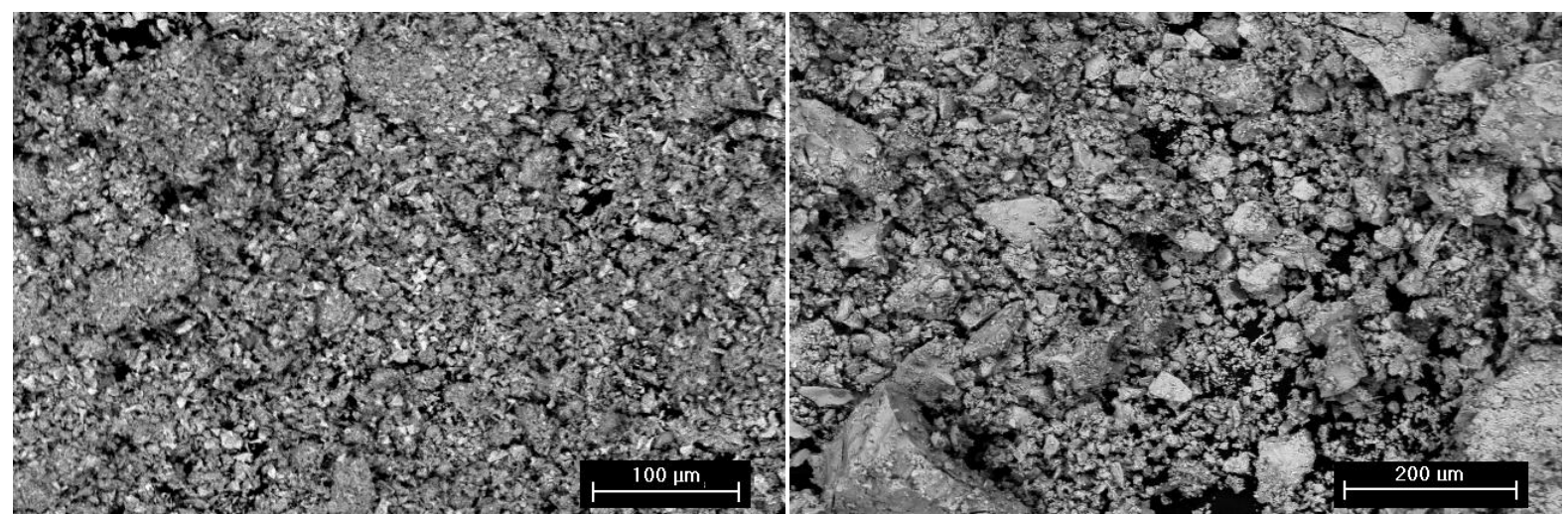

(a)

(b)

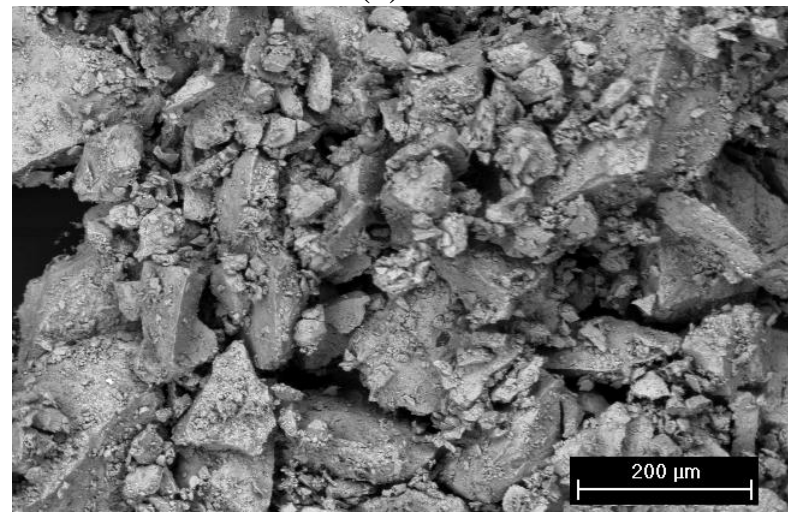

(c)

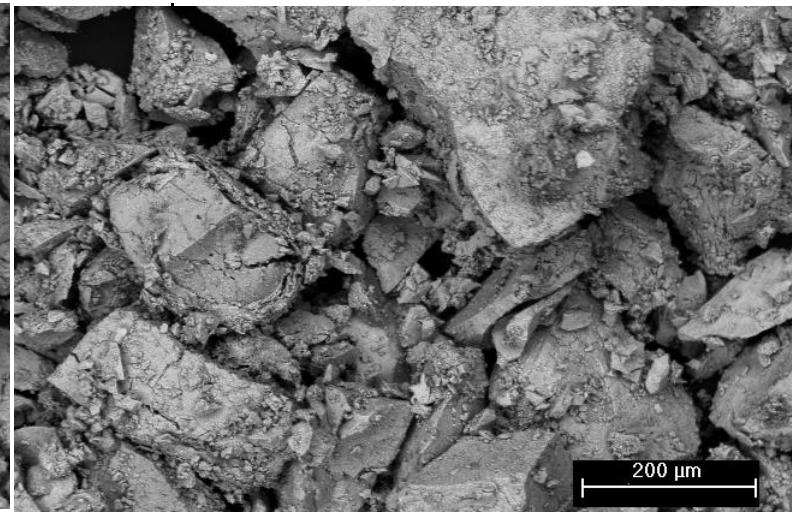

(d)

Figura 4.28: Micrografia obtida por microscopia eletrônica de varredura utilizando elétrons retro-espalhados dos carbonetos extraídos por dissolução química das amostras: (a) M2COMTT, (b) M2MPTT, (c) M2CSL50TT e (d) M2CSL70TT.

Tabela 4.2: Composição química obtida por EDS para os átomos metálicos dos carbonetos MC extraído por dissolução química, a primeira linha refere-se à composição química expressa em porcentagem em massa e a segunda linha em itálico refere-se à composição química expressa em porcentagem atômica.

\begin{tabular}{cccccc}
\hline Amostra & W & Mo & V & Cr & Fe \\
\hline \hline \multirow{2}{*}{ M2COMTT } & 31,15 & 32,92 & 25,31 & 9,60 & 1,02 \\
& $\mathbf{1 3 , 9 8}$ & $\mathbf{2 8 , 3 1}$ & $\mathbf{4 0 , 9 8}$ & $\mathbf{1 5 , 2 3}$ & $\mathbf{1 , 5 0}$ \\
\multirow{2}{*}{ M2MPTT } & 37,47 & 31,75 & 14,44 & 12,05 & 4,29 \\
& $\mathbf{1 8 , 0 9}$ & $\mathbf{2 9 , 3 7}$ & $\mathbf{2 5 , 1 5}$ & $\mathbf{2 0 , 5 7}$ & $\mathbf{6 , 8 2}$ \\
M2CSL50TT & 29,42 & 32,26 & 23,29 & 12,83 & 2,10 \\
\multirow{2}{*}{ M2CSL70TT } & $\mathbf{1 2 , 9 1}$ & $\mathbf{2 7 , 1 2}$ & $\mathbf{3 7 , 0 3}$ & $\mathbf{1 9 , 9 1}$ & $\mathbf{3 , 0 3}$ \\
& $\mathbf{3 3 , 5 1}$ & $\mathbf{2 5 , 9 8}$ & 23,36 & 13,52 & 3,63 \\
\hline
\end{tabular}


A amostra M2MPTT (FIG. 4.28 (b)) retirada do material obtido por metalurgia do pó mostra a presença de aglomerados mais grosseiros, quando comparada com o material obtido pelo processo convencional, e pode estar relacionada ao processo de sinterização de partículas vizinhas com orientação cristalográfica com grande diferença de orientação, de maneira que a rede de carboneto apresente um tamanho médio pequeno. A inferência desta proposição está baseada nas observações realizadas por Kula e Cohen, 1952.

Tabela 4.3: Composição química obtida por espectrometria de fluorescência de raios $\mathrm{X}$ para os átomos metálicos do carboneto MC extraído por dissolução química, a primeira linha refere-se à composição química expressa em porcentagem em massa e a segunda linha em itálico refere-se à composição química expressa em porcentagem atômica.

\begin{tabular}{cccccc}
\hline Amostra & W & Mo & V & Cr & Fe \\
\hline \hline \multirow{2}{*}{ M2COMTT } & 26,74 & 31,01 & 28,77 & 10,20 & 3,27 \\
& $\mathbf{1 1 , 2 9}$ & $\mathbf{2 5 , 0 9}$ & $\mathbf{4 3 , 8 4}$ & $\mathbf{1 5 , 2 3}$ & $\mathbf{4 , 5 5}$ \\
M2MPTT & 12,55 & 34,64 & 26,47 & 20,62 & 5,72 \\
& $\mathbf{2 7 , 5 6}$ & $\mathbf{3 9 , 7 0}$ & $\mathbf{1 6 , 1 1}$ & $\mathbf{1 2 , 8 1}$ & $\mathbf{3 , 8 2}$ \\
M2CSL50TT & 8,60 & 32,31 & 36,70 & 19,72 & 2,67 \\
& $\mathbf{2 0 , 4 7}$ & $\mathbf{4 0 , 1 3}$ & $\mathbf{2 4 , 2 0}$ & $\mathbf{1 3 , 2 7}$ & $\mathbf{1 , 9 3}$ \\
M2CSL70TT & 8,82 & 34,45 & 31,93 & 20,45 & 4,35 \\
& $\mathbf{2 0 , 6 3}$ & $\mathbf{4 2 , 0 5}$ & $\mathbf{2 0 , 7 0}$ & $\mathbf{1 3 , 5 3}$ & $\mathbf{3 , 0 9}$ \\
\hline
\end{tabular}

Como citado no capítulo 3 o material obtido por conformação por spray foi submetido uma etapa de laminação a quente com o objetivo de refinar os carbonetos primários. No entanto, observou-se nas micrografias apresentadas (FIG. 4.18 (c, d)) aglomerados relativamente grande que podem ser decorrentes da baixa deformação imposta para a fragmentação de rede de carbonetos. $\mathrm{O}$ aspecto angular dos carbonetos grosseiros do material conformado por spray pode estar relacionado ao crescimento dos carbonetos primários devido a uma temperatura de sobre-aquecimento alta, fato observado para amostras obtidas pelo método de produção convencional (McHargue et al., 1954; Kula e Cohen, 1954).

Na FIG. 4.29 são apresentadas as micrografias obtidas por microscopia eletrônica de varredura dos carbonetos extraídos das amostras M2MPTT, M2CSL50TT e M2CSL70TT, com maior aumento, onde foi possível observar que há heterogeneidades no 
contraste da imagem. A análise por EDS, nos pontos mais claros na imagem, relevou que estes são ricos em vanádio, enquanto que os pontos mais escuros possuem composição semelhante à apresentada na TAB. 4.2. O contraste da imagem obtida por elétrons retroespalhados é função do número atômico, portanto este resultado apresenta uma incongruência. Uma possível explicação para este fato é a menor condutividade elétrica do vanádio dentre os elementos de liga, portanto apresenta maior probabilidade de contraste por carregamento, sob este ponto de vista o resultado da análise química é coerente.

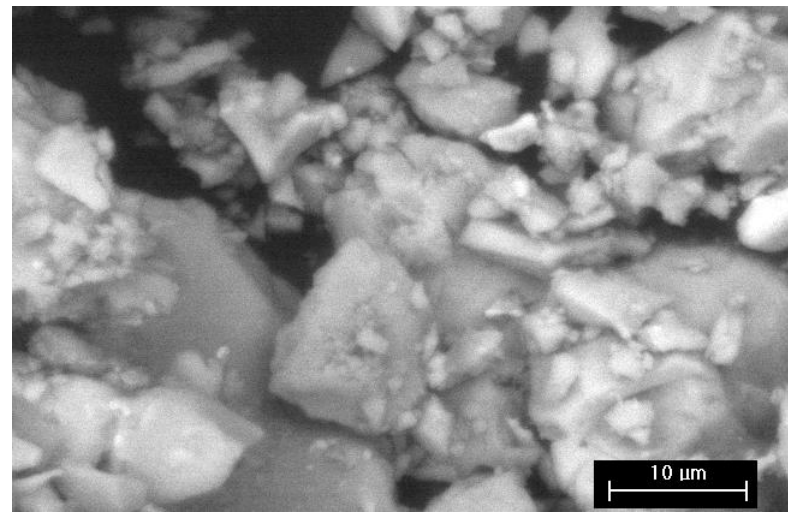

(a)

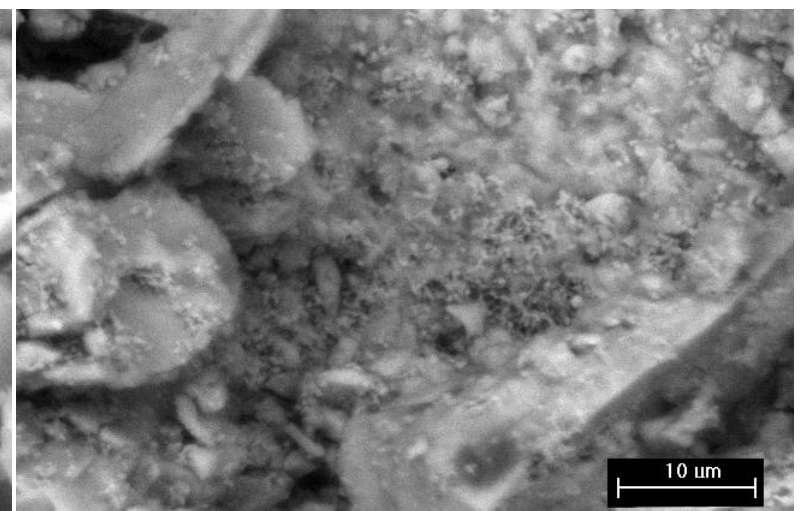

(b)

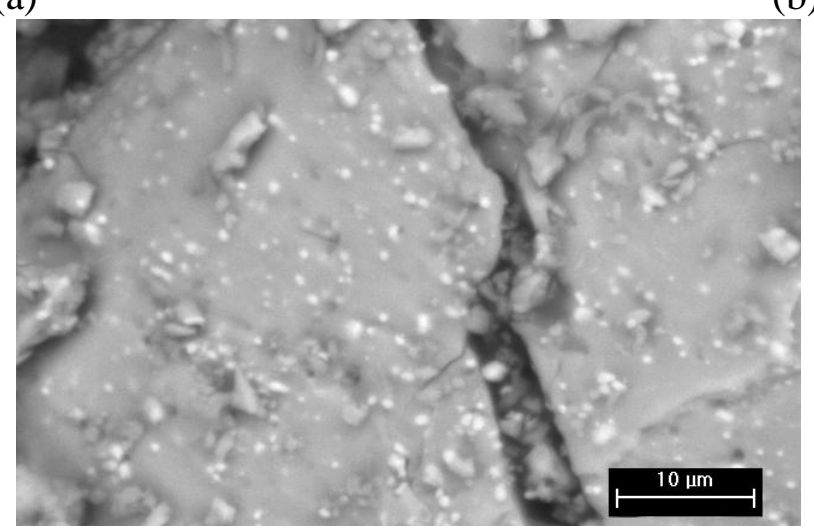

(c)

Figura 4.29: Micrografia obtida por microscopia eletrônica de varredura, com elétrons retro-espalhados, dos carbonetos extraídos da amostra: (a) M2MPTT, (b) M2CSL50TT e (c) M2CSL70TT.

Os resultados obtidos para a análise química por espectrometria de fluorescência de raios $\mathrm{X}$ por dispersão de energia mostram que a análise química pontual, desde que realizada em um número de pontos representativos, fornece um resultado bastante confiável.

A composição química obtida para o resíduo extraído após a dissolução química foi um resultado muito surpreeendente. Esperava-se a partir do levantamento bibliográfico realizado sobre a formação de carbonetos nos aço rápidos e em especial no 
AISI/SAE M2 que a fração de carbonetos do tipo MC, extraídas do material após o revenimento, fosse formada essencialmente por carbonetos primários. Esta população de carbonetos segundo a literatura tem uma composição química rica em vanádio (Kaiser, 1991; Kim et al., 1982; Lee et al., 1998; Kulmburg, 1998; Rong et al., 1992; Fischer e Kohlhaas, 1975; Ghomashchi e Sellars, 1984).

Segundo Karagöz et al. (1992a, 1992b, 1981) na etapa de revenimento ocorre a formação de carbonetos secundários do tipo $\mathrm{MC}$ e $\mathrm{M}_{2} \mathrm{C}$ este carbonetos tem tamanho médio entre $3 \mathrm{~nm}$ e $10 \mathrm{~nm}$ e representam cerca de 25 a $33 \%$ do volume de carbonetos primários. Considerando que a película filtrante utilizada na separação dos carbonetos extraídos possui poros com diâmetro médio de $200 \mathrm{~nm}$ avalia-se que a quantidade dos carbonetos secundários na fração extraída é pequena. Já esta população de carbonetos tem composição química reportada mais próxima à composição do resíduo extraído neste trabalho.

As frações de precipitados extraídos através da dissolução eletrolítica e química são apresentadas na TAB. 4.4.

Tabela 4.4: Frações (\% em massa) de precipitados extraídos.

\begin{tabular}{cccc}
\hline \multirow{2}{*}{ Amostra } & \multicolumn{3}{c}{ Fração de carbonetos } \\
& Total & $\begin{array}{c}\text { \% massa) } \\
\mathbf{M}_{\mathbf{6}} \mathbf{C}\end{array}$ & MC \\
\hline \hline M2COMTT & 9,72 & 4,57 & 5,15 \\
M2MPTT & 14,00 & 8,38 & 5,62 \\
M2CSL50TT & 20,61 & 13,60 & 7,01 \\
M2CSL70TT & 17,41 & 10,70 & 6,71 \\
\hline
\end{tabular}

Na literatura a quantificação dos carbonetos é usualmente expressa em termos da fração volumétrica, pois tradicionalmente a quantificação é realizada pela técnica de metalografia quantitativa.

No cálculo da fração volumétrica, TAB. 4.5, a partir da massa específica ponderada é necessário conhecer a estequiometria das fases presentes. A estequiometria do

carboneto $\mathrm{M}_{6} \mathrm{C}$ foi obtida pela análise pontual por EDS e é apresentada na TAB. 4.6. No estado revenido devido a dispersão de carbonetos nanométricos não é possível obter uma análise química da matriz por EDS. Para a avaliação da fração volumétrica a densidade da matriz foi considerada igual a densidade da ferrita. A massa 
específica do carboneto do tipo MC foi obtida pelo refinamento da estrutura pelo método de Rietveld, considerando a fórmula mínima $\mathrm{V}_{4} \mathrm{C}_{3}$, e está apresentada na TAB. 4.7.

Tabela 4.5: Frações (\% volumétrica) de precipitados extraídos.

\begin{tabular}{cccc}
\hline \multirow{2}{*}{ Amostra } & \multicolumn{3}{c}{$\begin{array}{c}\text { Fração de carbonetos } \\
\text { ( \% volumétrica) }\end{array}$} \\
& Total & $\mathbf{M}_{\mathbf{6}} \mathbf{C}$ & MC \\
\hline M2COMTT & 9,22 & 3,56 & 5,66 \\
M2MPTT & 12,33 & 6,48 & 5,85 \\
M2CSL50TT & 17,81 & 10,49 & 7,32 \\
M2CSL70TT & 15,30 & 8,26 & 7,04 \\
\hline
\end{tabular}

Tabela 4.6: Estequiometria do carboneto do tipo $\mathrm{M}_{6} \mathrm{C}$.

\begin{tabular}{cccccc}
\hline Elemento & W & Mo & V & Cr & Fe \\
\hline \hline \% massa & 40,67 & 20,25 & 2,93 & 3,09 & 33,06 \\
\% atômica & 19,38 & 18,50 & 5,04 & 5,21 & 51,87 \\
\hline
\end{tabular}

Tabela 4.7: Massa específica teórica do carboneto do tipo MC.

\begin{tabular}{cc}
\hline Amostra & $\begin{array}{c}\text { Massa específica } \\
\left(\mathbf{g c m}^{-3}\right)\end{array}$ \\
\hline \hline M2COMTT & 7,786 \\
M2MPTT & 7,737 \\
M2CSL50TT & 7,701 \\
M2CSL70TT & 7,654 \\
\hline
\end{tabular}

\subsection{Determinação dos parâmetros cristalográficos}

Na cronologia deste trabalho, o primeiro método a ser implementado foi a dissolução química, com solução de Berzelius, que permitia apenas a extração do carboneto do tipo MC. A análise química obtida para este carboneto determinou a necessidade da utilização de energias situadas na borda de absorção dos diversos elementos constituintes do carboneto, sendo fundamental a utilização de fonte de radiação síncrotron para a obtenção dos dados que seriam utilizados no refinamento da estrutura. Atualmente as instalações do Laboratório Nacional de Luz Síncroton (LNLS) são únicas na America do Sul e muito requisitadas. O sistema adotado pelo LNLS é a apresentação de projetos de pesquisas, que podem ser divididos em propostas de pesquisa submetidas semestralmente. Nestas propostas os pesquisadores estimam o tempo necessário para a realização da proposta de pesquisa, porém o tempo fornecido para a utilização das instalações é determinado pelo laboratório em função do parecer do avaliador da proposta de pesquisa. 
A realização da primeira proposta de pesquisa mostrou que o tempo estimado e aprovado era suficiente apenas para a obtenção de dados para o estudo do carboneto do tipo MC, que era o único extraído na ocasião. Conseqüentemente, inicialmente o trabalho experimental se concentrou na obtenção da quantidade mínina do carboneto do tipo MC por dissolução química para a realização das análises no LNLS. Por este motivo não foi possível realizar análises que permitissem o levantamento dos parâmetros cristalográficos do $\mathrm{M}_{6} \mathrm{C}$.

Os espectros de difração de raios $\mathrm{X}$ obtidos para os resíduos extraídos por dissolução química são apresentados na FIG. 4.30. Utilizando o método de identificação de fases por comparação com padrões das bases de dados foi possível verificar que este espectro é similar ao do carboneto do tipo MC (VC PDF 73-476).

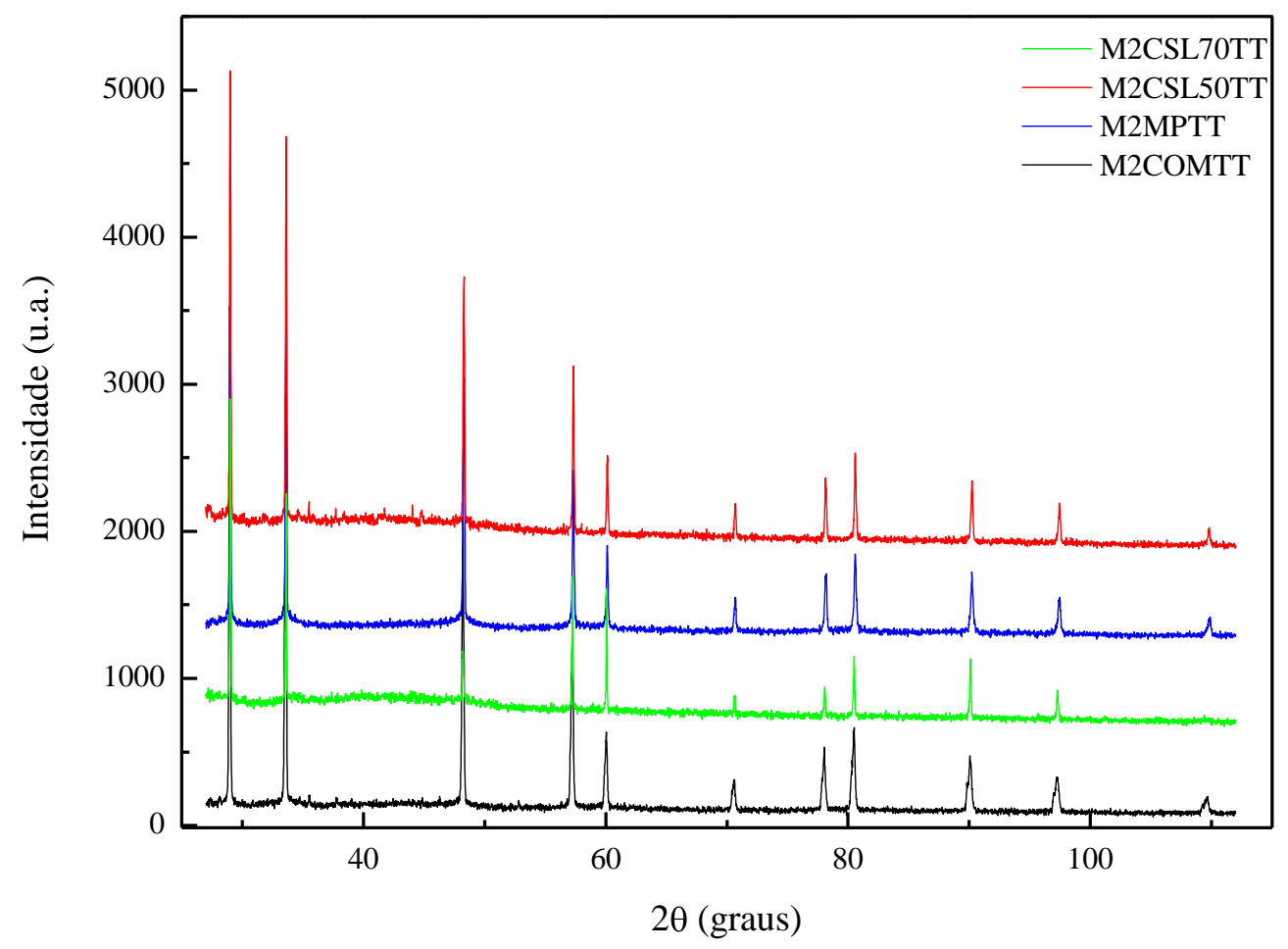

Figura 4.30: Espectros de difração de raios $\mathrm{X}$ obtidos para o resíduo extraído por dissolução química para as amostras: M2COMTT, M2MPTT, M2CSL50TT e M2CSL70TT.

Aplicando os métodos tradicionais para a determinação da estrutura a partir do espectro de difração de raios $\mathrm{X}$ obteve-se como melhor candidata uma estrutura cúbica de face centrada, com parâmetro de rede da ordem de 4,17 ̊. Considerando as informações obtidas por estes dois métodos adotou-se como estrutura cristalina o modelo da estrutura 
do grupo espacial $F m-3 m$, com duas posições atômicas: a posição $(0,0,0)$ ocupada pelo átomo de carbono e a posição $(1 / 2,1 / 2,1 / 2)$ ocupada pelos átomos metálicos.

Realizando-se o cálculo do fator de estrutura para esta estrutura cristalina obtêm-se:

$$
\begin{aligned}
& F^{2}=16\left(f_{C}+f_{M}\right)^{2} \text { se }(h+k+l) \text { é par, } \\
& F^{2}=16\left(f_{C}-f_{M}\right)^{2} \text { se }(h+k+l) \text { é ímpar, e } \\
& F^{2}=0 \text { para índices pares e ímpares misturados. }
\end{aligned}
$$

onde: $f_{c}$ é o fator de espalhamento do átomo de carbono, $f_{M}$ é o fator de espalhamento ponderado para os átomos metálicos e $h k l$ os índices de Miller do plano cristalográfico.

O fator de espalhamento do carbono para as energias utilizadas é muito menos intenso que os fatores de espalhamentos dos átomos metálicos (vide FIG. 4.31). Portanto a contribuição para a intensidade nesta estrutura é devida quase que essencialmente a composição dos fatores de espalhamento dos átomos metálicos.

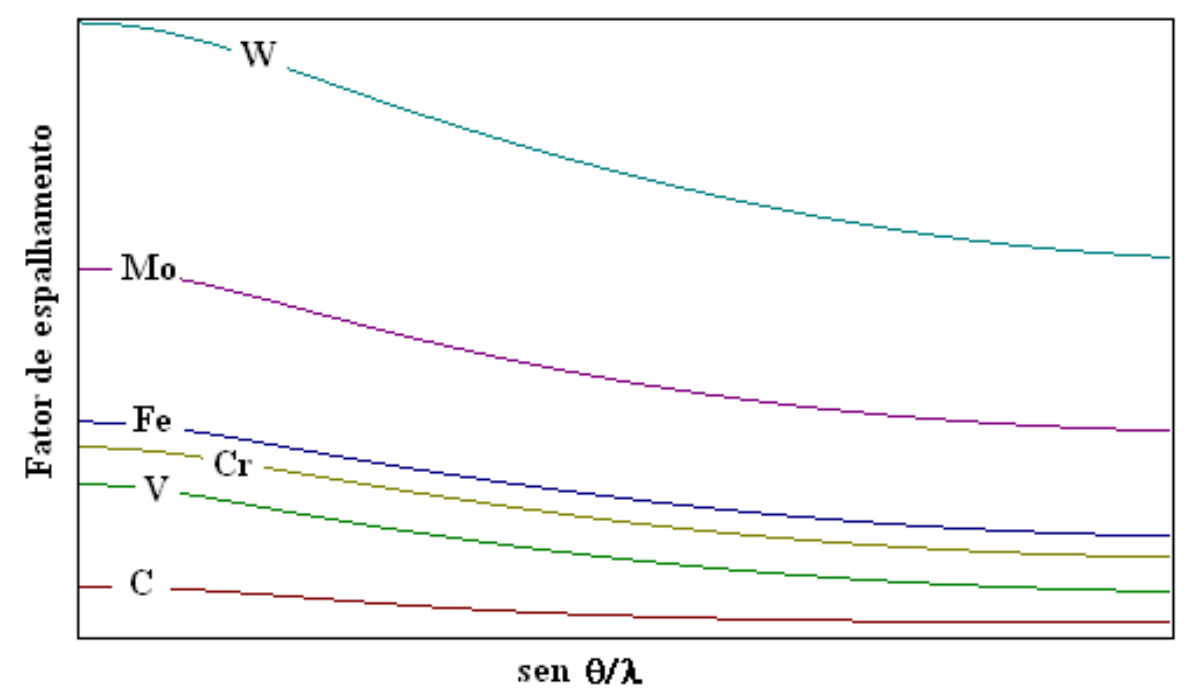

Figura 4.31: Curvas do fator de espalhamento em função do $\operatorname{sen} \theta / \lambda$ para $E_{\mathrm{f}}=5,4450 \mathrm{keV}$ (Cromer, 1980).

O estudo de estruturas compostas por átomos com alta diferença de fator de espalhamento apresentam melhores resultados com a utilização da difração de nêutrons. Porém, no caso específico desta estrutura esta técnica não se apresenta como uma alternativa, pois o vanádio não possui fator de espalhamento positivo para nêutrons, mesmo o estudo da estequiometria do carbono neste composto deve observar critérios 
rigorosos devido a extensa substituição no sítio do átomo metálico. Para o valor de fator de ocupação inicial da posição $(1 / 2,1 / 2,1 / 2)$ ocupada pelo átomo metálico foi adotada a composição química apresentada na TAB.4.3.

O refinamento conjunto dos padrões de difração de raios $\mathrm{X}$, obtidos nas quatro energias especificadas permitiu obter os parâmetros cristalográficos para este tipo de carboneto MC. Nas FIG. 4.32 a 4.35 são apresentados os gráficos do refinamento realizado para a amostra M2CSL50TT dos espectros obtidos para as energias de 5,4433 keV; 7,0903 $\mathrm{keV} ; 8,0005 \mathrm{keV}$ e 10,2730 keV; respectivamente. Nas figuras os dados experimentais são apresentados no campo superior na forma de símbolo (x), o espectro calculado é apresenta pela linha sólida e a curva abaixo do eixo x representa a diferença entre a intensidade observada e calculada para cada ponto.

A análise preliminar dos perfis, FIG. 4.36, já havia mostrado que as bases dos picos apresentavam um alargamento discrepante com a largura a meia altura dos picos sugerindo uma possível distribuição bimodal de tamanhos de cristalito da mesma fase cristalina (Ozaki et al., 2000), que foi confirmada pelo refino conjunto da mesma fase cristalina considerando-se a distribuição bimodal segundo a estratégia proposta por Young e Sakthivel (1988).

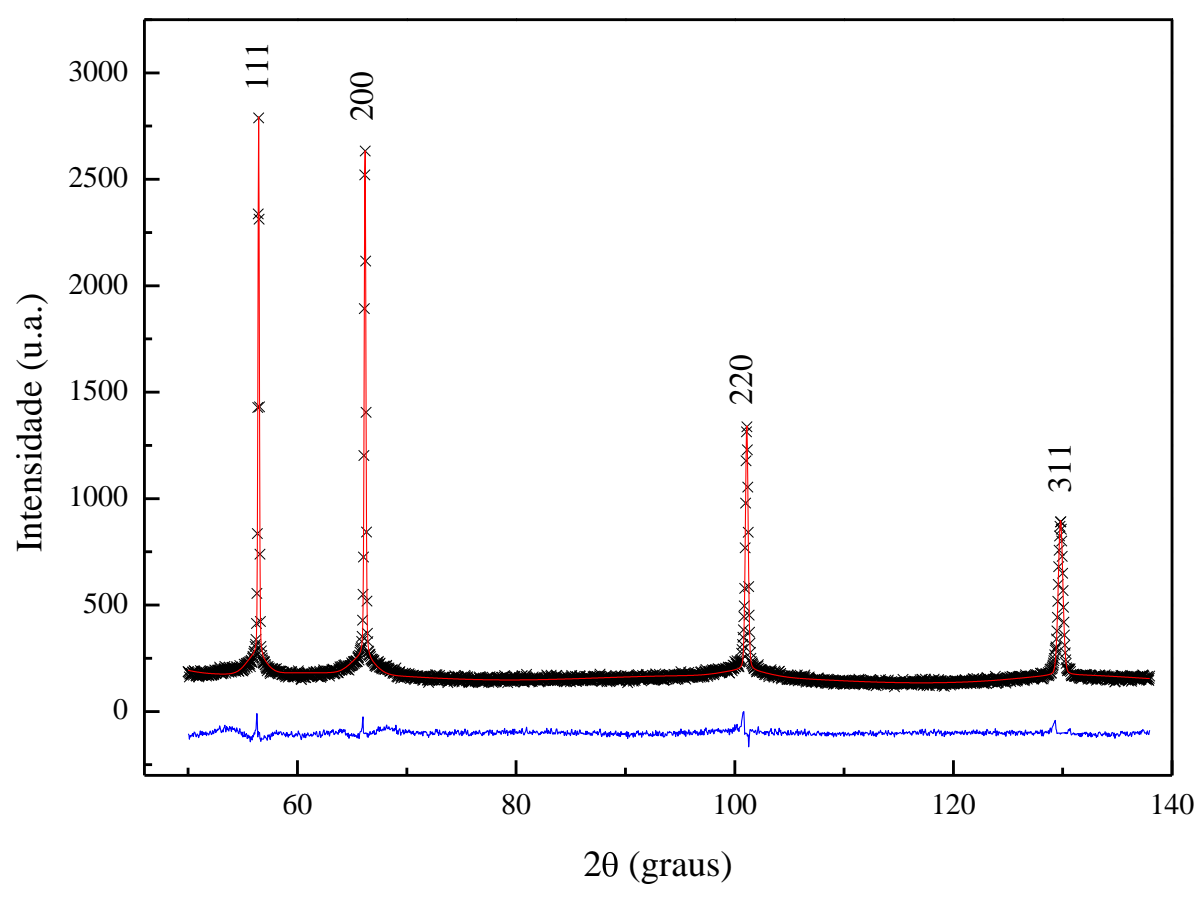

Figura 4.32: Espectro de difração refinado pelo método de Rietveld para o carboneto MC extraído da amostra M2CSL50TT para a energia de $\mathrm{E}_{\mathrm{f}}=5,4439 \mathrm{keV}$. 


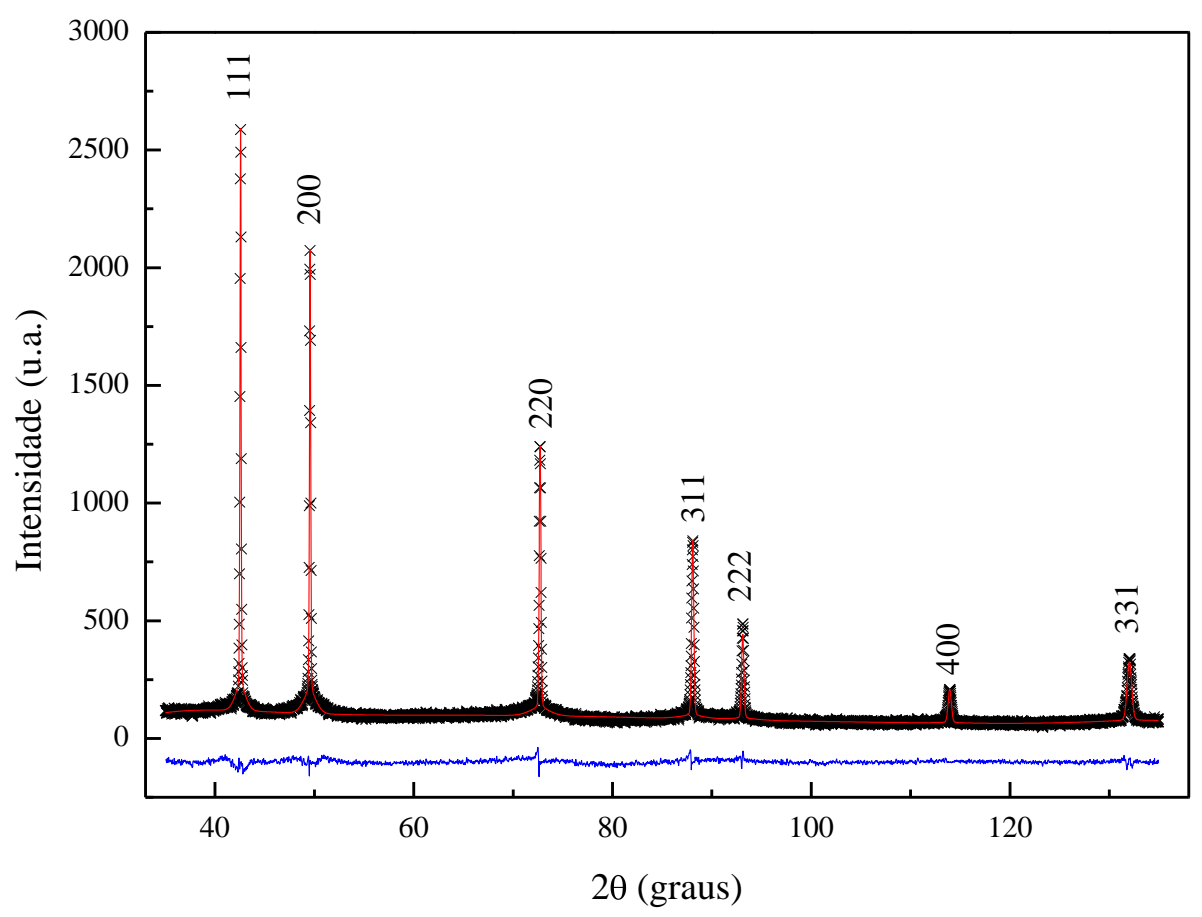

Figura 4.33: Espectro de difração refinado pelo método de Rietveld para o carboneto MC extraído da amostra M2CSL50TT para a energia de $\mathrm{E}_{\mathrm{f}}=7,1054 \mathrm{keV}$.

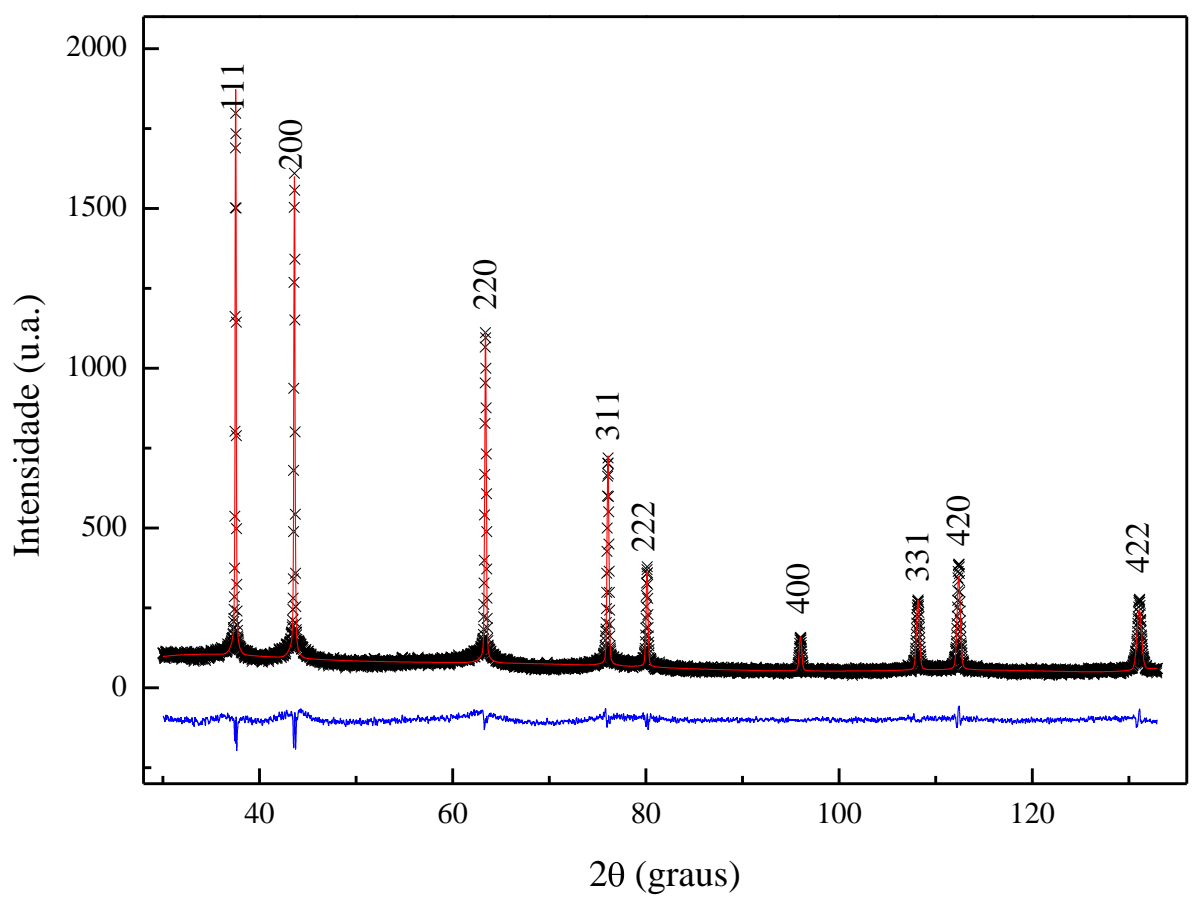

Figura 4.34: Espectro de difração refinado pelo método de Rietveld para o carboneto MC extraído da amostra M2CSL50TT para a energia de $\mathrm{E}_{\mathrm{f}}=8,0013 \mathrm{keV}$. 


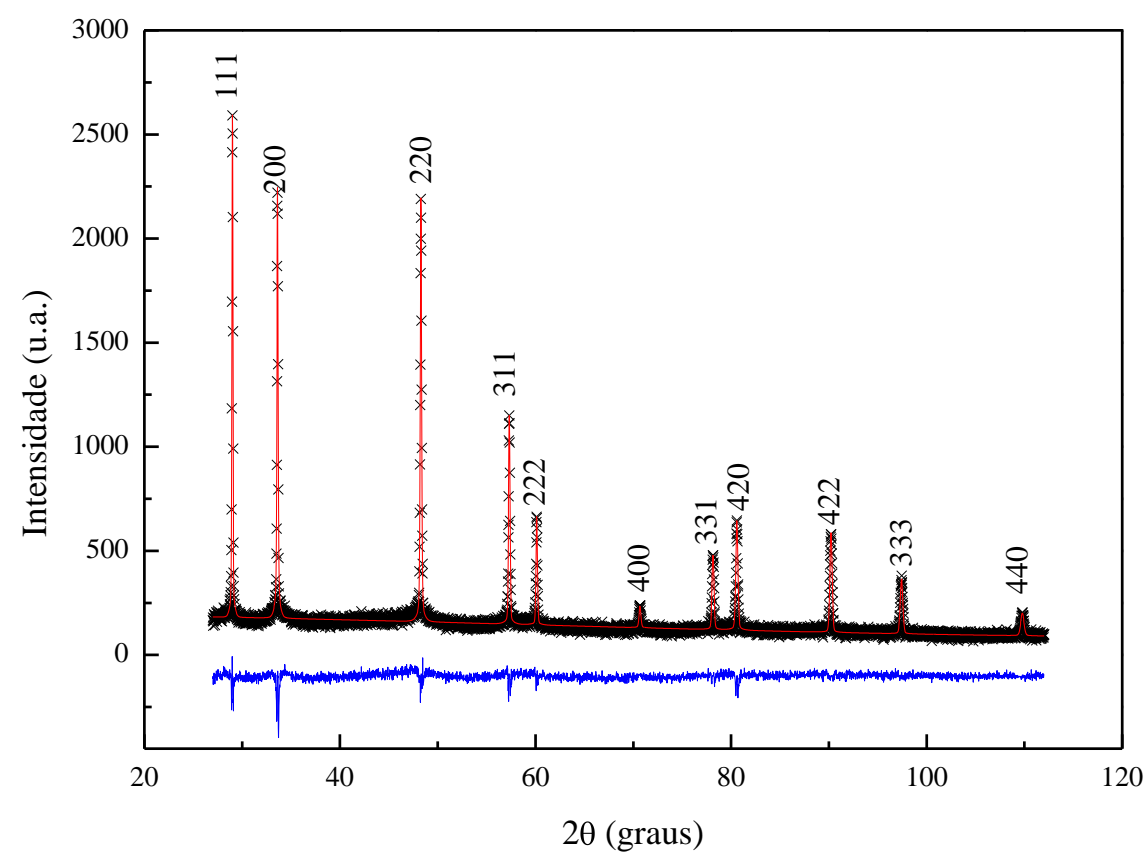

Figura 4.35: Espectro de difração refinado pelo método de Rietveld para o carboneto MC extraído da amostra M2CSL50TT para a energia de $\mathrm{E}_{\mathrm{f}}=10,2714 \mathrm{keV}$.

O MC é um carboneto estável e forma-se em todas as etapas de produção. Portanto espera-se que o mesmo apresente uma distribuição de tamanho bastante variável, considerando que durante os tratamentos térmicos subseqüente ocorra um refino na estrutura cristalina do mesmo.

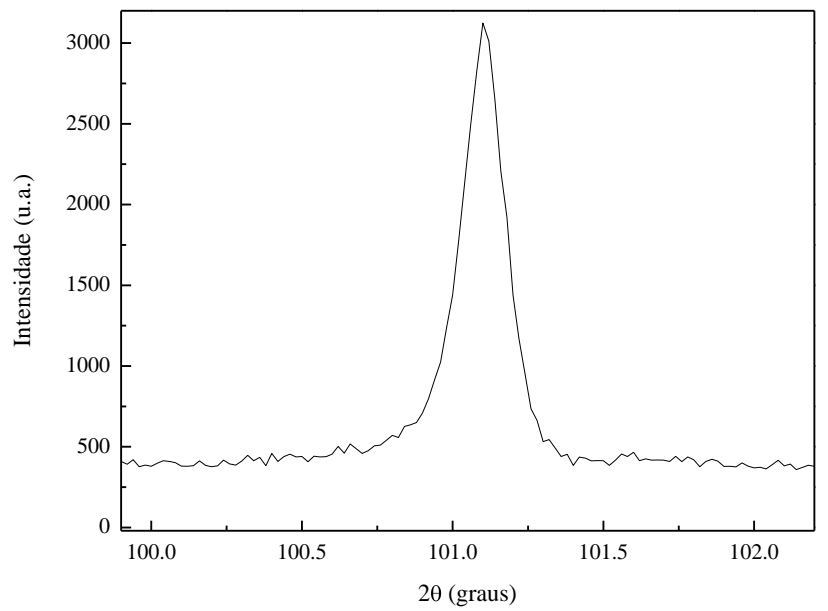

Figura 4.36 : Perfil da reflexão 220 do carboneto do tipo $\mathrm{MC}$ obtido com energia de $\mathrm{E}_{\mathrm{f}}=$ $5,4439 \mathrm{keV}$. 
Bénéteau et al. (2005) utilizaram o método de Rietveld, com dados obtidos por radiação síncrotron, no estudo in situ da dissolução de precipitados durante a austenitização de aços inoxidáveis (Fe-Cr-Mo-C) com alto teor de nitrogênio. Neste estudo os autores aproveitaram a grande quantidade de dados para refinar a composição química do carboneto do tipo $\mathrm{M}_{23} \mathrm{C}_{6}$. Assim como neste trabalho a maior dificuldade foi a não possibilidade de restrição para o fator de ocupação. Considerando que o $\mathrm{M}_{23} \mathrm{C}_{6}$, estrutura cristalina cúbica de face centrada $\left(\begin{array}{llll}F & m & -3 & m\end{array}\right)$ com 92 átomos metálicos distribuídos nos sítios $4 a, 8 c, 32 f$ e $48 h$ e o carbono ocupando o sítio $24 e$, é possível, por considerações estereográficas e químicas assumir que os átomos de molibdênio em função de seu tamanho ocuparam exclusivamente o sítio 8c, supõem-se que os átomos de ferro evitem os sítios $48 h$ e $32 f$ devido a presença de ligações com o carbono e portanto devem preferencialmente substituir o cromo nos sítios $4 a$ com empacotamento mais denso. A partir destas considerações os autores refinaram o fator de ocupação de cada sítio pela concorrência de dois átomos apenas.

No caso da estrutura do grupo espacial $F m-3 m$ adotada neste estudo nenhuma característica química pode ser considerada. Portanto, foram adotadas duas estratégias de refinamento: a primeira considerando-se que os átomos metálicos ocupariam apenas a posição 1/2, 1/2, 1/2 e suas posições equivalentes; e na segunda estratégia adotou-se a possibilidade da ocorrência de substituição do carbono por átomos metálicos, uma vez que as condições estereográficas permitem esta substituição com uma pequena deformação da célula unitária.

O refinamento do fator de ocupação para o átomo de ferro tendia a valores negativos, independente da estratégia de refinamento, sugerindo que este elemento está preferencialmente alojado nos carbonetos de baixa cristalinidade. E, portanto, o ferro foi desconsiderando como um elemento presente na fase com maior tamanho de cristalito, para a qual foi realizado o refinamento do fator de ocupação.

No programa GSAS o coeficiente $\mathrm{R}\left(\mathrm{F}^{2}\right)$, equivale ao coeficiente de $\mathrm{R}_{\mathrm{Bragg}}$ que avalia a concordância no modelo estrutural proposto. A melhor convergência foi obtida para a primeira estratégia de refinamento, os valores obtidos para este coeficiente são apresentados na TAB. 4.8 . 
Tabela 4.8: Coeficientes $\mathrm{R}\left(\mathrm{F}^{2}\right)$ obtidos para os refinamentos.

\begin{tabular}{llll}
\hline \multicolumn{1}{c}{ Amostra } & $\mathbf{E}(\mathbf{k e V})$ & $\mathbf{R}\left(\mathbf{F}^{\mathbf{2}}\right)$ & $\boldsymbol{\chi}^{\mathbf{2}}$ \\
\hline \hline \multirow{4}{*}{ M2COMTT } & 5,4433 & 0,0533 & \\
& 7,0903 & 0,0576 & 0,89 \\
& 8,0005 & 0,0701 & \\
& 10,2730 & 0,0610 & \\
M2MPTT & 5,4433 & 0,0667 & \\
& 7,0903 & 0,0701 & 1,34 \\
& 8,0005 & 0,1356 & \\
M2CSL50TT & 10,2730 & 0,1145 & \\
& 5,4433 & 0,0405 & \\
& 8,0903 & 0,0427 & 0,81 \\
& 10,2730 & 0,0333 & \\
M2CSL70TT & 5,4433 & 0,0421 & \\
& 7,0903 & 0,0345 & \\
& 8,0005 & 0,0397 & 0,99 \\
\hline
\end{tabular}

A estequiometria para o carboneto do tipo MC obtida para cada amostra e os respectivos parâmetros de rede são apresentados na TAB. 4.9.

Tabela 4.9: Estequiometria e parâmetros de rede do carboneto MC.

\begin{tabular}{llc}
\hline \multicolumn{1}{c}{ Amostra } & \multicolumn{1}{c}{ Estequiometria } & $\begin{array}{c}\text { Parâmetro de rede } \\
(\AA)\end{array}$ \\
\hline \hline M2COMTT & $\left(\mathrm{V}_{0,556} \mathrm{Cr}_{0,154} \mathrm{Mo}_{0,199} \mathrm{~W}_{0,081}\right)_{4} \mathrm{C}_{3}$ & $4,171055 \pm 0,000016$ \\
M2MPTT & $\left(\mathrm{V}_{0,436} \mathrm{Cr}_{0,179} \mathrm{Mo}_{0,255} \mathrm{~W}_{0,130}\right)_{4} \mathrm{C}_{3}$ & $4,175131 \pm 0,000050$ \\
M2CSL50TT & $\left(\mathrm{V}_{0,451} \mathrm{Cr}_{0,190} \mathrm{Mo}_{0,268} \mathrm{~W}_{0,089}\right)_{4} \mathrm{C}_{3}$ & $4,171072 \pm 0,000028$ \\
M2CSL70TT & $\left(\mathrm{V}_{0,445} \mathrm{Cr}_{0,199} \mathrm{Mo}_{0,261} \mathrm{~W}_{0,085}\right)_{4} \mathrm{C}_{3}$ & $4,170953 \pm 0,000016$ \\
\hline
\end{tabular}

\subsection{Considerações finais}

Os resultados mais intrigantes apresentados neste capítulo são relacionados ao carboneto misto de vanádio molibdênio e cromo do tipo MC extraído por dissolução química das outras fases, ainda não reportado na literatura, e a alta fração de carbonetos extraídos.

Estes resultados levantam questões importantes como: (1) Por que em um material tão estudado nunca se reportou tal carboneto?; (2) O carboneto está bem caracterizado?; (3) Como pode ter ocorrido a formação deste carboneto? As considerações a seguir procuram elucidar estas questões.

Não foram encontrados na literatura estudos específicos e detalhados sobre o efeito dos tratamentos térmicos de austenitização e revenimento nos carbonetos primários. 
Porém Stiller et al. (1984) já haviam observado a ocorrência de substituições elementares nos carbonetos primários após o revenimento do material (TAB. 2.13).

Recentemente Popescu (2007) verificou que durante a deformação a quente do material fundido o refino da rede de carbonetos ocorre por fragmentação mecânica e por difusão atômica dos átomos de liga formando um carboneto quaternário de vanádio, cromo, molibdênio e tungstênio.

Warbicher et al. (1999) observaram no estudo de um aço similar ao AISI/SAE M2 com adição de cobalto, no estado recozido, a existência de regiões nanométricas ricas em molibdênio, tungstênio e vanádio com desvios significativos em relação ao carboneto MC rico em vanádio observado no mesmo material.

As flutuações estequiométricas em carbonetos MC primários do mesmo material, após a austenitização, já haviam sido verificadas por Peter e Kohlhaas (1967). Neste caso os autores observaram a diminuição do teor de vanádio com um aumento significante da concentração de cromo e em menor proporção de tungstênio e molibdênio, (TAB. 2.8).

Por fim, os estudos de Karägoz et al. (1992a e 1992b) sobre a formação dos carbonetos secundários no aço AISI/SAE M2 mostraram que estes possuem uma composição química distinta dos carbonetos primários, sendo ricos em molibdênio, cromo e vanádio, TAB. 2.11. Resultado semelhante foi obtido por Stiller et al. (1984) no estudo de um aço com menor teor de cromo que o AISI/SAE M2, TAB. 2.13.

Wießner et al. (2005 e 2008) observaram através de análises de difração de raios $\mathrm{X}$ em alta temperatura o aumento do parâmetro de rede do carboneto do tipo $\mathrm{MC}$, atribuindo-o inicialmente ao efeito de dilatação térmica. Porém, os autores verificaram que no resfriamento os valores não eram coincidentes como os valores no aquecimento e não atingiam os valores iniciais, indicando a possibilidade de mudanças na composição química.

O exposto acima mostra que carbonetos do tipo MC com desvio de estequiometria em relação ao carboneto rico em vanádio ( $70 \%$ at.) já foram observados nas diversas etapas de produção e dos tratamentos térmicos posteriores do aço AISI/SAE M2. Portanto, pode-se supor que a falta de um estudo sistemático seja decorrente do não estabelecimento de um método de extração seletiva dos carbonetos.

$\mathrm{O}$ espectro de difração de raios $\mathrm{X}$ permitiu definir que o resíduo da dissolução química possuia estrutura cúbica de face centrada do tipo $\mathrm{NaCl}$. As características deste espectro, como por exemplo: a largura a meia altura dos picos obtidos em comparação com 
o alargamento instrumental, mostram que o resíduo é monofásico com distribuição bimodal de tamanho de cristalito. Esta análise preliminar do espectro em conjunto com a análise química do resíduo indicam que o vanádio, cromo, molibdênio e tungstênio somente podem estar ocupando os sítios cristalográficos desta estrutura.

A convergência do refinamento pelo método de Rietveld para a estrutura $F m$ $3 \mathrm{~m}$ permitiu determinar a estequiometria correta da fase com maior tamanho de cristalito, e mostrou que as substituições devem ocorrer essencialmente no sítio cristalográfico ocupado pelo átomos metálicos. A estequiometria dos carbonetos mostra que há uma tendência de convergência destes valores independente do histórico mecanotérmico anterior do material.

Além disso, o insucesso nas tentativas de ataques químicos superficiais para a revelação das fases presentes utilizando soluções comprovadas para este fim foi um indício importante da existência de diferenciação química entre o material estudado neste trabalho e os materiais relatados na literatura, apesar de não se observarem diferenças significativas por microscopia eletrônica de varredura.

O delineamento dos carbonetos utilizando-se solução de Berzelius (FIG. 4.15 a 4.18) é uma forte evidência da diferenciação química, quando se considera que este reagente inicialmente reage com a matriz e o carboneto do tipo $\mathrm{M}_{6} \mathrm{C}$ formando uma película acobreada sobre os mesmos.

Indiretamente o enriquecimento em tungstênio do carboneto do tipo $\mathrm{M}_{6} \mathrm{C}$, TAB. 4.6 é um indicativo que o molibdênio deve estar dissolvido no carboneto do tipo MC e na matriz.

Permanece, neste ponto, a questão do por que este tipo de carboneto se formou neste caso. Um fato importante deve ser considerado neste ponto: o tratamento térmico de austenitização e revenimento utilizado neste trabalho.

No ciclo de tratamento térmico tradicional (FIG. 2.15) o material é austenitizado e resfriado até a temperatura ambiente. Os ciclos de revenimento subsequientes são realizados pelo aquecimento partindo-se da temperatura ambiente até a temperatura e tempo de revenimento seguido de resfriamento até a temperatura ambiente novamente. Este ciclo tradicional não foi utilizado no tratamento térmico dos materiais utilizados neste trabalho, conforme pode ser visto na FIG. 3.3.

A austenitização sem a termalização até a temperatura ambiente é uma alteração significativa do ciclo, considerando-se que os mecanismos atuantes neste estágio 
são a difusão atômica e a solubilidade e que taxas de reações são diferentes no aquecimento e no resfriamento.

Portanto, a difusividade parece ser o mecanismo que atua na formação deste carboneto. A fração relativamente alta destes carbonetos sugere que os mesmos são transformações dos carbonetos MC primários pela substituição do vanádio pelo cromo e pelo molibdênio até o limite de solubilidade neste sistema quaternário.

Não há estudos sobre o sistema quaternário (V-Cr-Mo-W)-C. Porém os estudos dos sistemas ternários mostram que a solubilidade entre as fases destes carbonetos depende da temperatura e das fases consideradas. A estrutura cúbica de face centrada do carboneto de vanádio pode dissolver até 30 \% atômico de cromo e $12 \%$ de carboneto de tungstênio, este valores servem apenas como uma referência para o caso do sistema quartenário, uma vez que a distribuição eletrônica dos átomos deste sistema é muito diferente.

Uma das evidências que a formação do carboneto MC observado nos materiais estudados neste trabalho ocorra pela difusão dos elementos de liga da matriz para os carbonetos é o empobrecimento da matriz na área de contato com o carboneto primário, conforme pode ser visto na FIG. 4.15 (c).

A difusão também é favorecida pela fração elevada de carboneto que gera alta densidade de interconexões entre os carbonetos. No caso destes materiais a densidade de interconexões permite que o material mantenha a forma geométrica mesmo após a dissolução da matriz, conforme pode ser visto nas FIG. 4.22 a 4.25 e 4.27.

A taxa de resfriamento em banho de sal é mais baixa que ao ar ou no óleo propiciando as condições para difusão atômica e para o refino da estrutura cristalina da matriz. A segregação dos elementos de liga e do carbono para fora do núcleo de ferrita refinado ocorre em duas situações distintas. Nas regiões próximas aos carbonetos primários a segregação ocorre pelo enriquecimento dos contornos em elementos de liga e carbono. Os resultados obtidos neste trabalho sugerem que o tungstênio segregado da matriz refina a estrutura cristalina do $\mathrm{M}_{6} \mathrm{C}$ substituindo o molibdênio. $\mathrm{O}$ molibdênio, por sua vez, parece que em conjunto com o cromo e o vanádio forma uma estrutura cúbica de face centrada estável, forçando a segregação do vanádio para a matriz. Esta situação parece ser favorecida pelo não resfriamento até a temperatura ambiente após a austenitização, resultando na formação do carboneto do tipo MC observado neste trabalho.

No interior das células da rede de carboneto a segregação dos elementos de liga e do carbono para fora dos núcleos de ferrita atinge o limite de solubilidade destes elementos na fase ferrítica precipitando os carbonetos secundários. 
Em relação à elevada fração de carbonetos verificada neste carboneto, quando comparada aos valores da literatura as seguintes ponderações podem ser feitas:

(1) Os resultados encontrados na literatura referem-se, em sua maioria, a análises realizadas em material produzido por metalurgia convencional. Sob este ponto de vista, o resultado obtido para o material comercial utilizado neste trabalho apresenta concordância com os valores publicados.

(2) A fração de carbonetos depende do teor de carbono adicionado ao aço. No caso do material obtido por conformação por spray o teor de carbono está no limite superior do valor nominal. Além disto, este material possui nitrogênio dissolvido. O nitrogênio além de formar nitretos com estruturas semelhantes aos dos carbonetos, pode ainda formar carbo-nitreto (Jack e Jack, 1973). Aumentando, assim, a fração de carbonetos, ou neste caso carbo-nitretos neste material.

(3) No caso da amostra produzida por metalurgia do pó, espera-se que a maior homogeneidade na distribuição de carbonetos proporcione no revenimento condições mais favoráveis para a esferoidização dos carbonetos e conseqüentemente um aumento da fração total de carbonetos. As condições de tratamento térmico realizadas aliadas às características microestruturais parecem ter propiciado a formação máxima de carbonetos possível para este material. 


\section{Conclusões}

A realização deste trabalho proporcionou:

1. O desenvolvimento de um método, composto por dissolução química e eletrolítica, para a extração seletiva de carbonetos primários e secundários nos aços rápidos AISI/SAE M2 após o tratamento térmico de austenitização e revenimento.

2. A quantificação da fração total dos carbonetos permitiu verificar que esta fração é dependente do processo de obtenção e da composição química do aço. A quantificação das frações dos carbonetos do tipo $\mathrm{M}_{6} \mathrm{C}$ e $\mathrm{MC}$ mostrou que as condições de tratamento térmico utilizadas neste trabalho favorecem a formação do carboneto do tipo $\mathrm{MC}$, independentemente da fração total de carbonetos no material.

3. A extração seletiva permitiu o estudo da influência da austenitização e do revenimento sobre os carbonetos primários, possibilitando a identificação de um carboneto com estequiometria ainda não reportada na literatura.

4. A utilização do método de Rietveld, com dados obtidos por difração de raios X gerados por radiação de luz síncrotron, no refino da estrutura cristalina do carboneto do tipo MC possibilitou a determinação dos parâmetros cristalográficos deste carboneto.

5. A estequiometria para o carboneto do tipo MC, após os tratamentos térmicos de austenitização e revenimento, apresentou valores muito semelhantes independentemente do processo de obtenção do aço, da composição química. 


\section{Sugestões para trabalhos futuros}

a) A célula hidro-clorídica mostrou-se eficaz na extração de precipitados, não só de aços ferramenta como de outros tipos. Sugere-se o estudo para estabelecimento dos parâmetros que permitam a utilização deste método para a extração de precipitados em aços;

b) Refino da estrutura do carboneto do tipo $\mathrm{M}_{6} \mathrm{C}$;

c) Estudo das relações de orientação entre os carbonetos e a matriz nos aço AISI/SAE M2;

d) Estudo da influência da orientação preferencial na quantificação dos carbonetos pelo método de Rietveld. 


\section{Trabalhos germinados}

SERNA, M. M.; ROSSI, J. L. MC complex carbide in AISI M2 high-speed steel. Materials Letters, em publicação.

SERNA, M. M. ; GALEGO, E ; ROSSI, J.L. . Crystalline structure of $\mathrm{M}_{2} \mathrm{C}$ carbide in spray formed AISI M2 high-speed steel. In: 17 ${ }^{\text {a }}$ Reunião Anual de Usuários do LNLS, 2007, Campinas. Resumo de Trabalhos Cientifícos, v. 1. p. 123-123, 2007.

SERNA, M. M. ; JESUS, E.R.B. ; GALEGO, E ; MARTINEZ, L.G. ; CORRÊA, H.P.S. ; ROSSI, J.L. . An overview of the microstructures present in high-speed steel - carbides crystallography. Materials Science Forum, v. 530, p. 48-52, 2006.

SERNA, M. M. ; ROSSI, J.L. . Análise de carbonetos no aço rápido AISI M2 pelo método de Rietveld. In: $16^{\mathrm{a}}$. Reunião Anual de Usuários do LNLS, 2006, Campinas. Resumo de Trabalhos Científicos, v. 1,2006. 


\section{Bibliografia}

ADNANE, L.; KESRI, R.; HAMAR-THIBAULT, S. Vanadium carbides formed from the melt by Solidification in Fe-V-X-C alloys (X-Cr, Mo, Nb). Journal of Alloys and Compounds, 178, p.71-84, 1992.

ANDRÉN, H.O. Atom probe microanalysis of a tempered high speed steel. Scripta Metallurgica, 15, p.749-752, 1981.

BÉNÉTEAU, A.; WEISBECKER, P.; GEANDIER, G.; AEBY-GAUTIER, E.; APPOLAIRE, B. Austenitization and precipitate dissolution in high nitrogen steel: an in situ high temperature X-ray synchrotron diffraction analysis using the Rietveld method. Materials Science and Engeneering A, 393, p.63-70, 2005.

BILLINGH, J.; BELL P.S.; LEWIS, M.H. Superlattice with monoclinic symmetry based on compound $\mathrm{V}_{6} \mathrm{C}_{5}$. Philosophical Magazine, 25, 3, p.661-\&, 1972.

BILLINGH, J.; LEWIS M.H. Dislocation mechanisms for nucleation of transformations in vanadium carbide. Philosophical Magazine, 24. 188, p.231-\&, 1971.

BLICKWEDE, D.J.; COHEN, M. The isolation of carbides from high speed steel. Metals Transactions, 185, p.578-584, 1949.

BLICKWEDE, D.J.; COHEN, M.; ROBERTS, G.A. The effect of vanadium and carbon on the constitution of high speed steel. Transactions of the American Society for Metals, 42, p. 1161-1196, 1950.

BOCCALINI JÚNIOR, M. Um Estudo da Solidificação do Aço Rápido AISI M2 - Efeitos da Composição Química e da Velocidade de Resfriamento sobre a Microestrutura Bruta de Fusão. 1996. Tese (Doutorado) - Escola Politécnica - USP, São Paulo.

BUHRKE, V.E.; JENKINS, R.; SMITH, D.K. A Pratical Guide for the Preparation of Specimens for X-ray Fluorescence and X-Ray Diffraction Analysis. New York-NY-USA, 
John Wiley \& Sons Inc., 1998.

BURKE, K.E. Chemical extraction of refractory inclusions from iron and nickel-base alloys. Metallography, 8, p.473-488, 1975.

CROMER, D.T. FPRIME - Program to Interpolate Cross Sections and Compute Anomalous Scattering Factors, mail stop G730, Los Alamos National Laboratory, 1980.

CULLITY, B.D.; STOCK, S.R. Elements of X-ray Diffraction, 3.ed., New Jersey, Prentice Hall Inc., 2001.

DING, P.; GONGQI, S.; SHOUZE, Z. A scanning electron nicroscopy study of carbides in high speed steels. Material Characterization, 29, p.15-24, 1992.

DING, P.; GONGQI, S.; SHOUZE, Z. As cast carbides in high speed steel. Metallurgical Transactions A, 24A, p. 1265-1272, 1993.

EPIECIER, T.; ACEVEDO, D.; PEREZ, M. Crystallographic structure of vanadium carbide precipitates in a model Fe-C-V steel. Philosophical Magazine, 88,1,p.31-45, 2008.

FISCHER, A.; KOHLHASS, E. Observations on the microstructures of high speed tool steels. Praktische Metallographie, 12, p. 393-406, 1975.

FRAKER, A.C.; STADELMA,H.H. $\varepsilon$ - carbides of molybdenum-iron, molybdenum-cobalt and molybdenum-nickel. Transactions of the Metallurgical Society of AIME, 245, p. 847854, 1969.

FREDRIKSSON, H.; BRISING, S. The formation of carbides during solidification of high-speed steels, Scandinavian Journal of Metallurgy, 5, p.268-275, 1976.

GALDA, E.J.; KRAFT, R.W. The effects of Mo and W on solidification of high speed steels, Metallurgical Transactions, 5, p.1727-1733, 1974.

GHOMASHCHI, M.R. Quantitative microstructural analysis of M2 grade high speed steel during high temperature treatment. Acta Materiala, 46, p.5207-5220, 1998. 
GHOMASHCHI, M.R.; SELLAR, C.M. Microstructural changes in as-cast M2 grade high speed steel during high temperature treatment. Metal Science, 18, p.44-48, 1984.

GIRON, G.;DURAND-CHARRE, M. High-temperature phase-equilibria in the system FeMo-C. Zeitschrift fur Metallkunde, 86, p. 15-21, 1995.

GLUSKER, J.P.; TRUEBLOOD, K.N. Crystal Structure Analysis a Primer. New YorkNY-USA, Oxford University Press, 2a. ed., 1985.

GOLDSCHMIDT, H.J. Interstitial Alloys, Butterworths, London, 1967

GONGQI, S.; DING, P.; SHOUZE, Z. Effect of vanadium on cast carbide in high speed steels. Materials Science and Technology, 8, p. 449-454, 1992.

HÄGLUND, J.; FERNÁNDEZ GUILLERMET, A.; GRIMVALL, G.; KÖRLING, M. Theory of bonding in transition-metal carbides and nitrides. Physical Review B, 48, 16, p.11685-11691, 1993.

HOYLE, G. High Speed Steel, 1 ed., Cambridge, Butterworth \& Co. (Publishers) Ltd., 1988.

JACK, D.H.; JACK, K.H. Carbides and nitrides in steel. Materials Science and Engineering, 11, p. 1-27, 1973.

JESUS, E. R. B. Ferramentas de Usinagem em Aço Rápido AISI M2 Obtido por Conformação por "Spray”. 2004. Tese (Doutorado) - Instituto de Pesquisas Energéticas e Nucleares, São Paulo.

JURČI, P. Microstructural Development in rapidly solidified powder of M2 type high speed steel during annealing. Powder Metallurgy, 41, 4, p.269-273, 1998.

KAISER ,F.; COHEN, M. Carbides in high speed sSteel - their nature and quantity. Metal Progress, June, p.79-85, 1952. 
KAISER, F.X. Physicochemical method for determining the total volume fraction of carbide in annealed high speed steels. Materials Characterization, 27, p.127-132, 1991.

KARAGOZ, S.; LIEM, I.; BISCHOFF, E.; FISCHMEISTER, H.F. Determination of carbide and matrix compositions in high-speed steels by analytical electron microscopy. Metallurgical Transactions A, 20, p.2695- 2701, 1989.

KARAGÖZ, S.; ANDRÉN, H.O. Secondary hardening in high speed steels, Zeitschrif für Metallkunde, 83, 6, p.386-394, 1992a.

KARAGÖZ, S.; FISCHMEISTER, H.F.; ANDRÉN, H.O.; GUANG-JUN, C. Microstrutural changes during overtempering of high speed steels. Metallurgical Transactions A, 23-A, p.1631-1640, 1992b.

KIM, Y.W.; STRUTT, P.R.; NOWOTNY, H. Laser melting and heat treatment of M2 tool steel: a microstructural characterization. Metallurgical Transactions A, 10A, p.881-886, 1979.

KIM, C.; BISS, V.; HOSFORD, W.F. A new procedure for determining volume fraction of primary carbides in high speed and related tool steels. Metallurgical Transactions A, 13A, p.185-191, 1982.

KESRI, R.; DURAND-CHARRE, M. Metallurgical structure and phase-diagram of Fe-CV system - comparison with other systems forming MC carbides. Materials Science And Technology, 4, 8,p.692-699, 1988a.

KESRI, R.; HAMAR-THIBAULT, S. Long-Range Ordered Structures in MC Carbides in Cast-Irons. Acta Metallurgica, 36. 1, p.149-166, 1988b,

KOSOLAPOVA, T.Ya. Carbides - Properties, Production, and Applications. New YorkUSA, Plenum Press-New York, 1971.

KULA,E.; COHEN, M. Grain growth in high speed steel. Transactions of the American Society for Metals, 46, p.727-798, 1954. 
KULMBURG, A. The microstructure of tool steels - an overview for the practice. Part I: Classification, systematic and heat treatment of tool steels. Praktische Metallographie, 35, 4, p.181-202, 1998a.

KULMBURG, A. The microstructure of tool steels - an overview for the practice. Part II: Particular microstructural features of the individual groups of steels. Praktische Metallographie, 35, 5, p.267-279, 1998b.

LARSON, A.C.; VON-DREELE, R.B. General Structure Analysis System (GSAS), Los Alamos National Laboratory Report LAUR 86-748, 2004

LECKIE-EWING, P. A study of the microhardness of the major carbides in some high speed steels. Transactions of the American Society for Metals, 44, p. 348-366, 1952.

LEE, E.O.; PARK, W.J.; BAIK, K.O.; AHN, S. Different carbide types and their effect on bend properties of a spray-formed high-speed steel. Scripta Materialia, 39, p.1133-1138, 1998a.

LEE, E.O.; PARK, W.J.; JUNG, J.Y. AHN, S. Solidification microstructure and $\mathrm{M}_{2} \mathrm{C}$ carbide decomposition in a spray-formed high-speed steel. Metallurgical and Materials Transactions A, 29, p. 1395-1404, 1998b.

LIPATNIKOV, V.N.; GUSEV, A.I. Order-disorder phase transformations and specific heat of nonstoichiometric vanadium carbide. Physics of the Solid State, 41, 3, p. 474-480, 1999.

LIU, B.X.; CHENG, X.Y. A metastable $\mathrm{Cr}$ carbide of $\mathrm{NaCl}$ structure formed by carbon-ion implantation into chromium films. Journal of Physics-Condensed Matter, 4, 16, p.L265L268, 1992.

JI, N.; LEBRUN, J.L.; SPRAUEL, J.M. Analysis of broadened X-ray diffraction profiles: application to the characterization of carbon steels, Materials Science and Engineering A, 127, p.71-77, 1990. 
McCUSKER, L.B; VON DREELE, R.B.; COX, D.E.; LOUER, D.; SCARDI, P. Rietveld refinement guidelines, Journal of Applied Crystallography, 32, p.36-50, 1999.

McLAUGHLIN, J.; KRAFAT, R.W.; GOLDSTEIN, J.I. Characterization of the solidification structures whitin the dendritic core of M2 high speed steel. Metallurgical Transactions A, 8A, p.1787-1792, 1977.

McHARGUE, J.; HAMMOND, J.P.; CROUSE, C.S. The angular appearing carbides in high speed steels. Transactions of the American Society for Metals, 46, p.716-726, 1954. MESQUITA, R.A.; BARBOSA, C.A. Spray forming high speed steel - properties and processing. Materials Science and Engineering A, 383, p.87-95, 2004.

OZAKI, K.; URITA, T.; MATSUDA, Y.; KOGA, H. Austenitization and carbide dissolution of high speed steel AISI-M2 in short time heating. $20^{\text {th }}$ ASM Heat Treating Society Conference Processing, 9-12 October 2000, St.Louis, MO, 2000.

PAIVA-SANTOS, C.O. Aplicações do Método de Rietveld, Apostila Instituto de Química. UNESP, 2005.

PARTHÉ, E.; YVON, K. On the crystal chemistry of the close packed transition metal carbides. II. A proposal for the notation of the different crystal structures. Acta Crystallographic, B26, p. 153-163, 1970.

PEMBERTON, R. The separation and analysis of metallic carbides from steel. Analyst, 77, p.287-292, 1952.

PETER, W.; KOHLHAAS, E. Über die zusammensetzung und die mengenanteileverschiedener carbidtypen in schnellarbeitsstählen. Mikrochimica Acta, S, 2, p.235-248, 1967.

PIPPEL, E.; WOLTERSDORF, J.; PÖCKL, G.; LICHTENEGGER, G. Microstructure and nanochemistry of carbide precipitates in high-speed steel S 6-5-2-5. 
POPESCU, V.I. The quaternary carbides in ledeburitic steels. U.P.B. Science Bulletin, Series B: Chemistry and Materials Science, 69, 1, p.25-34, 2007.

RAFAJA, D.; LENGAUER, W.; ETTMAYER, P.; LIPATNIKOV, V.N. Rietveld analysis of the ordering in $\mathrm{V}_{8} \mathrm{C}_{7}$. Journal of Alloys and Compounds, 269, p.60-62, 1998.

RONG, W.; ANDRÉN, H.O.; WISELL, H.; DUNLOP, G.L. The role of alloy composition in the precipitation behaviour of high speed steels. Acta Mettallurgica et Materialia., 40, 7, p.1727-1738, 1992.

SAHU, P.; DE, M.; KAJIWARA, S. Microstructural characterization of Fe-Mn-C martensites athermally transformed at low temperature by Rietveld method. Materials Science and Engineering A, 333, p.10-23, 2002.

SHTANSKY, D.V.; INDEN, G. Phase transformation in Fe-Mo-C and Fe-W-C steels - I. The structural evolution during tempering at $700^{\circ} \mathrm{C}$. Acta Metallurgica, 7, p.2861-2878, 1997.

STILLER,K.; SVENSSON, L.E.; HOWELL, P.R.; RONG, W.; ANDRÉN, H.O.; DUNLOP, G.L. High resolution microanalytical study of precipitation in a powder metallurgical high speed steel. Acta Metallurgica, 32, 9, p.1457-1467, 1984.

STORMS, E.K. The Refractory Carbides. New York-NY-USA, Academic Press Inc., 1967.

STOUT, G.H.; JENSEN, L.H. X-ray Structure Determination - A Practical Guide. New York - NY-USA, Wiley Interscience Publication, 2a. ed., 1989.

UPADHYAYA, G.S. Nature and Properties of Refractory Carbides. Commack-NYUSA, Nova Science Publishers Inc., 1996.

VENABLES, J.D.; KAHN, D.; LYE, R.G. Structure of the ordered compound $\mathrm{V}_{6} \mathrm{C}_{5}$. Philosophical Magazine, 18, p.177-192, 1968. 
WIEßNER, M.; KLEBER, S.; KULMBURG, A. in-situ investigation during tempering of a high speed steel with X-ray diffraction, Particle \& Particle Systems Characterization, 22, p.407-417, 2005.

WARBICHER, P.; PAPST, I.; HOFER, F.; PÖCKL, G. Micro-characterization and nanoanalysis of S 6-5-2-5 high speed steel. Praktische Metallographie, 36, p.621-630, 1999

WIEßNER, M.; LEISCH, M.; EMMINGER, H.; KULMBURG, A. phase transformation study of a high speed steel powder by high temperature X-ray diffraction. Materials Characterization, 59, p.937-943, 2008.

YOSIDA, Y.; OGURO, I. Superconductivity in a high temperature cubic phase of $\mathrm{MoC}_{\mathrm{x}}$ encapsulated in the multiwall carbon nanocages. Physica C, 442,p.97-100, 2006.

YOUNG, R.A.; SAKTHIVEL, A. bimodal distributions of profile broadening effects in Rietveld refinement. Journal Applied Crystallography, 21, p.416-415, 1988.

YOUNG, R.A. The Rietveld Method, IUCr Monographs on Crystallography - 5, 1 ed., New York, Oxford University Press Inc., 1996.

ZANONI, K.R.S.; FRANCO JR, A.R.; MILAN, J.C.G.; HUPALO,M.F. Influência da temperatura e do tempo de austenitização na microestrutura, dureza e tenacidade do aço AISI M2. Anais do 61 . Congresso Anual da ABM, 24 a 27 de julho de 1006, Rio de Janeiro 


\section{Anexo 1 \\ Bibliografia do Grupo de Metalurgia do Pó}

ARAUJO FILHO, O.O. Estudo Comparativo de Aços Rápidos AISI M3:2 Produzidos por Diferentes Processos de Fabricação. 2006. Tese (Doutorado) - Instituto de Pesquisas Energéticas e Nucleares - USP, São Paulo.

ARAUJO FILHO, O.O.; AMBROZIO FILHO, F.; NEVES, M.D.M. RIBEIRO, O.C.S.; SILVA, C.H.L. Tranverse rupture strength of a P/M tool steel. Materials Research, 8, 2, p.173-176, 2005.

ARAUJO, E.G. Influência das Adições de $\mathrm{NbC}$ e Ligas a Base de Fósforo na Sinterização do Aço Rápido M2. 1993. Dissertação (Mestrado) - Instituto de Pesquisas Energéticas e Nucleares - USP, São Paulo.

ARAUJO, E.G. Influência das Adições de Portadores de Fósforo e da Alumina na Sinterização do Aço Rápido M2. 2000. Tese (Doutorado) - Instituto de Pesquisas Energéticas e Nucleares - USP, São Paulo.

ARAUJO, E.G.; SICILIANO JUNIOR, F.; AMBROZIO FILHO, F.; ALMEIDA FILHO, D.A.; SOUZA, V.A.; NEVES, M.D.M. Sintering of high speed steels containing niobium. Advances in Powder Metallurgy and Particulate Materials, p.397-410, 1992.

BOEHS, L.; FRIEDRICH, D.N.; CALDEIRA, P.F.; AMBROZIO FILHO, F.; LIMA, L.F.C.P.; NEVES, M.D.M.; RIBEIRO, O.C.S.; NOGUEIRA, R.A. Influence on sharpening and coating operations on the wear of sintered high speed steel tools. Materials Science Forum, 41-418, p.48-53, 2003.

LIBERATI, J.F. Compactação Isostática a Quente do Pó de Aço Rápido AISI M2. 2001. Dissertação (Mestrado) - Instituto de Pesquisas Energéticas e Nucleares, São Paulo.

NOGUEIRA, R.A.; RIBEIRO, O.C.S.; NEVES, M.D.M.; SALGADO, L.; AMBROZIO FILHO, F. Effect of heat treatment on microstructural of commercial and vacuum sintered 
high speed steels AISI M2 and T15. Materials Science Forum, 498-499, p.186-191, 2005.

NOGUEIRA, R.A.; YOSHIDA, S.; FUNARO, R.; AMBROZIO, F. Evaluation of salt bath and vaccum heat treatment of AISI M2 and M3/2 high speed steels, Materials Science and Technology, p.271-280, 2006.

PANELli, R. Processamento do Aço AISI M2 com Adição de 10\% vol. de NbC Utilizando a Técnica de Mechanical Alloying. 1999. Dissertação (Mestrado) - Instituto de Pesquisas Energéticas e Nucleares, São Paulo.

PANELLI, R.; AMBROZIO FILHO, F. Compaction of AISI M2 + 10\% vol. NbC processed by high energy mill. Materials Science Forum, 299-300, p.463-469, 1999.

SALGADO, L.; JESUS FILHO, E.S.; JESUS, E.R.B.; AMBROZIO FILHO, F. ROSSI, J.L. Mechanical and microstructural characterisation of P/M high speed steel valve seat inserts. Materials Science Forum, 416-418, p.312-316, 2003.

SOARES JUNIOR, E.; VATAVUK, J.; PANELLI, R.; PILlIS, M.F. Evaluation of mechanical properties and microstructure of a high carbon-vanadium tool steel produced by powder metallurgy. Materials Science Forum, 530-531, p.140-144, 2006. 